Selected PISs for experiment 1 (Wild-Hip1_Hemi)

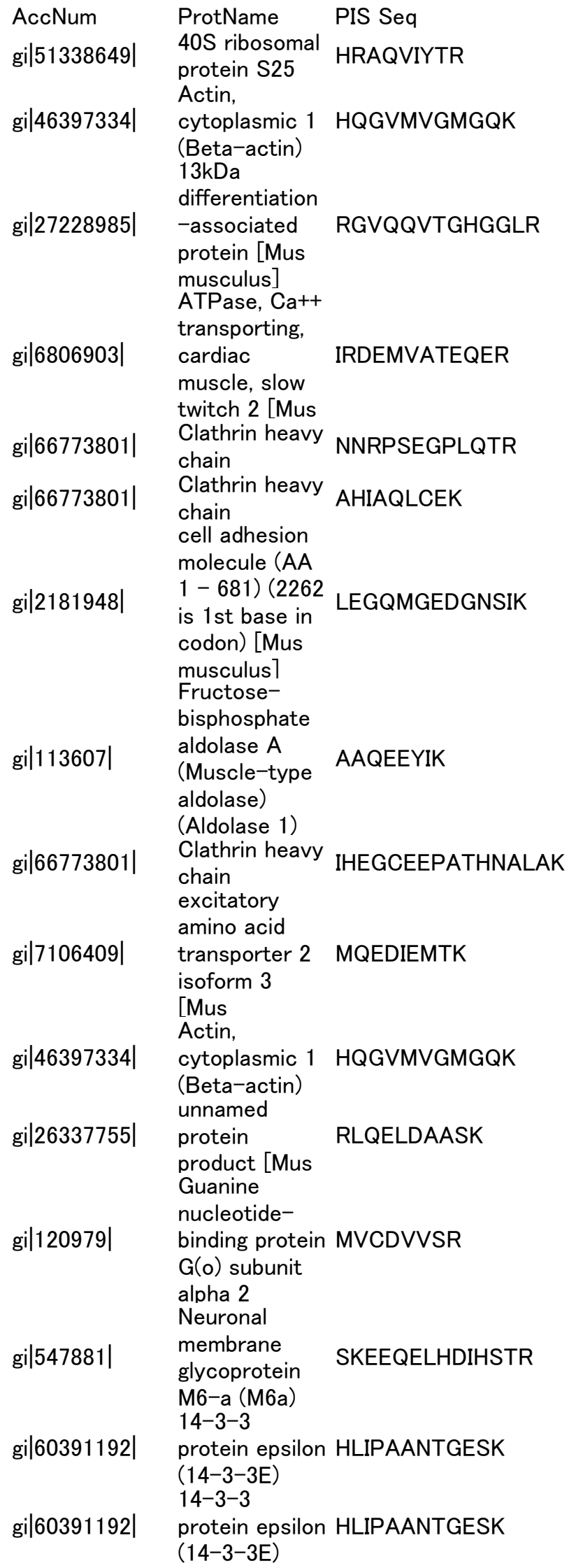




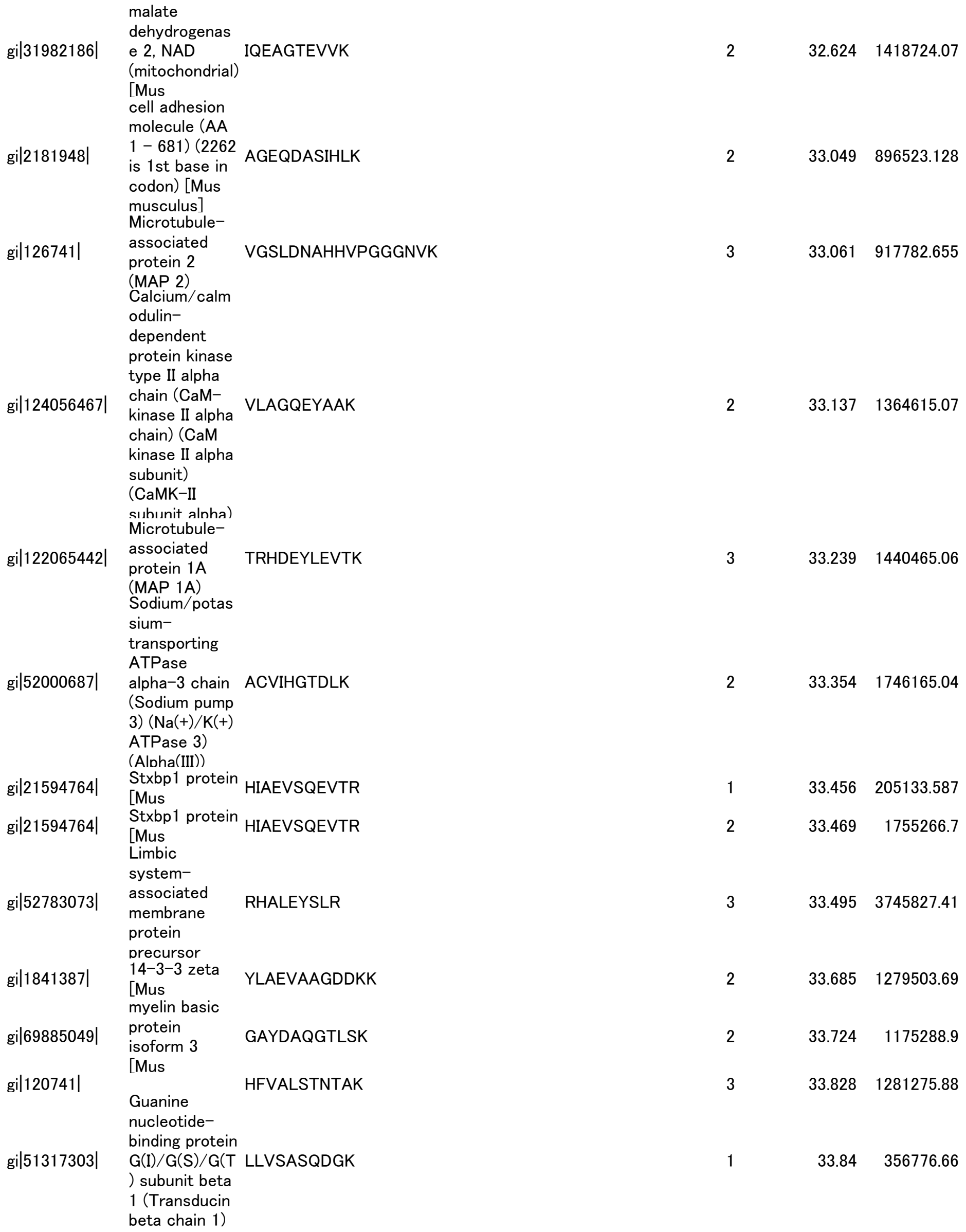




\begin{tabular}{|c|c|c|c|c|c|c|}
\hline \multirow{3}{*}{$\begin{array}{l}\text { gi|4262551| } \\
\text { gi|74142419| }\end{array}$} & \multicolumn{6}{|c|}{ G-protein } \\
\hline & $\begin{array}{l}\text { XLalphas [Mus } \\
\text { musculus] } \\
\text { unnamed }\end{array}$ & ASLPARAAAAAR & & 3 & 33.879 & 907344.953 \\
\hline & $\begin{array}{l}\text { protein } \\
\text { product [Mus } \\
\text { G-protein }\end{array}$ & RTALVANTSNMPVAAR & Oxidation (M) & 3 & 33.979 & 2181538.13 \\
\hline gi|4262551| & $\begin{array}{l}\text { XLalphas [Mus } \\
\text { musculus] }\end{array}$ & ASLPARAAAAAR & & 2 & 33.981 & 2182183.76 \\
\hline gi|51702824| & $\begin{array}{l}60 \mathrm{~S} \text { ribosomal } \\
\text { protein L8 } \\
\text { G-protein }\end{array}$ & AVVGVVAGGGR & & 2 & 34.031 & 1584651.36 \\
\hline gi|4262551| & $\begin{array}{l}\text { XLalphas [Mus } \\
\text { musculus] } \\
\text { Serine/threoni } \\
\text { ne-protein } \\
\text { phosphatase } \\
\text { 2B catalytic } \\
\text { subunit alpha } \\
\text { isoform }\end{array}$ & ASLPARAAAAAR & & 1 & 34.044 & 42393.678 \\
\hline gi|54038800| & $\begin{array}{l}\text { (Calmodulin- } \\
\text { dependent } \\
\text { calcineurin A } \\
\text { subunit alpha } \\
\text { isoform) } \\
\text { (CAM-PRP } \\
\text { catalvtic. }\end{array}$ & YENNVMNIR & Oxidation (M) & 2 & 34.081 & 820559.638 \\
\hline gi|2598562| & $\begin{array}{l}\text { BIP [Mus } \\
\text { musculus] }\end{array}$ & NGRVEIIANDQGNR & & 2 & 34.094 & 309904.19 \\
\hline gi|49065832| & $\begin{array}{l}\text { 40S ribosomal } \\
\text { protein S7 }\end{array}$ & HVVFIAQR & & 2 & 34.221 & 1802882 \\
\hline gi|73920802| & $\begin{array}{l}\text { Synapsin-1 } \\
\text { (Synapsin I) }\end{array}$ & GSHSQSSSPGALTLGR & & 3 & 34.359 & 1934560.53 \\
\hline gi|81885934| & $\begin{array}{l}\text { Tubulin beta- } \\
2 \mathrm{~A} \text { chain } \\
\text { myelin basic }\end{array}$ & TAVCDIPPR & & 2 & 34.361 & 2189554.1 \\
\hline gi|69885049| & $\begin{array}{l}\text { protein } \\
\text { isoform } 3 \\
\text { [Mus } \\
\text { ATPase, Ca++ } \\
\text { transporting, }\end{array}$ & YLATASTMDHAR & & 1 & 34.424 & 103678.385 \\
\hline gi|6806903| & $\begin{array}{l}\text { cardiac } \\
\text { muscle, slow } \\
\text { twitch } 2 \text { [Mus } \\
\text { Alpha- }\end{array}$ & KSEIGIAMGSGTAVAK & Oxidation (M) & 3 & 34.665 & 987886.706 \\
\hline & $\begin{array}{l}\text { synuclein } \\
\text { (Non-A beta } \\
\text { component of }\end{array}$ & & & & & \\
\hline gi|13432217| & $\begin{array}{l}\text { AD amyloid) } \\
\text { (Non-A4 } \\
\text { component of } \\
\text { amyloid } \\
\text { precursor) } \\
\text { (NACP) } \\
\text { ATP synthase }\end{array}$ & EGVVHGVTTVAEK & & 3 & 34.855 & 1891924.72 \\
\hline gi|416677| & $\begin{array}{l}\text { subunit alpha, } \\
\text { mitochondrial } \\
\text { precursor } \\
\text { myosin, light }\end{array}$ & ISVREPMQTGIK & Oxidation (M) & 3 & 35.2 & 5032377.95 \\
\hline gi|33620739| & $\begin{array}{l}\text { alkali, smooth } \\
\text { muscle and } \\
\text { non-muscle } \\
\text { [Mus }\end{array}$ & HVLVTLGEK & & 2 & 35.239 & 1655775.9 \\
\hline
\end{tabular}




\begin{tabular}{|c|c|c|c|c|c|c|}
\hline gi|66773801| & $\begin{array}{l}\text { Clathrin heavy } \\
\text { chain }\end{array}$ & RDPHLACVAYER & & 2 & 35.289 & 403471.266 \\
\hline gi|21594764| & $\begin{array}{l}\text { Stxbp1 protein } \\
\text { [Mus } \\
\text { unnamed }\end{array}$ & YSTHLHLAEDCMK & Oxidation (M) & 2 & 35.302 & 437711.98 \\
\hline gi|74142419| & $\begin{array}{l}\text { protein } \\
\text { product [Mus } \\
\text { unnamed }\end{array}$ & LPANHPLLTGQR & & 1 & 35.33 & 55756.492 \\
\hline gi|74142419| & $\begin{array}{l}\text { protein } \\
\text { product [Mus } \\
\text { Heat shock } \\
\text { cognate } 71\end{array}$ & LPANHPLLTGQR & & 3 & 35.368 & 4525022.12 \\
\hline gi|51702275| & $\begin{array}{l}\text { kDa protein } \\
\text { (Heat shock } \\
70 \mathrm{kDa} \text { protein } \\
\text { ADP/A IP } \\
\text { translocase } 1 \\
\text { (Adenine } \\
\text { nucleotide } \\
\text { translocator 1) } \\
\text { (ANT 1) } \\
\text { (ADP,ATP }\end{array}$ & VEIIANDQGNR & & 1 & 35.378 & 359097.282 \\
\hline gi|21903382| & $\begin{array}{l}\text { carrier protein } \\
\text { 1) (Solute } \\
\text { carrier family } \\
25 \text { member } 4 \text { ) } \\
\text { (ADP,ATP } \\
\text { carrier protein, } \\
\text { heart/skeletal } \\
\text { muscle } \\
\text { icnform T1) } \\
\text { Actin. }\end{array}$ & $\begin{array}{l}\text { LLLQVQHASK } \\
\text {, }\end{array}$ & & 3 & 35.457 & 25531636.8 \\
\hline gi|46397334| & $\begin{array}{l}\text { cytoplasmic } 1 \\
\text { (Beta-actin) }\end{array}$ & MQKEITALAPSTMK & 2 Oxidation (M) & 3 & 35.507 & 1908543.95 \\
\hline gi|20455323| & $\begin{array}{l}\text { Tubulin beta-3 } \\
\text { chain } \\
\text { Heat shock } \\
\text { cognate } 71\end{array}$ & ISVYYNEASSHK & & 2 & 35.635 & 815885.673 \\
\hline gi|51702275| & $\begin{array}{l}\text { kDa protein } \\
\text { (Heat shock } \\
70 \mathrm{kDa} \text { protein } \\
\text { Heat shock } \\
\text { cognate } 71\end{array}$ & RFDDAVVQSDMK & Oxidation (M) & 1 & 35.775 & 95276.567 \\
\hline gi|51702275| & $\begin{array}{l}\text { kDa protein } \\
\text { (Heat shock } \\
70 \mathrm{kDa} \text { protein } \\
\mathrm{Na}+/ \mathrm{K}+-\end{array}$ & RFDDAVVQSDMK & Oxidation (M) & 2 & 35.776 & 969008.53 \\
\hline gi|110052| & $\begin{array}{l}\text { exchanging } \\
\text { ATPase (EC } \\
3.6 .3 .9) \text { beta } \\
\text { chain - mouse } \\
\text { ATP synthase }\end{array}$ & INAANIATDDERDK & & 3 & 35.813 & 2941262.02 \\
\hline gi|20454828| & $\begin{array}{l}\text { B chain, } \\
\text { mitochondrial } \\
\text { precursor } \\
\text { Apolipoprotein }\end{array}$ & IAQLEEVK & & 2 & 35.928 & 2046419.73 \\
\hline gi|114041| & $\begin{array}{l}\text { E precursor } \\
\text { (Apo-E) } \\
\text { ATP synthase }\end{array}$ & TANLGAGAAQPLRDR & & 3 & 36.017 & 1321078.2 \\
\hline gi|78099820| & $\begin{array}{l}\text { delta chain, } \\
\text { mitochondrial } \\
\text { precursor }\end{array}$ & IEANEALVK & & 2 & 36.055 & 2341160.21 \\
\hline
\end{tabular}




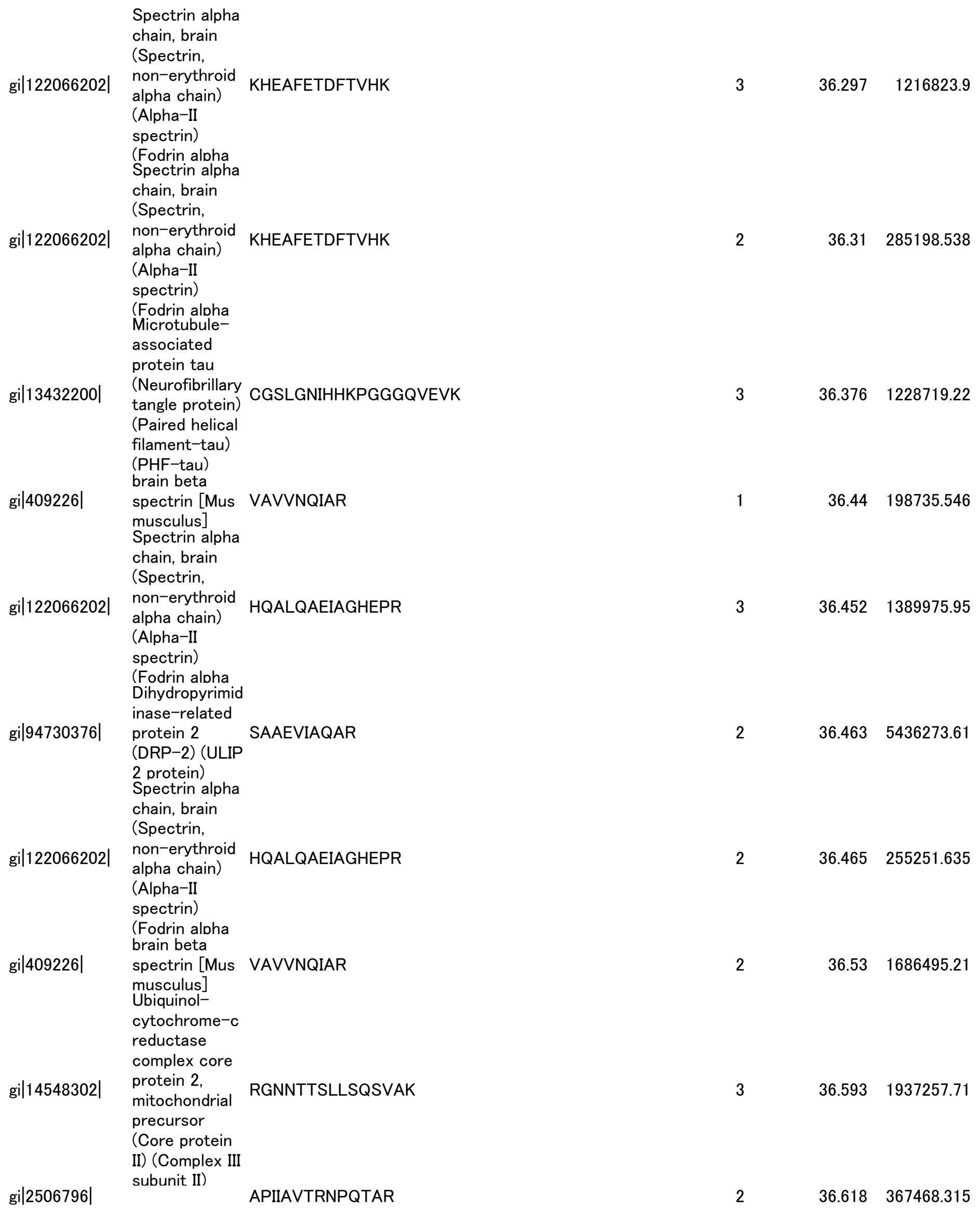




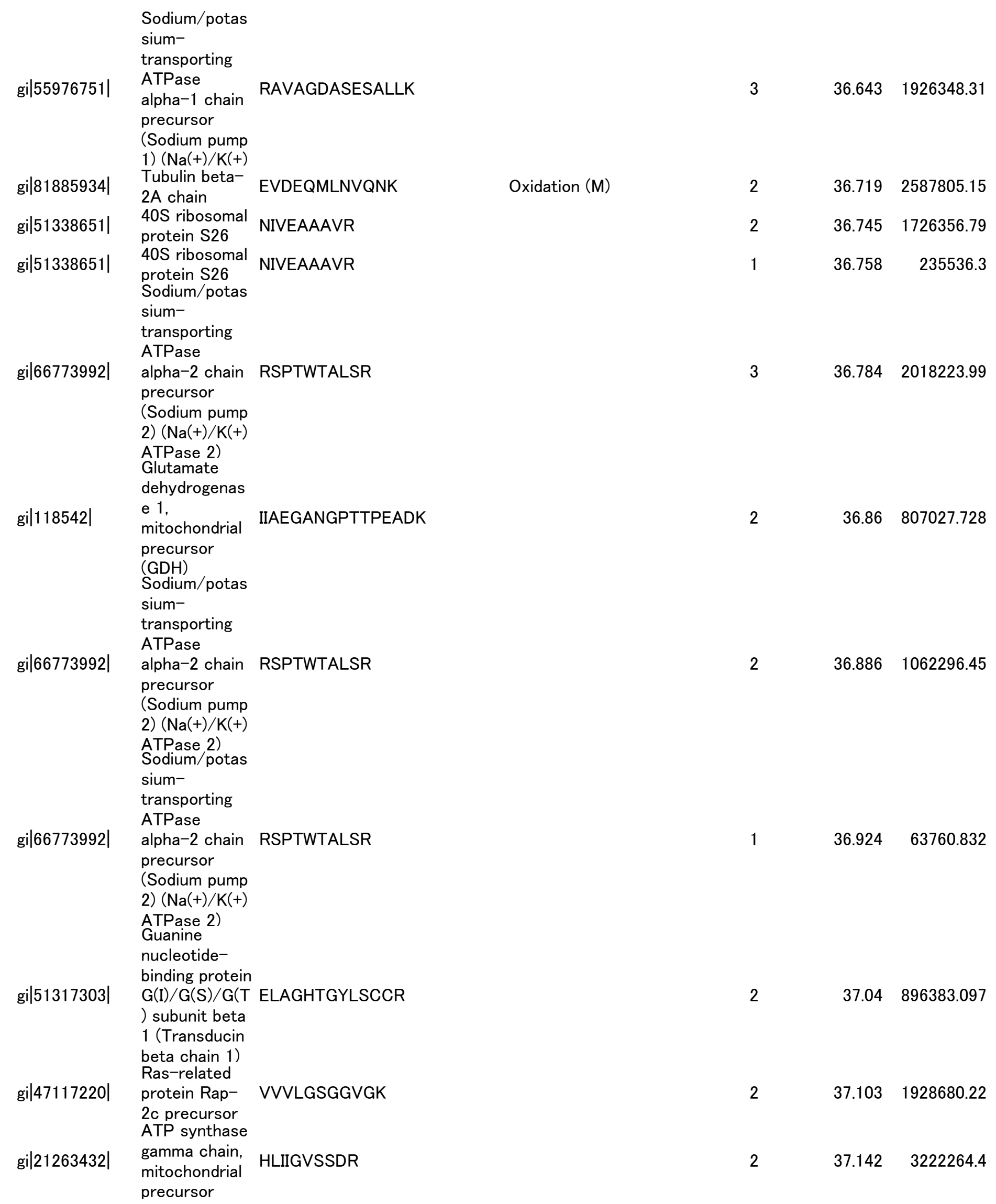




\begin{tabular}{|c|c|c|c|c|c|c|}
\hline & $\begin{array}{l}\text { Gamma- } \\
\text { enolase (2- } \\
\text { phospho-D- } \\
\text { glycerate } \\
\text { hydro-lyase) }\end{array}$ & & & & & \\
\hline gi|119348| & $\begin{array}{l}\text { (Neural } \\
\text { enolase) } \\
\text { (Neuron- } \\
\text { specific } \\
\text { enolase) (NSE) } \\
\text { (Enolase 2) } \\
\text { Ras-related }\end{array}$ & LGAEVYHTLK & & 3 & 37.166 & 4251486.68 \\
\hline gi|47117220| & $\begin{array}{l}\text { protein Rap- } \\
\text { 2c precursor } \\
\text { Glutamate } \\
\text { dehydrogenas }\end{array}$ & VVVLGSGGVGK & & 1 & 37.192 & 93688.609 \\
\hline gi|118542| & $\begin{array}{l}\text { e 1, } \\
\text { mitochondrial } \\
\text { precursor } \\
\text { (GDH) }\end{array}$ & TAAYVNAIEK & & 1 & 37.256 & 200087.527 \\
\hline gi|3980175| & $\begin{array}{l}\text { Thy } 1.2 \\
\text { antigen [Mus }\end{array}$ & SRVTLSNQPYIK & & 3 & 37.624 & 3372331.95 \\
\hline gi|3980175| & $\begin{array}{l}\text { Thy } 1.2 \\
\text { antigen [Mus } \\
\text { synaptosomal- }\end{array}$ & SRVTLSNQPYIK & & 1 & 37.637 & 88190.508 \\
\hline gi|122889819| & $\begin{array}{l}\text { associated } \\
\text { protein } 25 \\
\text { [Mus } \\
\text { A }{ }^{--2} \text { complex } \\
\text { subunit mu-1 } \\
\text { (Adaptin mu- } \\
\text { 1) (AP-2 mu- } \\
2 \text { chain) } \\
\text { (Clathrin coat } \\
\text { assembly } \\
\text { protein AP50) } \\
\text { (Clathrin }\end{array}$ & MLQLVEESK & Oxidation (M) & 1 & 37.804 & 204328.599 \\
\hline gi|51316977| & $\begin{array}{l}\text { coat- } \\
\text { associated } \\
\text { protein AP50) } \\
\text { (Plasma } \\
\text { membrane } \\
\text { adaptor AP-2 } \\
50 \text { kDa } \\
\text { protein) } \\
\text { (Clathrin } \\
\text { sccomhlı, }\end{array}$ & SNFKPSLLAQK & & 1 & 37.817 & 89005.299 \\
\hline
\end{tabular}




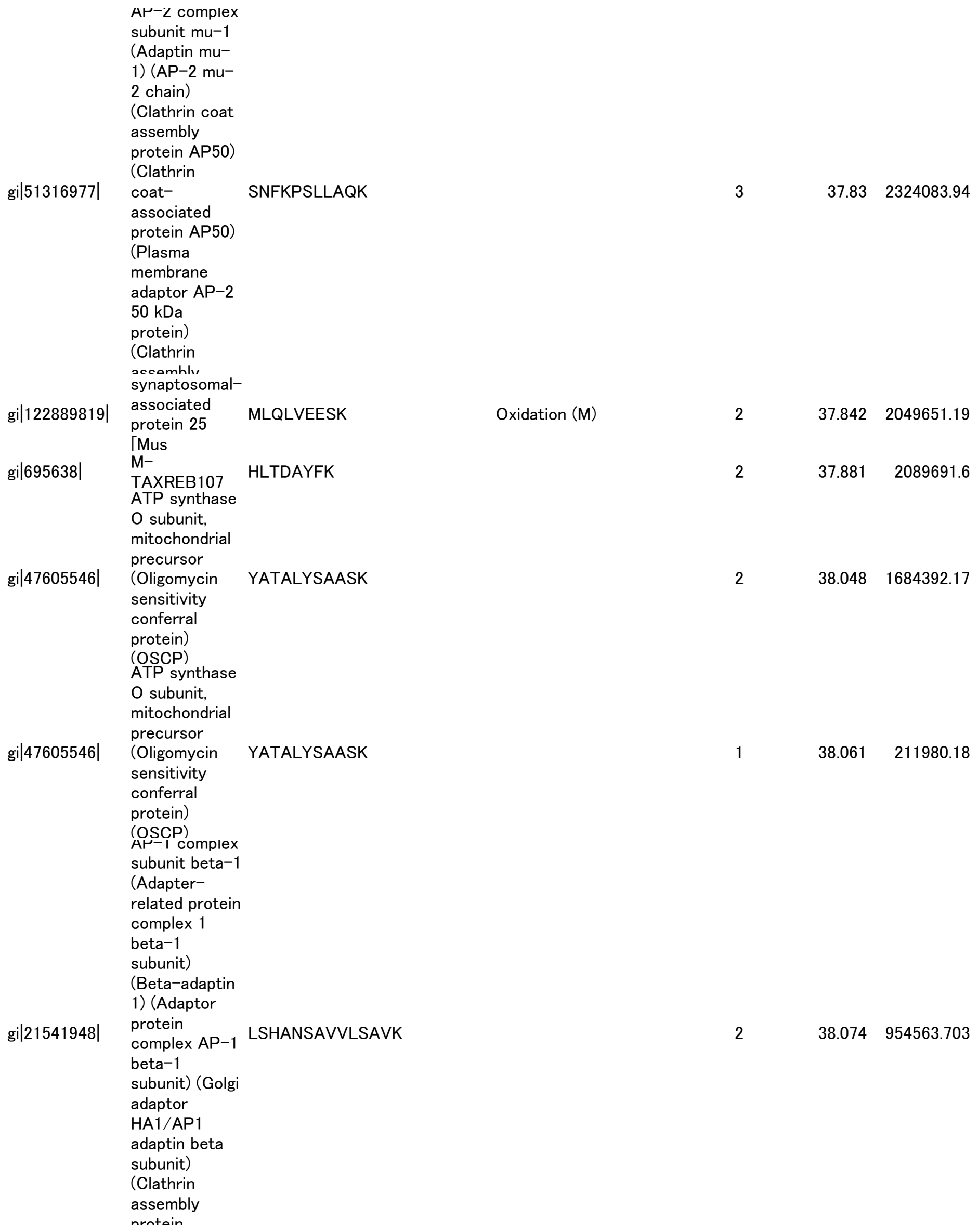




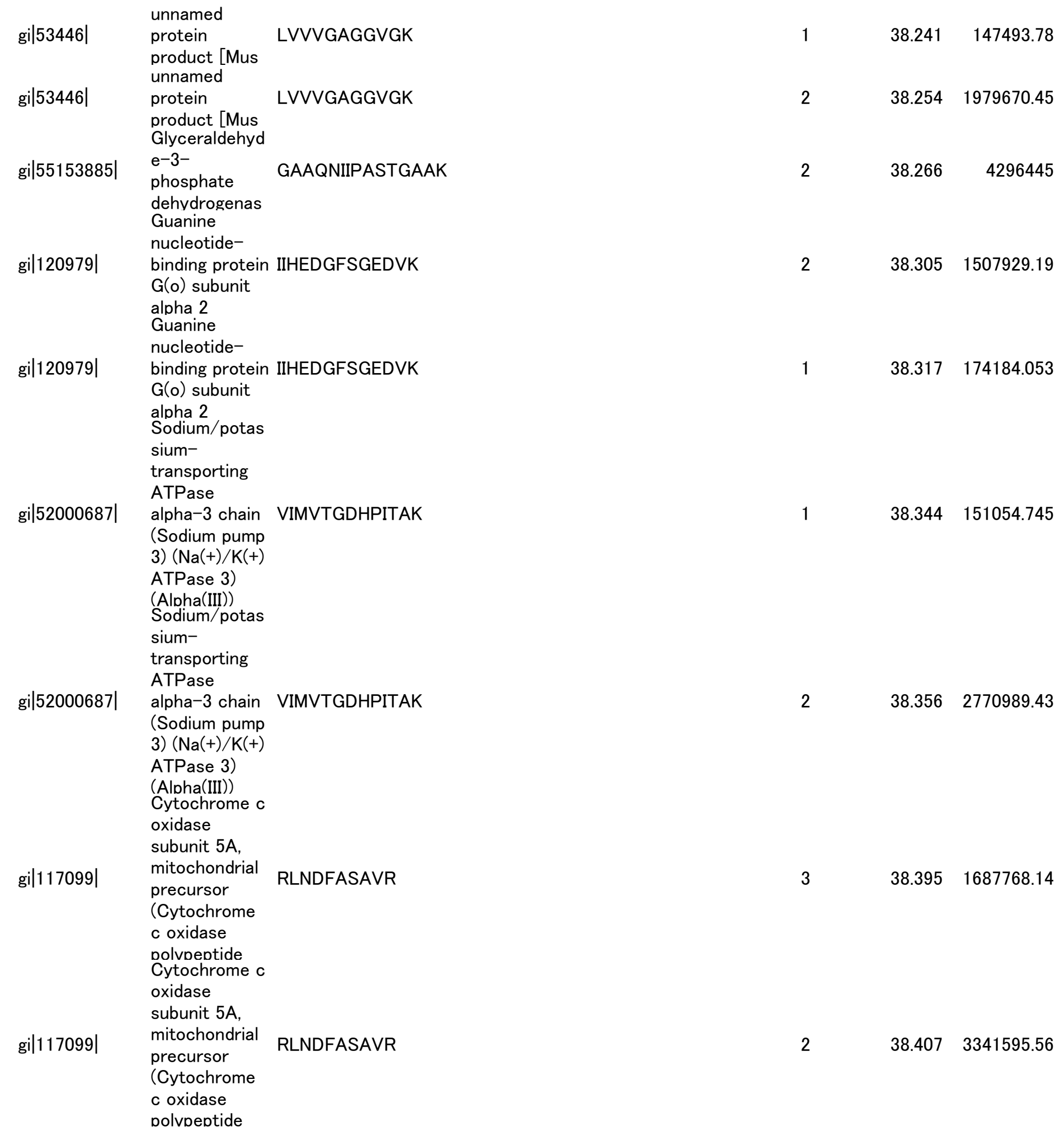




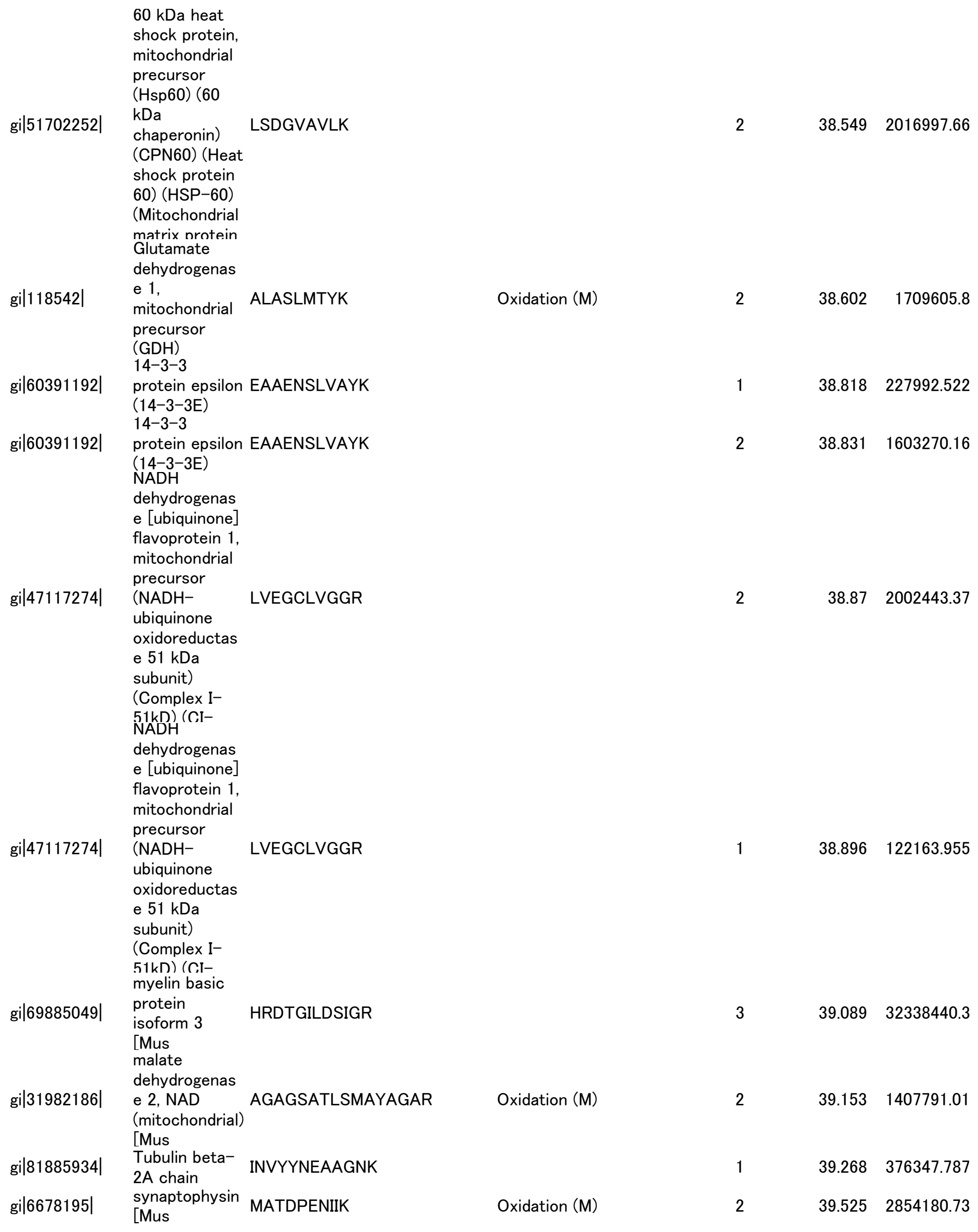




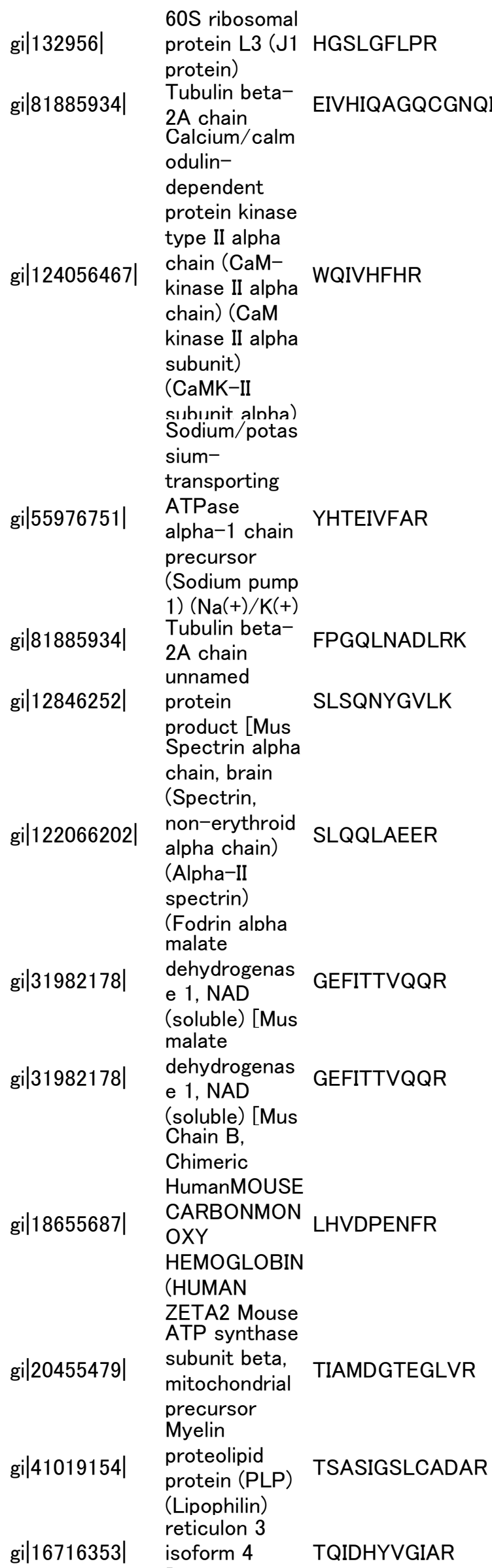

(Alpha-II

spectrin)

(Fodrin alpha malate

gi|31982178| dehydrogenas e 1, NAD

(soluble) [Mus

Chain B,

Chimeric

HumanMOUSE

gi|18655687|

CARBONMON

OXY

LHVDPENFR

HEMOGLOBIN

(HUMAN

\section{ZETA2 Mouse}

ATP synthase

gi|20455479| subunit beta, mitochondrial

TIAMDGTEGLVR

precursor Myelin

gi|41019154| proteolipid protein (PLP)

40.048143055 .41 


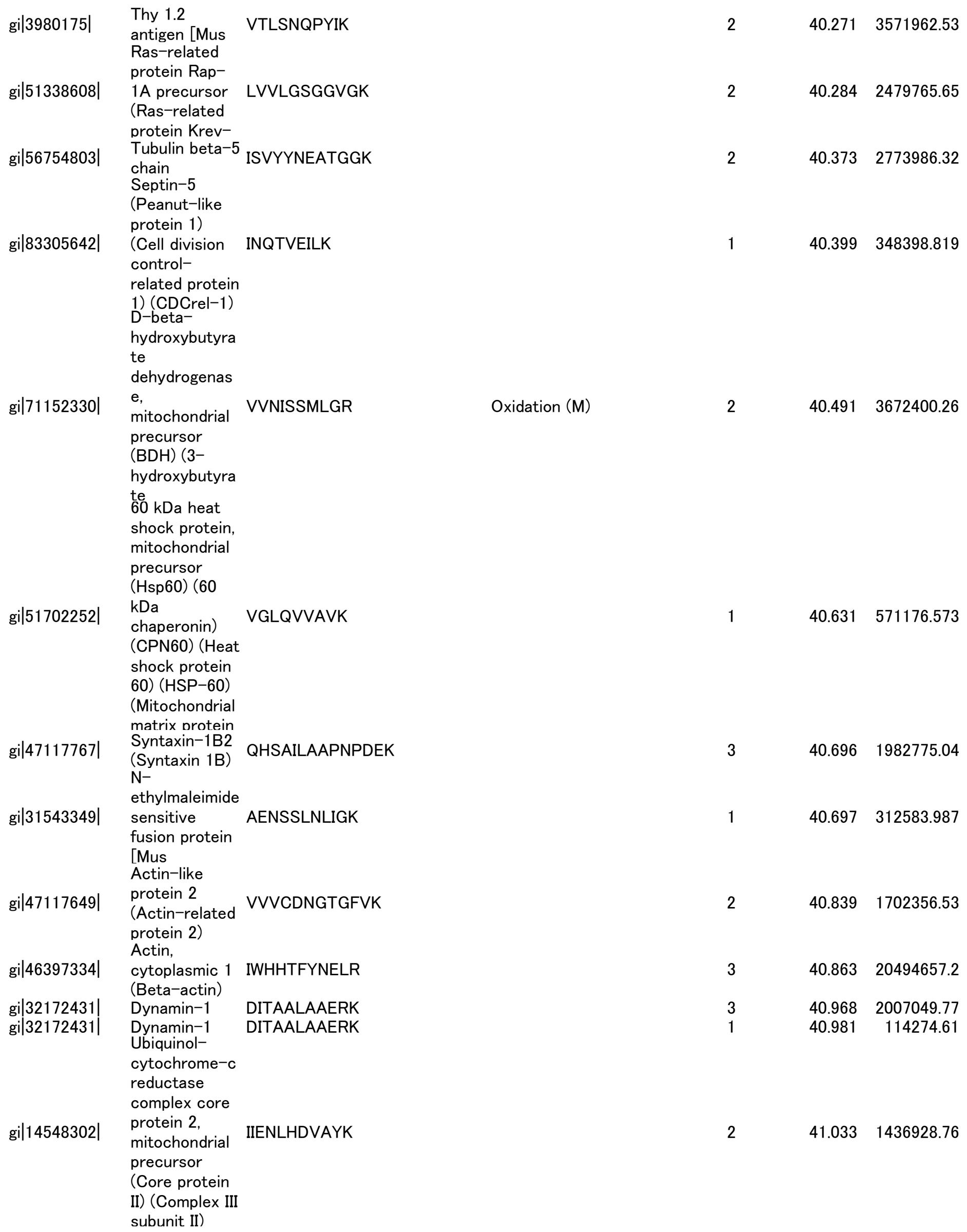

precursor

(BDH) (3-

hydroxybutyra

$60 \mathrm{kDa}$ heat

shock protein,

mitochondrial

precursor

(Hsp60) $(60$

gi|51702252| $\mathrm{kDa}$

chaperonin)

VGLQVVAVK

(CPN60) (Heat

shock protein

60) (HSP-60)

(Mitochondrial

matrix protein

gi|47117767| Syntaxin-1B2

(Syntaxin 1B)

QHSAILAAPNPDEK

$40.399 \quad 348398.819$

$\mathrm{N}-$

ethylmaleimide

gi|31543349|

sensitive

AENSSLNLIGK

$40.631 \quad 571176.573$

fusion protein

[Mus

Actin-like

gi|47117649|

protein 2

(Actin-related

VVVCDNGTGFVK

$40.696 \quad 1982775.04$

protein 2)

Actin,

gi|46397334|

cytoplasmic 1 IWHHTFYNELR

$40.863 \quad 20494657.2$

gi|32172431|

(Beta-actin)

gi|32172431|

Dynamin-1

DITAALAAERK

$40.968 \quad 2007049.77$

Dynamin-1

DITAALAAERK

$40.981 \quad 114274.61$

Ubiquinol-

cytochrome-c

reductase

complex core

gi|14548302| $\quad \begin{aligned} & \text { protein 2, } \\ & \text { mitochondrial }\end{aligned}$

IIENLHDVAYK

2

$41.033 \quad 1436928.76$

precursor

(Core protein

II) (Complex III subunit II) 


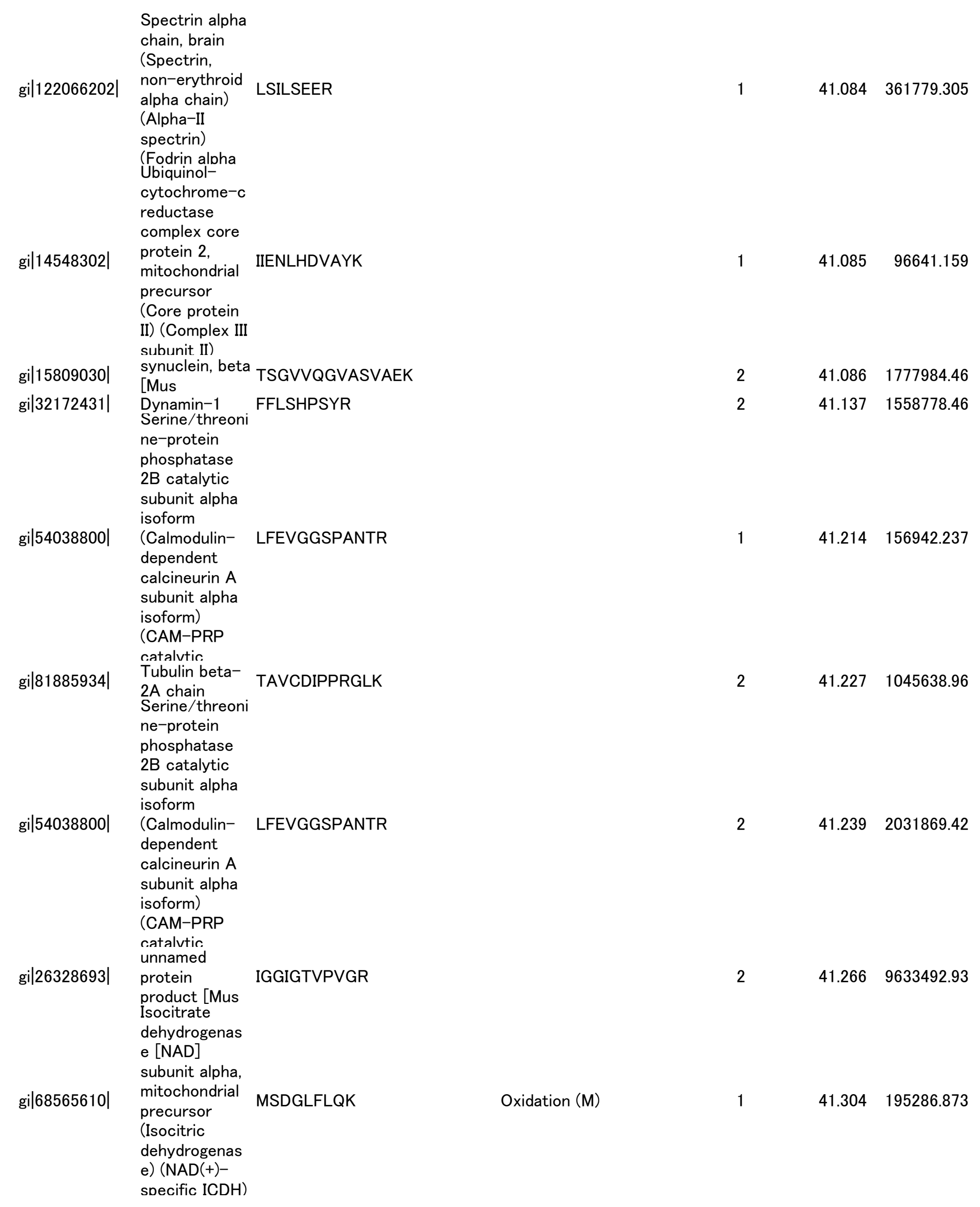




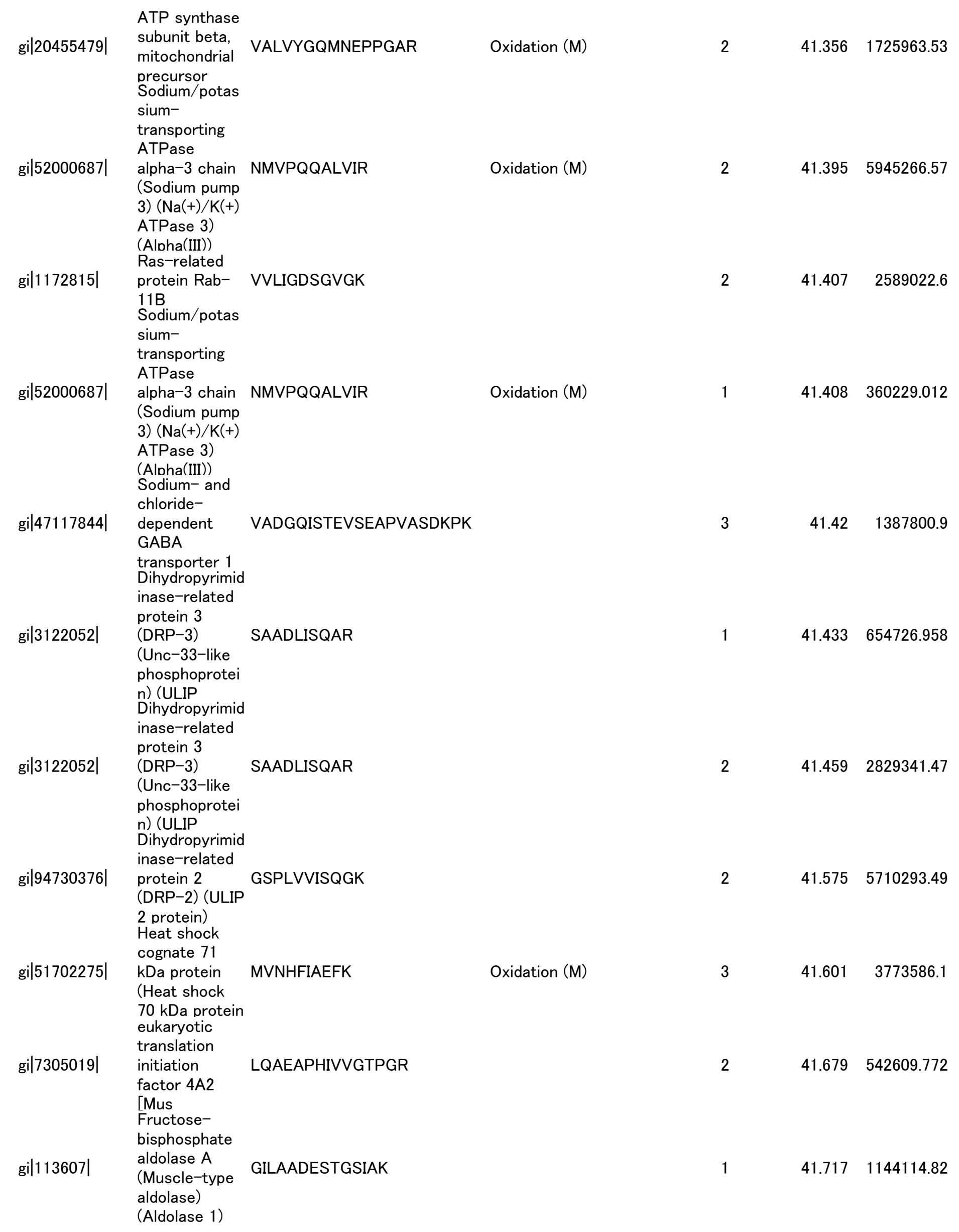




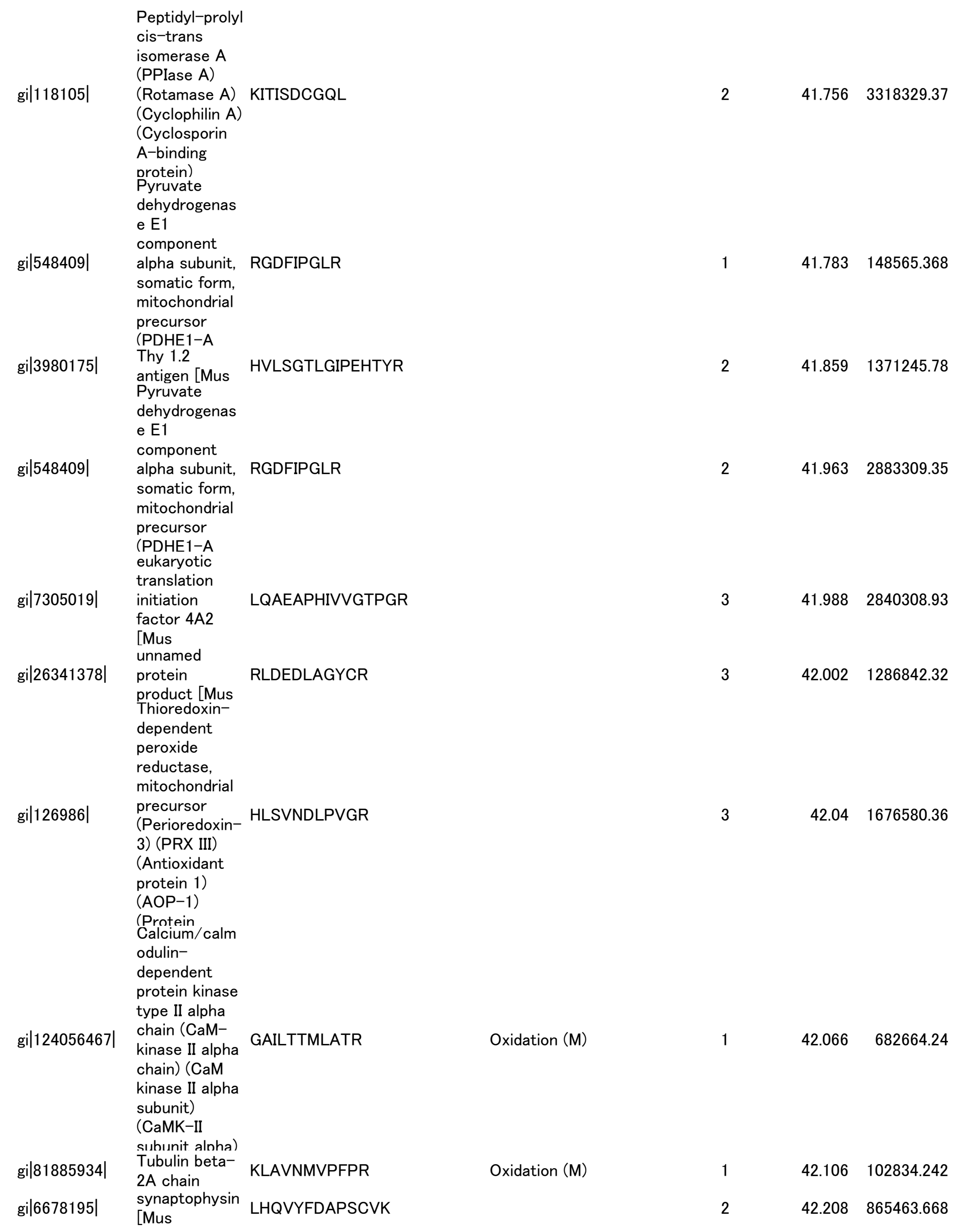




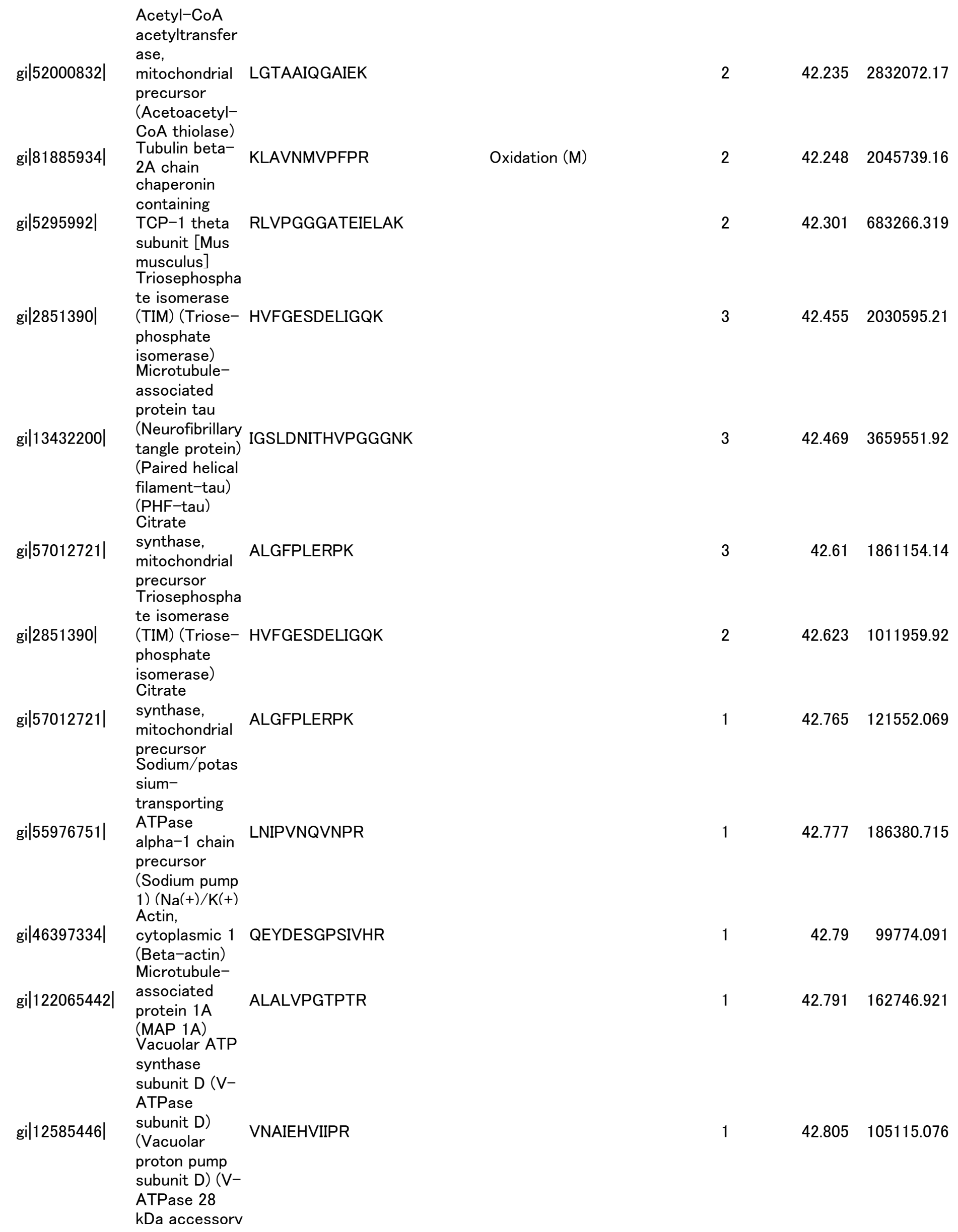




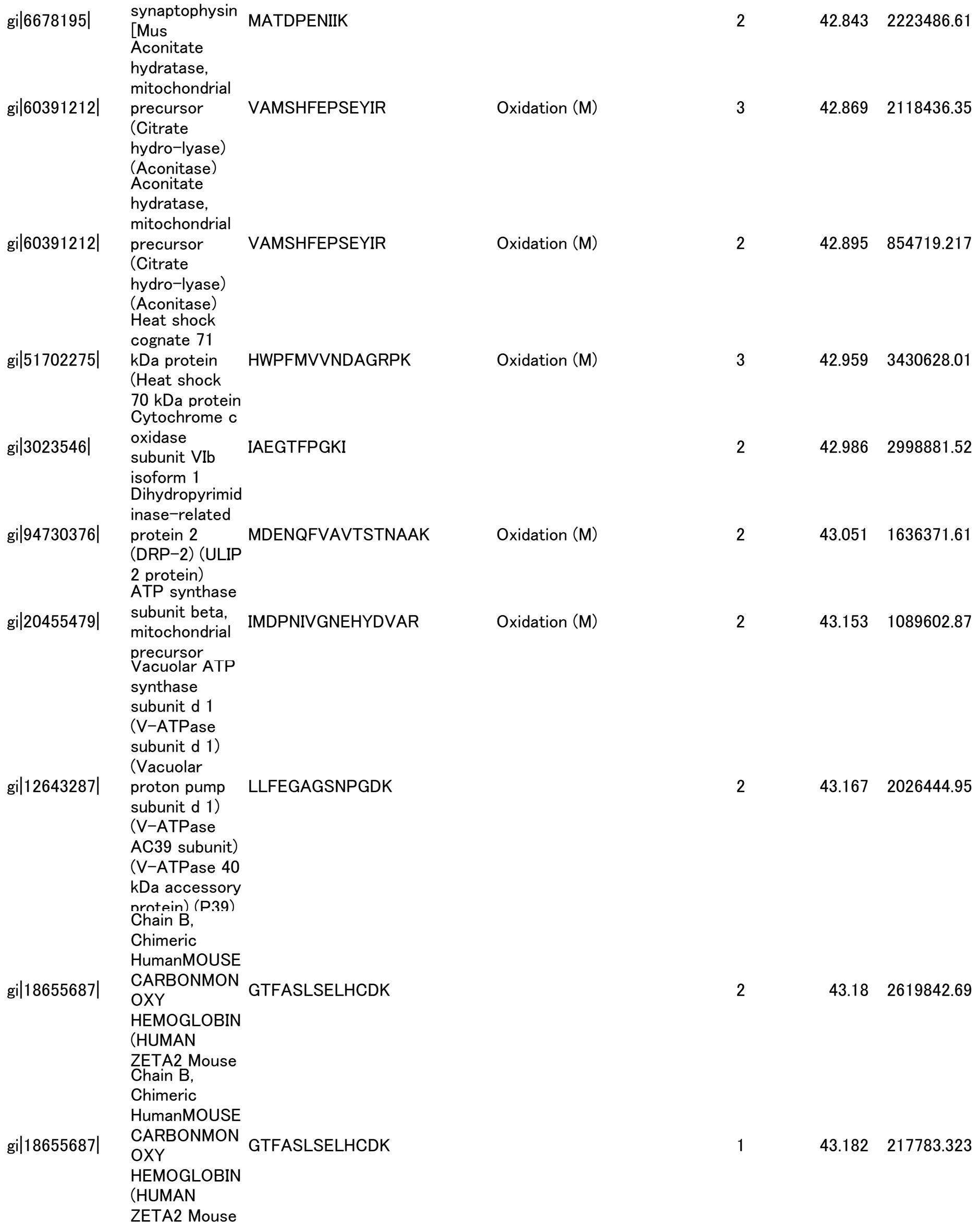




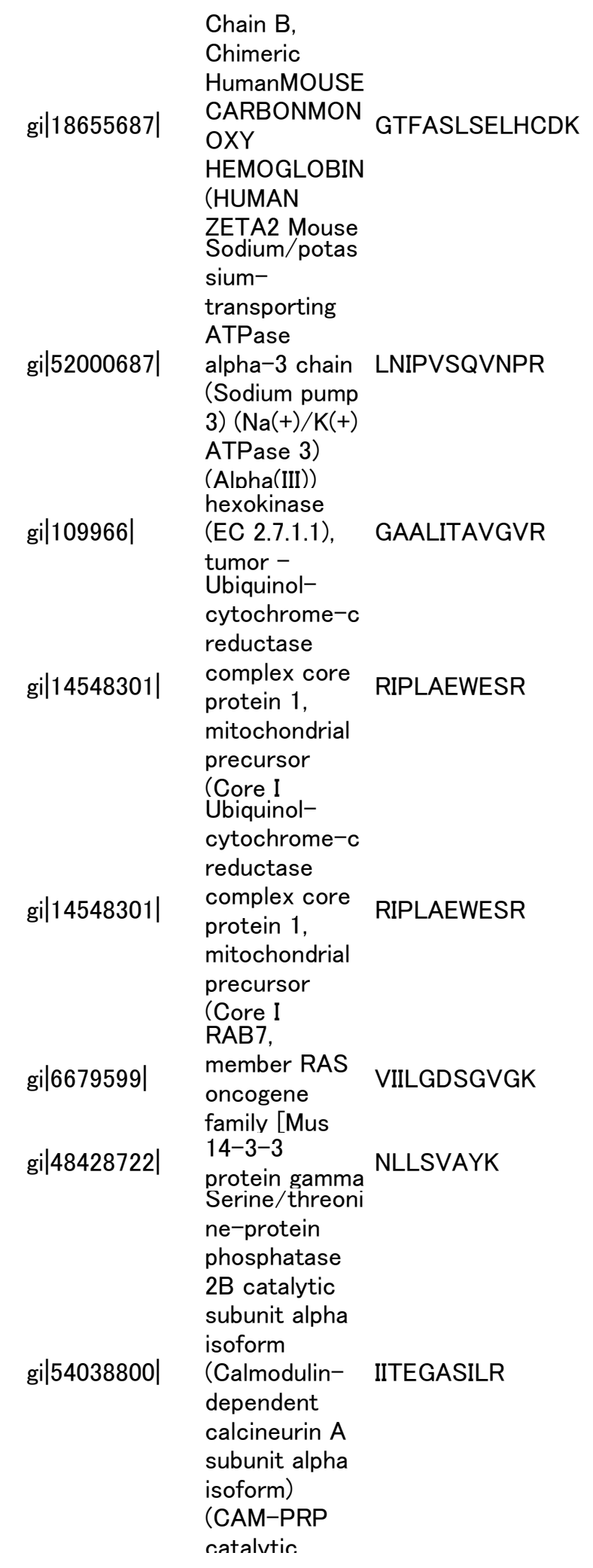




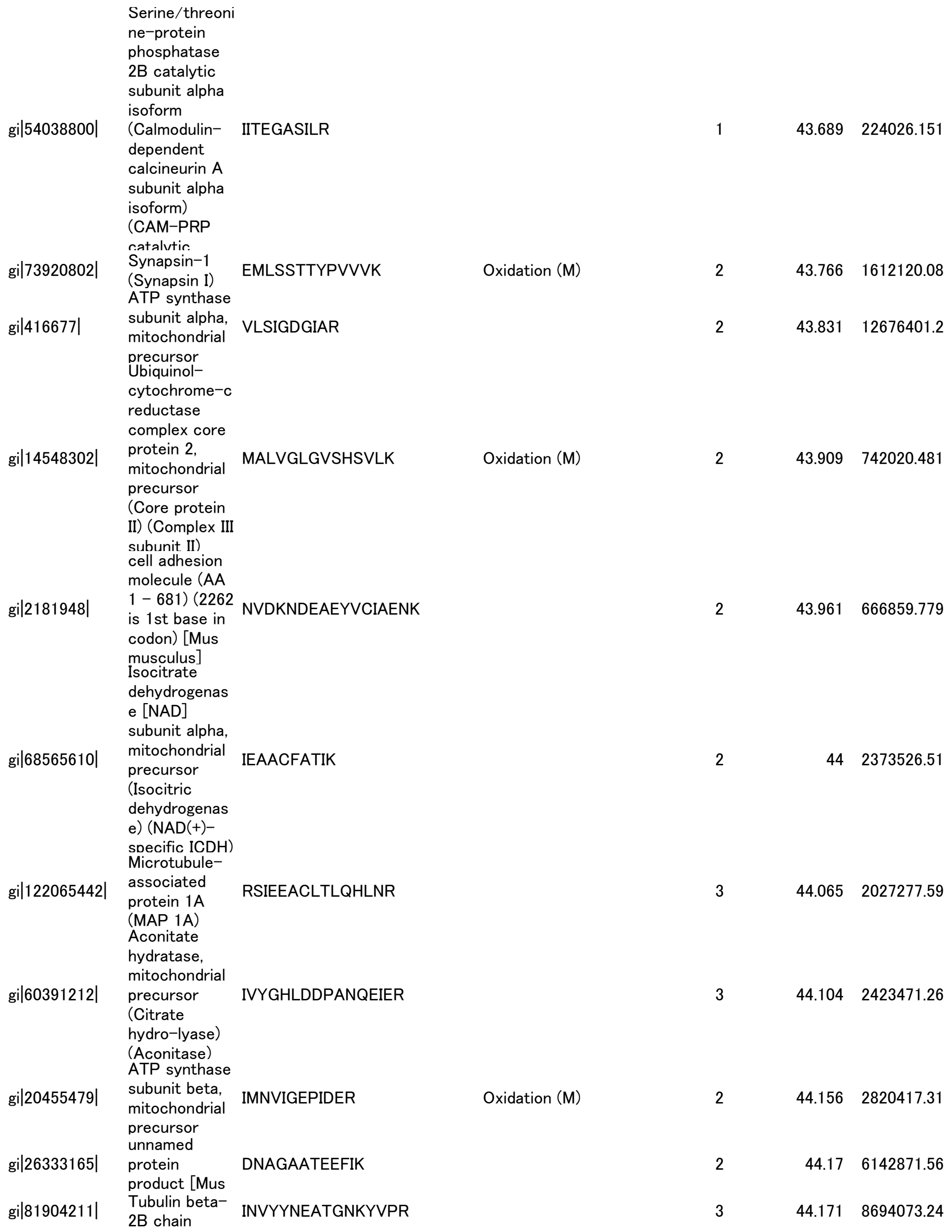




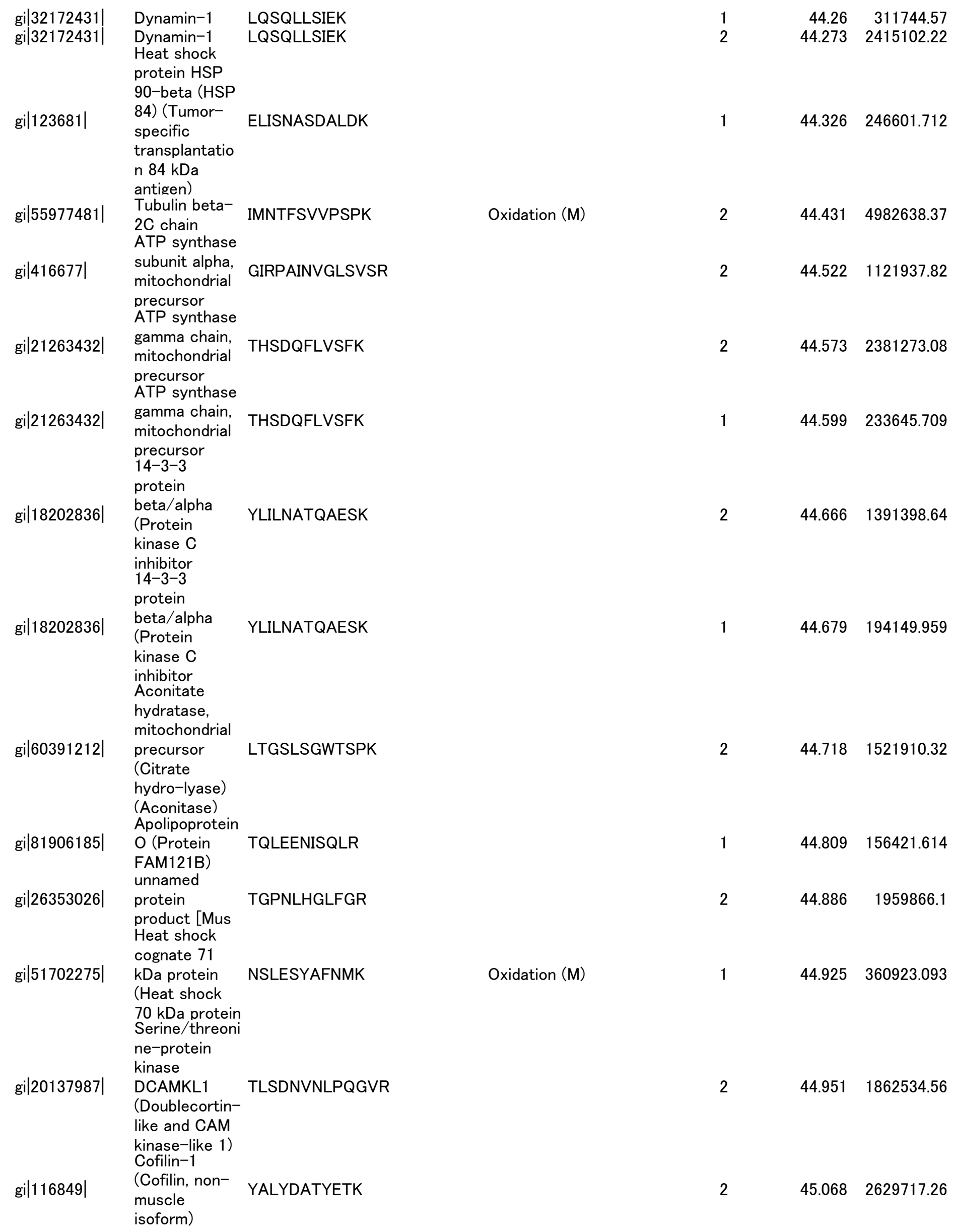




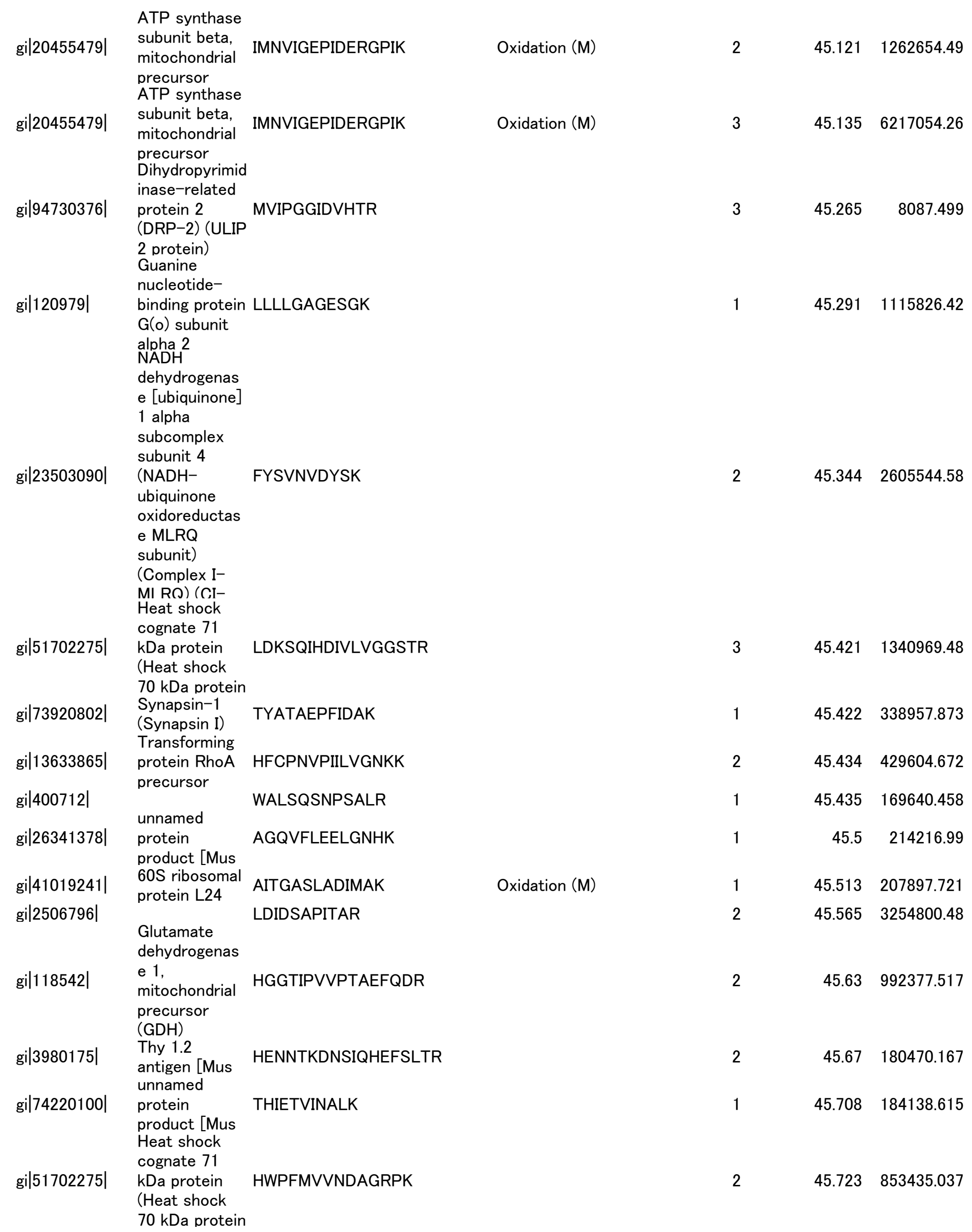




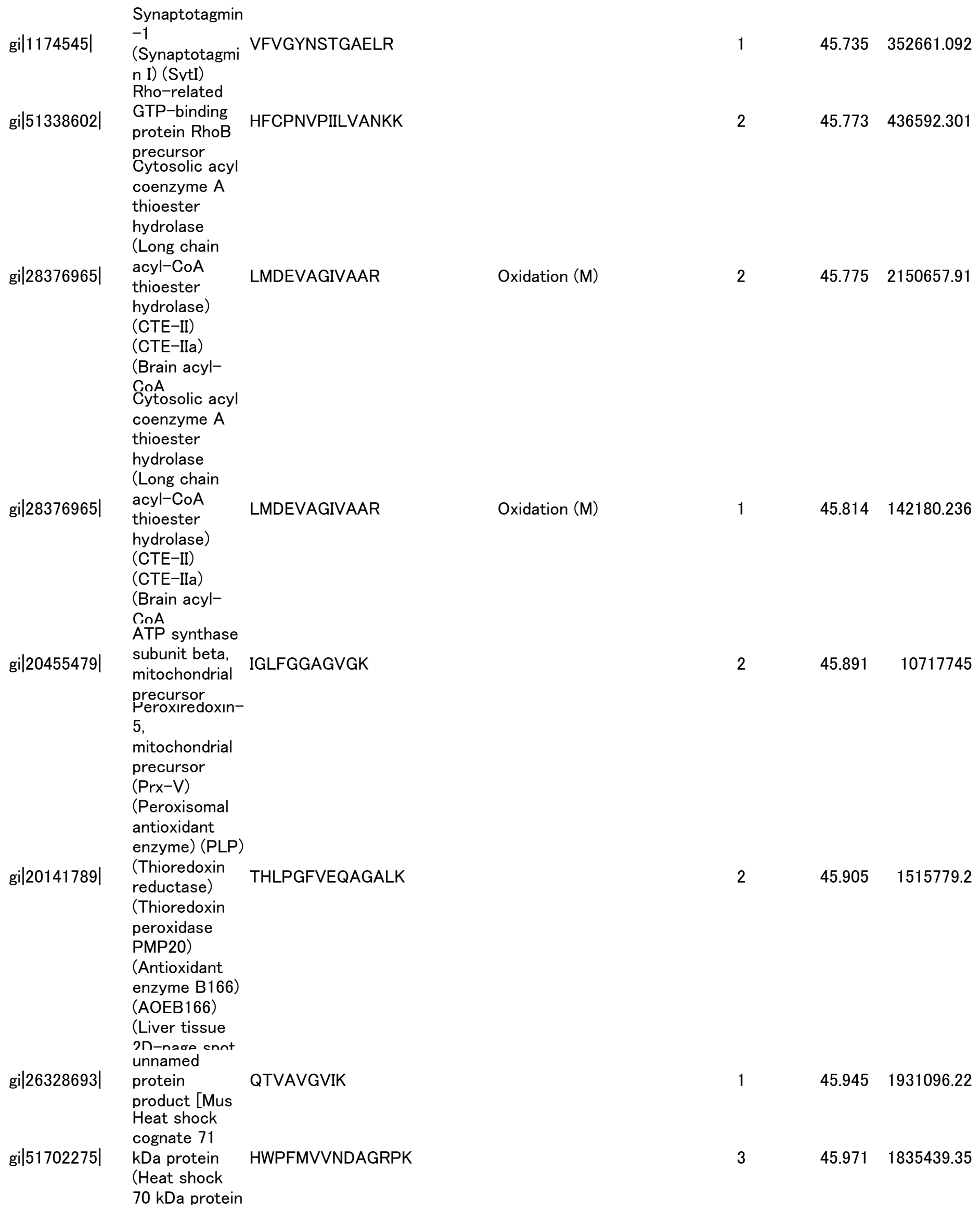




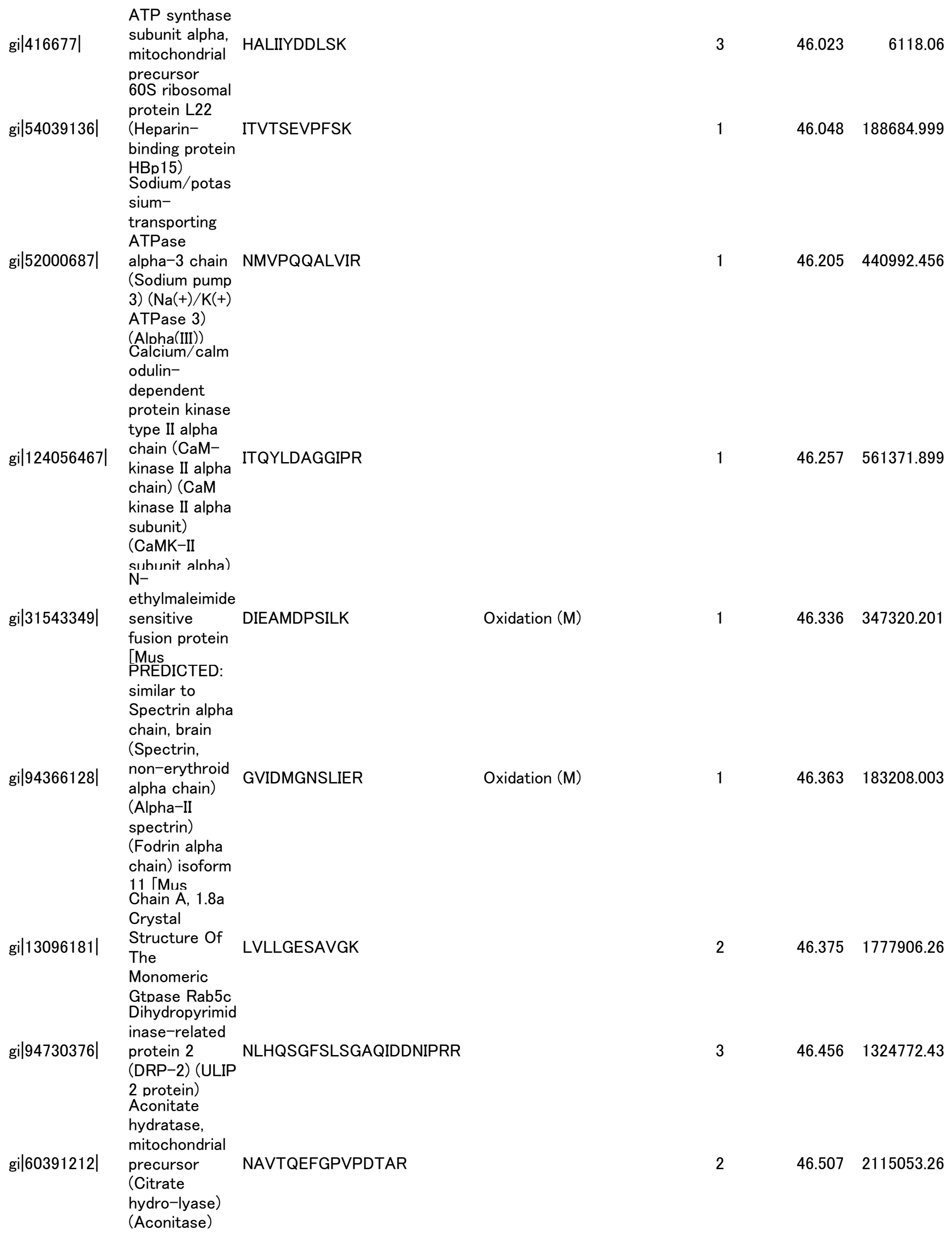




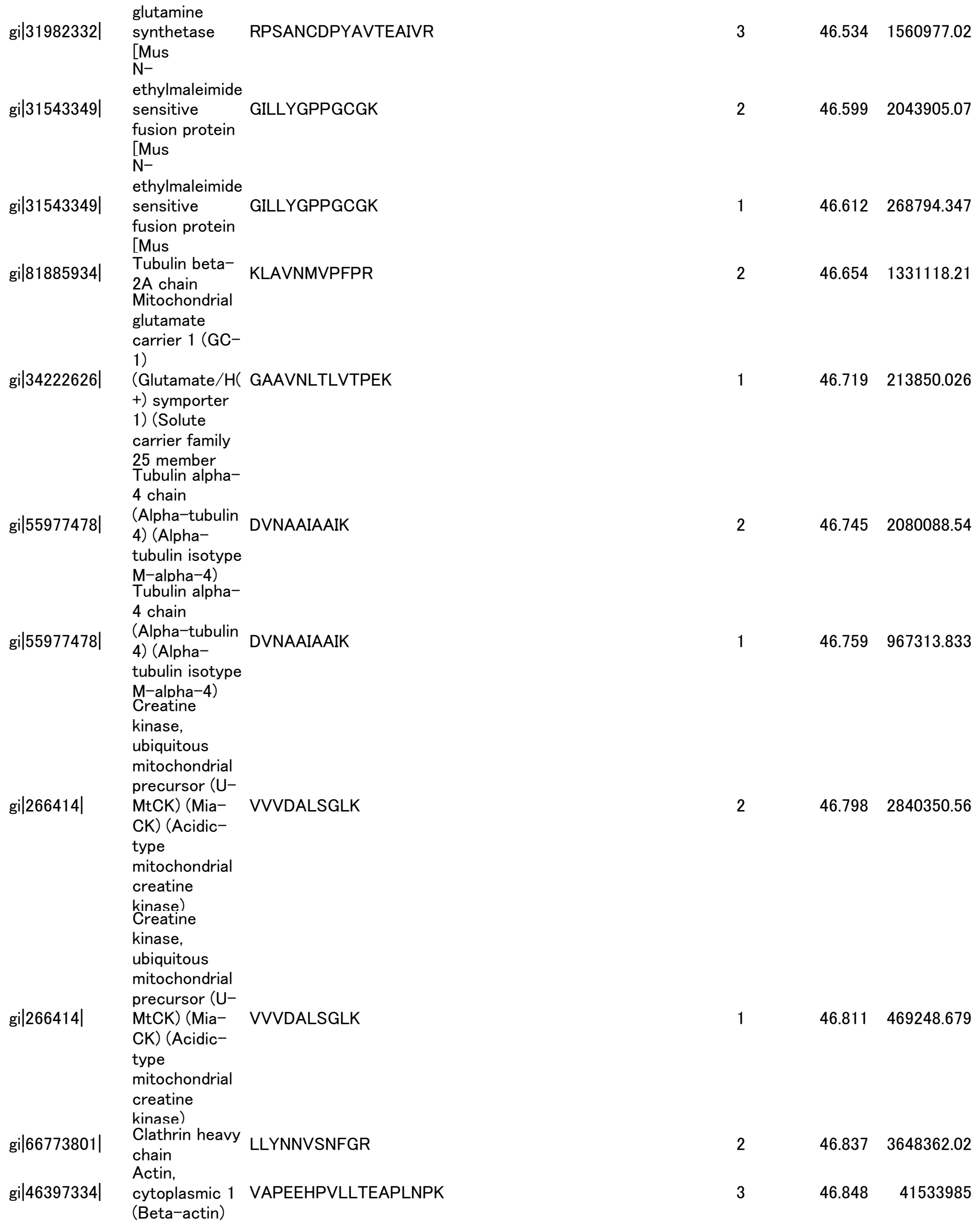

usion protein

[Mus

$\mathrm{N}-$

ethylmaleimide

gi|31543349|

sensitive

GILLYGPPGCGK

$46.612 \quad 268794.347$

fusion protein

[Mus

gi|81885934| Tubulin beta-

2A chain

KLAVNMVPFPR

Mitochondrial

glutamate

carrier 1 (GC-

1)

gi|34222626) (Glutamate/H( GAAVNLTLVTPEK

+) symporter

1) (Solute

carrier family

25 member

Tubulin alpha-

4 chain

gi|55977478| (Alpha-tubulin

4) (Alpha-

DVNAAIAAIK

2

$46.745 \quad 2080088.54$

(Abulin isotype

M-alpha-4)

Tubulin alpha-

4 chain

gi|55977478| (Alpha-tubulin

4) (Alpha-

DVNAAIAAIK

tubulin isotype

M-alpha-4)

Creatine

kinase,

ubiquitous

mitochondrial

precursor (U-

gi|266414| MtCK) (Mia-

VVVDALSGLK

$46.798 \quad 2840350.56$

CK) (Acidic-

type

mitochondrial

creatine

kinase)

Creatine

kinase,

ubiquitous

mitochondrial

precursor (U-

gi|266414|

MtCK) (Mia-

VVVDALSGLK

$46.759 \quad 967313.833$

CK) (Acidic-

type

mitochondrial

creatine

kinase)

gi|66773801|

Clathrin heavy

chain

LLYNNVSNFGR

Actin,

gi|46397334|

cytoplasmic 1 VAPEEHPVLLTEAPLNPK

(Beta-actin)

$2 \quad 46.837 \quad 3648362.02$

$3 \quad 46.848 \quad 41533985$ 


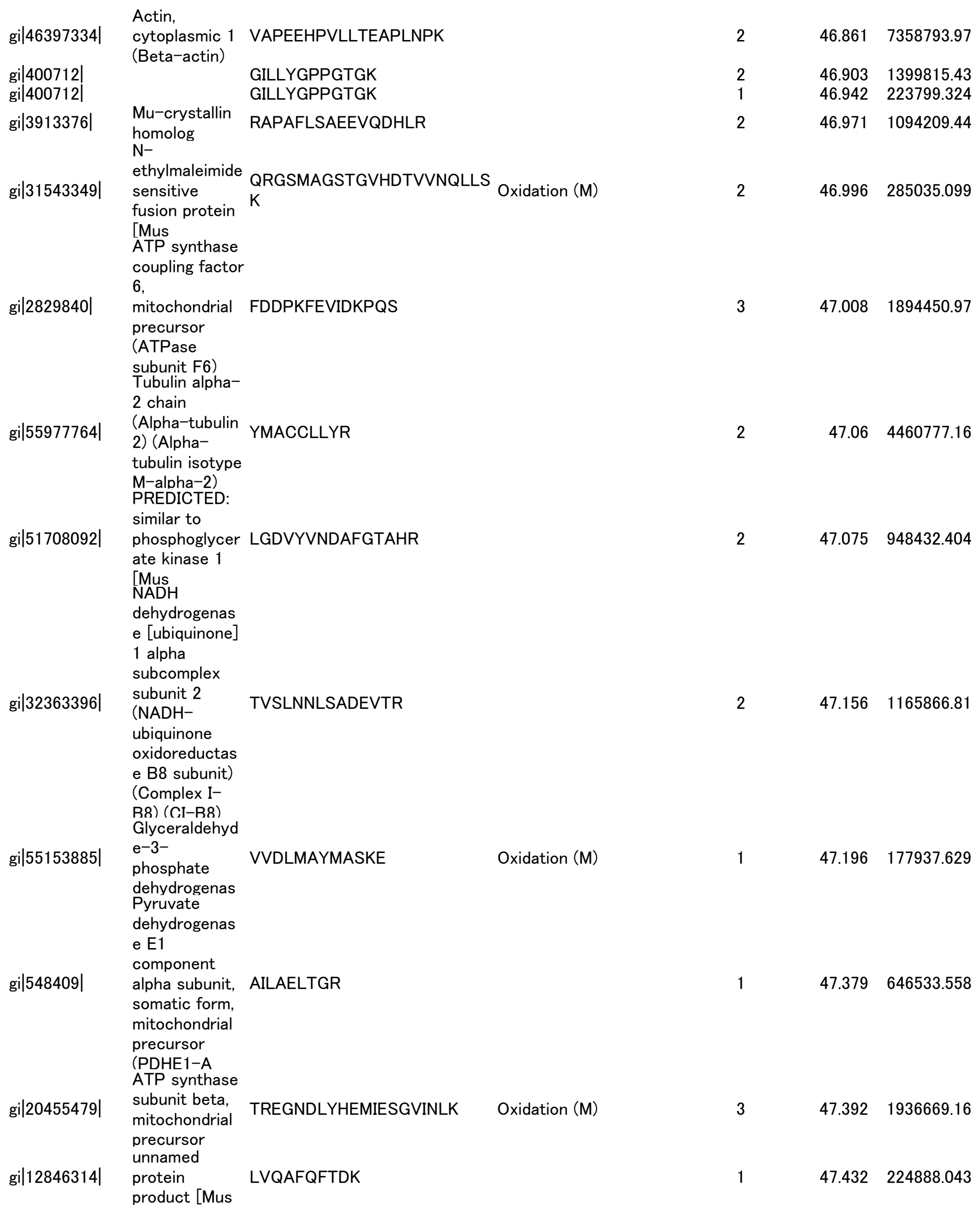




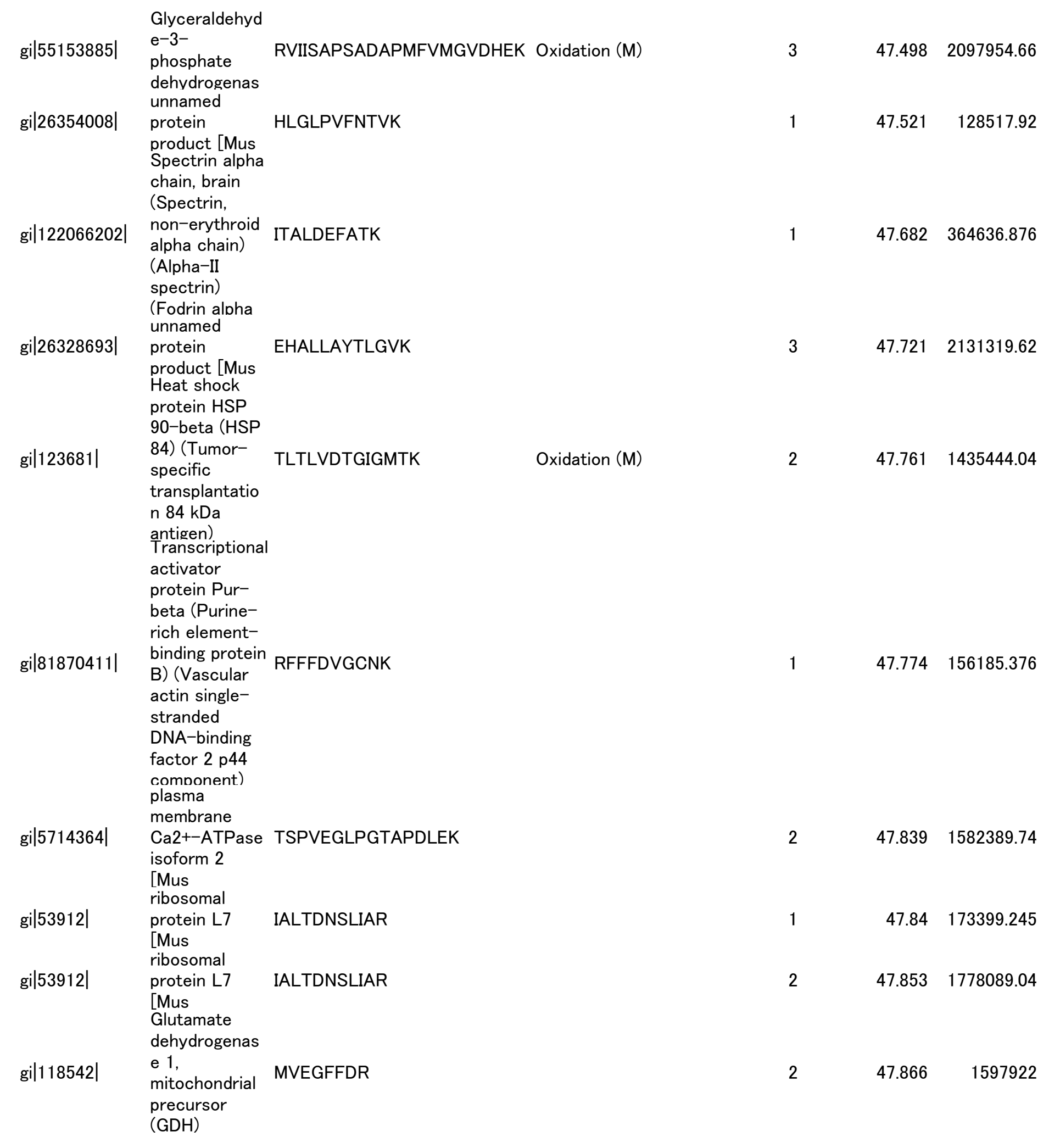




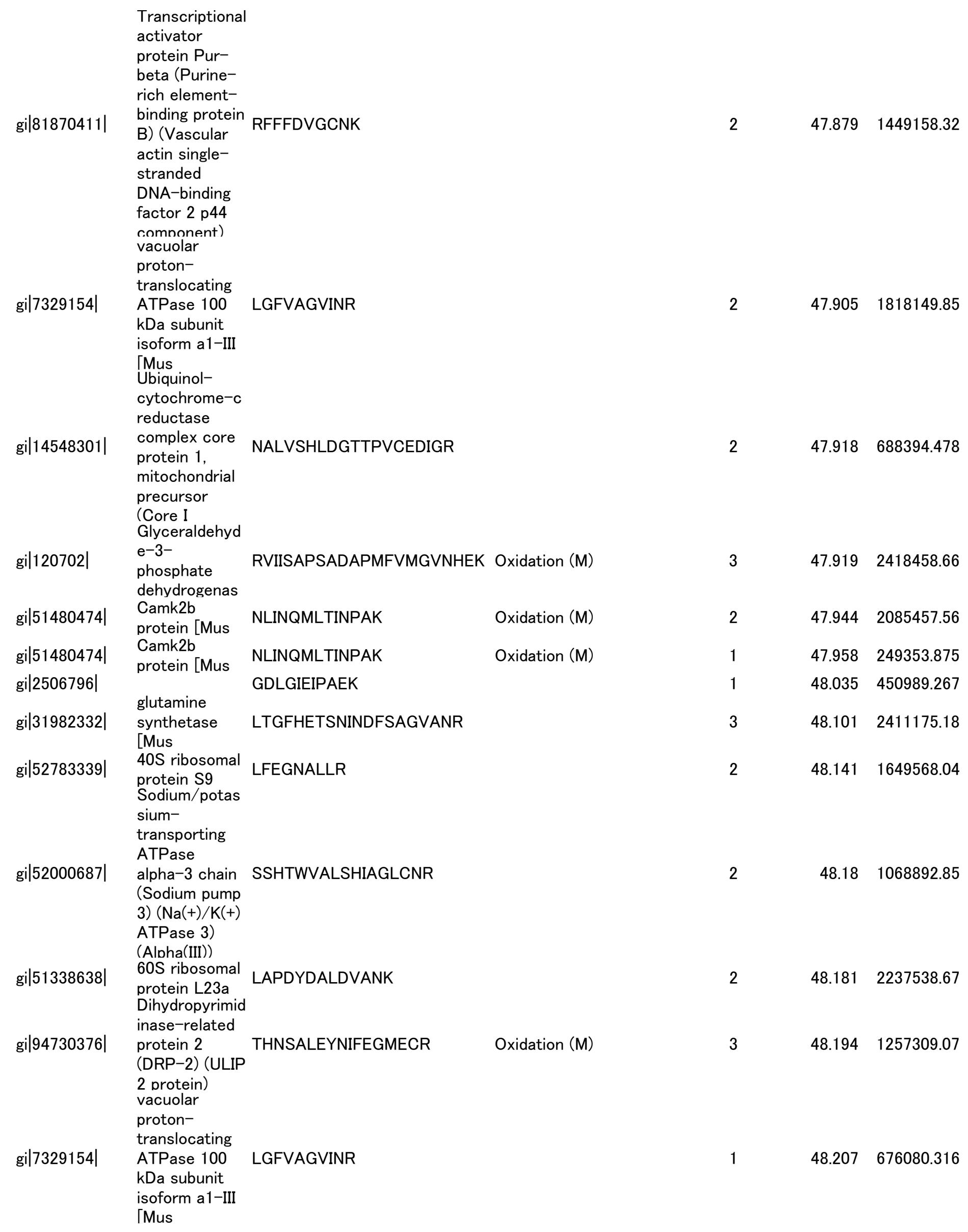




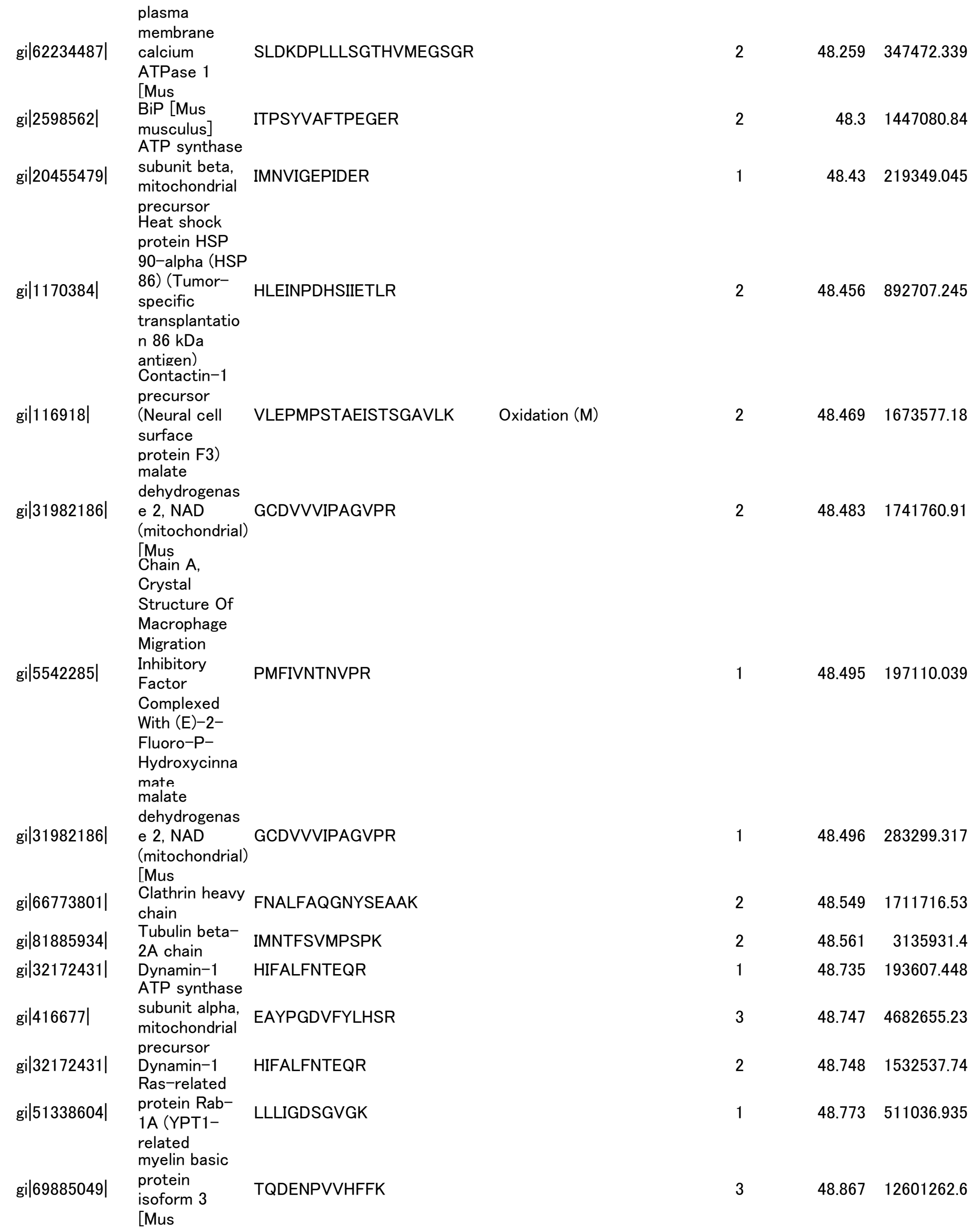




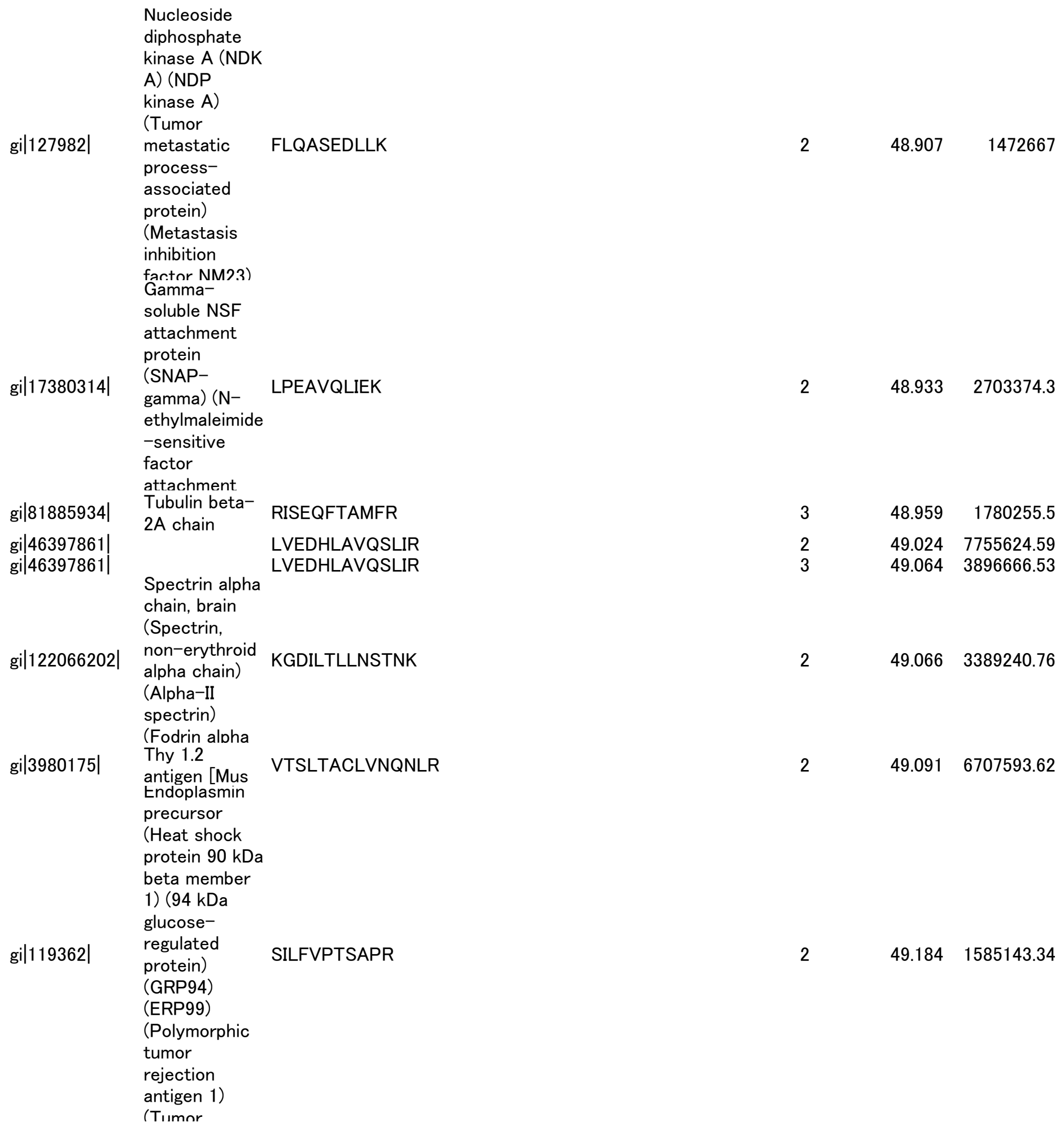

(Alpha-II spectrin)

(GRP94)

(ERP99)

(Polymorphic tumor 


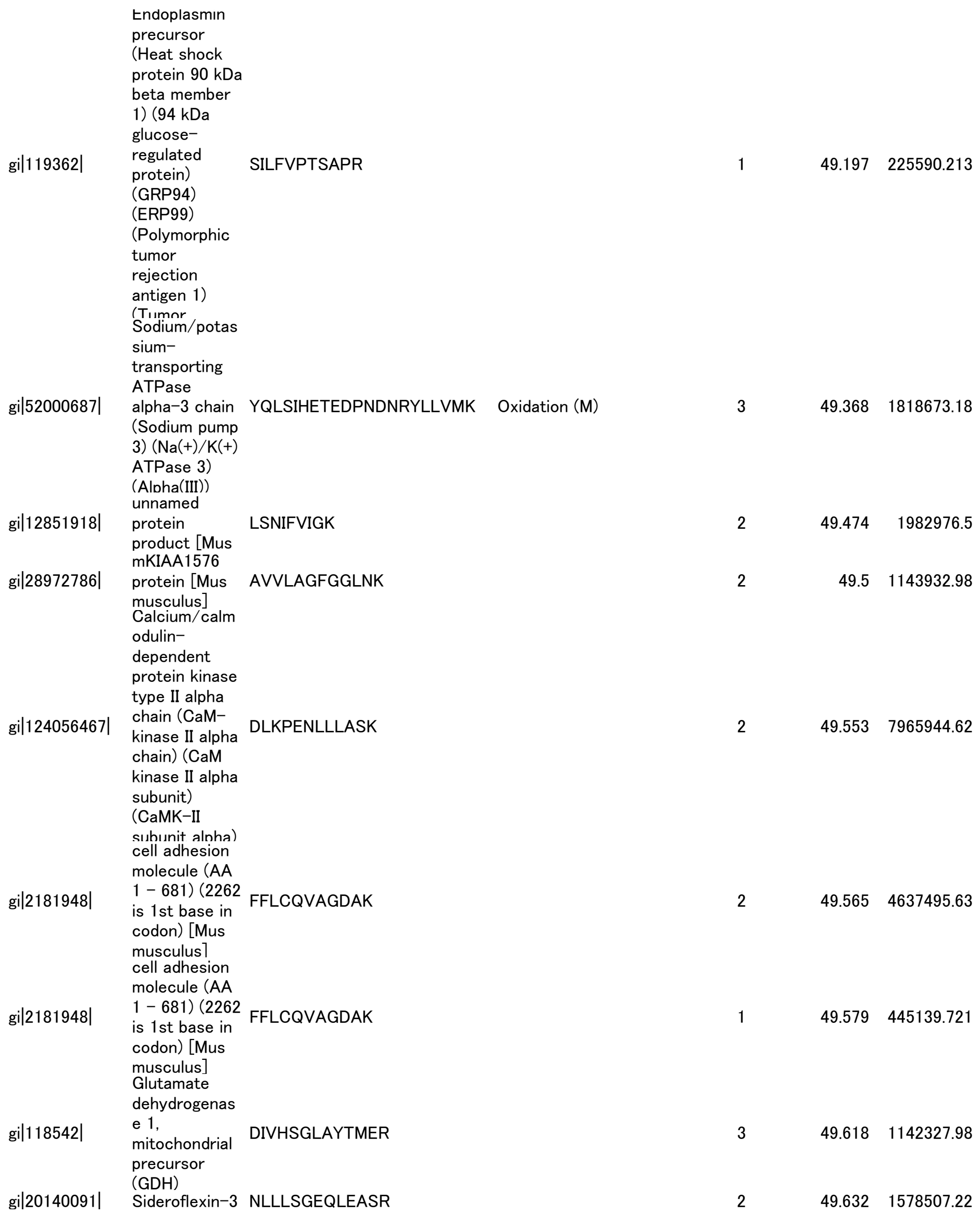




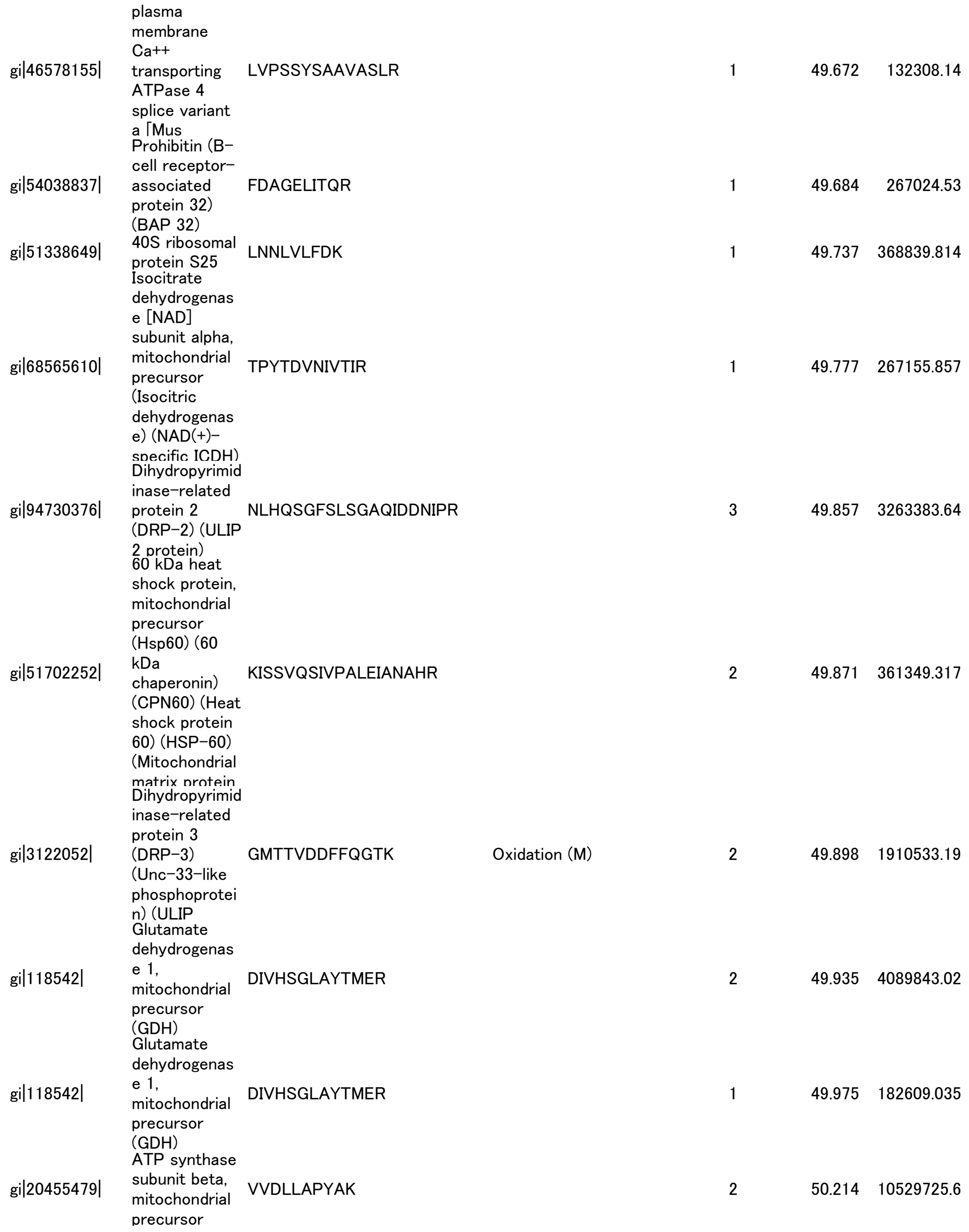




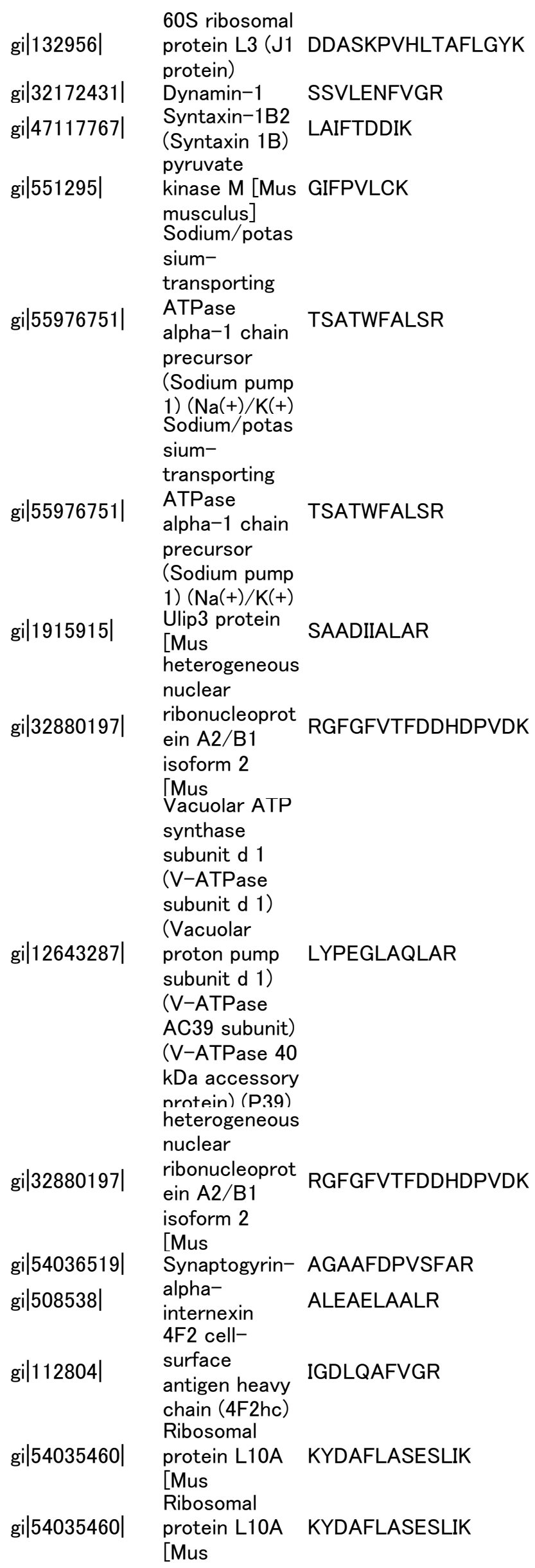




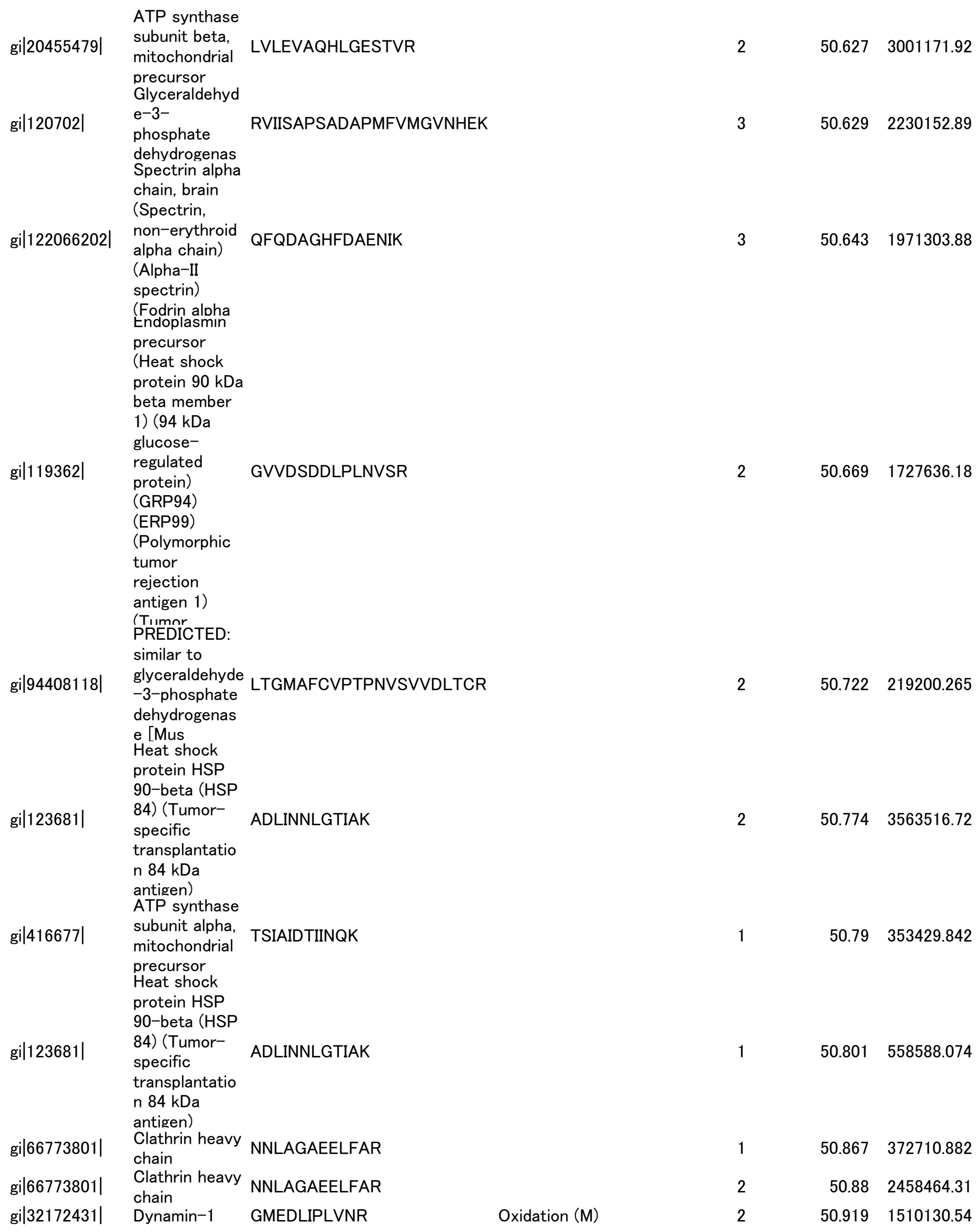

(Alpha-II spectrin) 


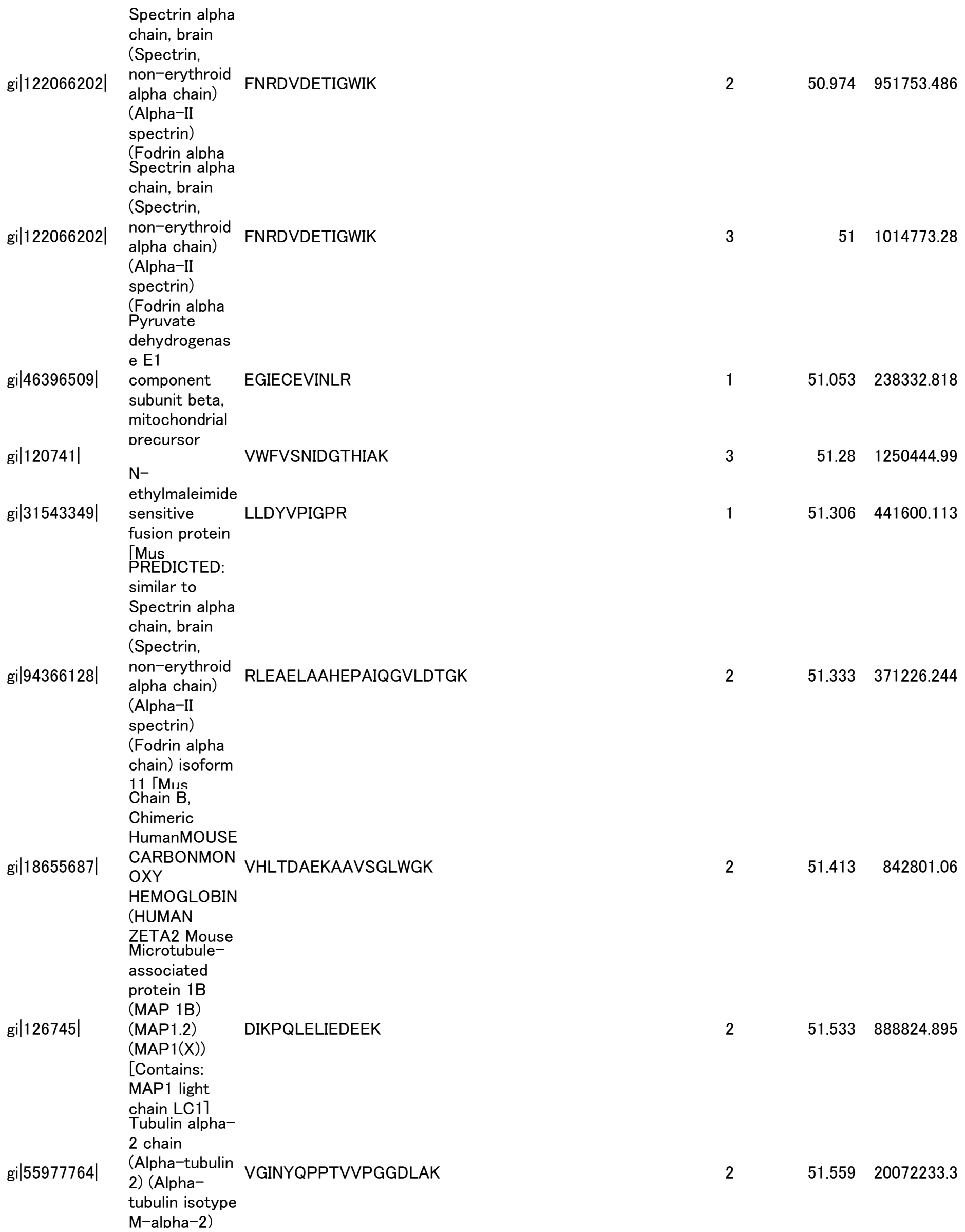

(Alpha-II

spectrin)

(Fodrin alpha

Spectrin alpha

chain, brain

(Spectrin,

gi|122066202| non-erythroid alpha chain)

FNRDVDETIGWIK

(Alpha-II

spectrin)

(Fodrin alpha

Pyruvate

dehydrogenas

e E1

gi|46396509| component

EGIECEVINLR

1

$51.053 \quad 238332.818$

mitochondrial

gi|120741|

precursor

VWFVSNIDGTHIAK

$\mathrm{N}-$

LLDYVPIGPR

fusion protein

[Mus

PREDICTED:

similar to

Spectrin alpha

chain, brain

(Spectrin,

gi|94366128| non-erythroid alpha chain)

RLEAELAAHEPAIQGVLDTGK

2

$51.333 \quad 371226.244$

(Alpha-Il

spectrin)

(Fodrin alpha

chain) isoform

11「Mus

Chimeric

HumanMOUSE

gil186556871 CARBONMON

OXY

VHLTDAEKAAVSGLWGK

2

$51.413 \quad 842801.06$

HEMOGLOBIN

(HUMAN

ZETA2 Mouse

Microtubule-

associated

protein 1B

(MAP 1B)

gi|126745|

(MAP1.2)

(MAP1(X))

[Contains:

MAP1 light

chain LC11

Tubulin alpha-

2 chain

gil55977764 (Alpha-tubulin

2) (Alpha-

DIKPQLELIEDEEK

2

$51.533 \quad 888824.895$

tubulin isotype

M-alpha-2)

VGINYQPPTVVPGGDLAK 


\begin{tabular}{|c|c|c|c|c|c|c|}
\hline & $\begin{array}{l}\mathrm{N}- \\
\text { ethylmaleimide }\end{array}$ & & & & & \\
\hline gi|31543349| & $\begin{array}{l}\text { sensitive } \\
\text { fusion protein } \\
\text { [Mus } \\
\text { Microtubule- }\end{array}$ & LLDYVPIGPR & & 2 & 51.585 & 2283173.23 \\
\hline gi|122065442| & $\begin{array}{l}\text { associated } \\
\text { protein 1A } \\
\text { (MAP 1A) } \\
\text { Sodium/potas } \\
\text { sium- } \\
\text { transporting }\end{array}$ & VVSNTIEPLTLFHK & & 3 & 51.679 & 1219348.74 \\
\hline gi|55976751| & $\begin{array}{l}\text { ATPase } \\
\text { alpha-1 chain } \\
\text { precursor } \\
\text { (Sodium pump } \\
\text { 1) }(\mathrm{Na}(+) / \mathrm{K}(+) \\
\text { Microtubule- }\end{array}$ & AVFQANQENLPILK & & 2 & 51.692 & 1795052.67 \\
\hline gi|122065442| & $\begin{array}{l}\text { associated } \\
\text { protein } 1 \mathrm{~A} \\
\text { (MAP 1A) } \\
\text { Pyruvate } \\
\text { dehydrogenas } \\
\text { e E1 }\end{array}$ & VVSNTIEPLTLFHK & & 2 & 51.706 & 651862.956 \\
\hline gi|46396509| & $\begin{array}{l}\text { component } \\
\text { subunit beta, } \\
\text { mitochondrial }\end{array}$ & TIRPMDIEAIEASVMK & 2 Oxidation (M) & 3 & 51.733 & 1267593.5 \\
\hline & $\begin{array}{l}\text { precursor } \\
\text { PREDICTED: } \\
\text { protein } \\
\text { tyrosine }\end{array}$ & & & & & \\
\hline gi|63540701| & $\begin{array}{l}\text { phosphatase, } \\
\text { receptor type } \\
Z \text {, polypeptide } \\
1 \text { isoform } 1 \\
\text { 「Mus }\end{array}$ & FAVLYQPLAGNDQAK & & 2 & 51.757 & 13768217 \\
\hline gi|81885934| & $\begin{array}{l}\text { Tubulin beta- } \\
2 A \text { chain } \\
\text { Heat shock } \\
\text { cognate } 71\end{array}$ & AILVDLEPGTMDSVR & Oxidation (M) & 2 & 51.76 & 13020542.7 \\
\hline gi|51702275| & $\begin{array}{l}\text { kDa protein } \\
\text { (Heat shock }\end{array}$ & ARFEELNADLFR & & 2 & 51.799 & 3326142.77 \\
\hline & $\begin{array}{l}70 \mathrm{kDa} \text { protein } \\
\text { Heat shock } \\
\text { cognate } 71\end{array}$ & & & & & \\
\hline gi|51702275| & $\begin{array}{l}\text { kDa protein } \\
\text { (Heat shock } \\
70 \mathrm{kDa} \text { protein } \\
\text { malate } \\
\text { dehydrogenas }\end{array}$ & ARFEELNADLFR & & 1 & 51.826 & 175245.39 \\
\hline gi|31982186| & $\begin{array}{l}\text { e 2, NAD } \\
\text { (mitochondrial) } \\
\text { [Mus }\end{array}$ & GYLGPEQLPDCLK & & 1 & 51.839 & 169859.524 \\
\hline gi|66773801| & $\begin{array}{l}\text { Clathrin heavy } \\
\text { chain } \\
\text { Cytochrome c }\end{array}$ & ALEHFTDLYDIK & & 2 & 51.893 & 1398602.92 \\
\hline gi|3023546| & $\begin{array}{l}\text { oxidase } \\
\text { subunit VIb } \\
\text { isoform } 1\end{array}$ & NCWQNYLDFHR & & 2 & 51.973 & 833055.186 \\
\hline
\end{tabular}




\begin{tabular}{|c|c|c|c|c|c|c|}
\hline \multirow[b]{2}{*}{ gi|46396509| } & \multicolumn{6}{|l|}{$\begin{array}{l}\text { Pyruvate } \\
\text { dehydrogenas } \\
\text { e E1 }\end{array}$} \\
\hline & $\begin{array}{l}\text { component } \\
\text { subunit beta, } \\
\text { mitochondrial } \\
\text { precursor } \\
\mathrm{N}-\end{array}$ & TIRPMDIEAIEASVMK & 2 Oxidation (M) & 2 & 51.986 & 589636.093 \\
\hline gi|31543349| & $\begin{array}{l}\text { ethylmaleimide } \\
\text { sensitive } \\
\text { fusion protein } \\
\text { [Mus } \\
\text { Fructose- } \\
\text { bisphosphate }\end{array}$ & IAEESNFPFIK & & 2 & 52.051 & 1696927.32 \\
\hline gi|113607| & $\begin{array}{l}\text { aldolase A } \\
\text { (Muscle-type } \\
\text { aldolase) } \\
\text { (Aldolase 1) } \\
\mathrm{N}- \\
\text { ethylmaleimide }\end{array}$ & $\begin{array}{l}\text { GVVPLAGTNGETTTQGLDGLS } \\
\text { ER }\end{array}$ & & 2 & 52.079 & 4506882.15 \\
\hline gi|31543349| & $\begin{array}{l}\text { sensitive } \\
\text { fusion protein } \\
\text { [Mus } \\
\text { mKIAA1168 }\end{array}$ & IAEESNFPFIK & & 1 & 52.118 & 258426.854 \\
\hline gi|39104558| & $\begin{array}{l}\text { protein [Mus } \\
\text { musculus] } \\
¥ A T P a s e, H+ \\
\text { transporting }\end{array}$ & YAPLHLVPLIER & & 3 & 52.212 & 1712080.6 \\
\hline gi|16307356| & $\begin{array}{l}\text { lysosomal V1 } \\
\text { subunit C1 } \\
\text { [Mus } \\
\text { Synaptotagmin }\end{array}$ & IDCNLLEFK & & 2 & 52.399 & 4978662.49 \\
\hline gi|1174545| & $\begin{array}{l}-1 \\
\text { (Synaptotagmi } \\
\mathrm{n} \mathrm{I} \text { ) (SytI) } \\
\text { vacuolar } \\
\text { proton- } \\
\text { translocating }\end{array}$ & LGDICFSLR & & 1 & 52.439 & 439125.377 \\
\hline gi|7329154| & $\begin{array}{l}\text { ATPase } 100 \\
\mathrm{kDa} \text { subunit } \\
\text { isoform a1-III } \\
\text { 「Mus } \\
\text { Acetyl-CoA } \\
\text { acetyltransfer } \\
\text { ase, }\end{array}$ & ANIPIMDTGENPEVPFPR & Oxidation (M) & 2 & 52.48 & 853139.936 \\
\hline gi|52000832| & $\begin{array}{l}\text { mitochondrial } \\
\text { precursor } \\
\text { (Acetoacetyl- } \\
\text { CoA thiolase) }\end{array}$ & FASEITPITISVK & & 1 & 52.547 & 479270.19 \\
\hline gi|50403756| & $\begin{array}{l}40 \text { S ribosomal } \\
\text { protein } 523\end{array}$ & VANVSLLALYK & & 2 & 52.64 & 1651973.7 \\
\hline gi|50403756| & $\begin{array}{l}40 S \text { ribosomal } \\
\text { protein S23 } \\
\text { Microtubule- }\end{array}$ & VANVSLLALYK & & 1 & 52.68 & 315486.966 \\
\hline gi|126741| & $\begin{array}{l}\text { associated } \\
\text { protein 2 } \\
\text { (MAP 2) }\end{array}$ & VSEGPRPFAPVFFQSDDK & & 2 & 52.694 & 594666.919 \\
\hline gi|55977481| & $\begin{array}{l}\text { Tubulin beta- } \\
2 \mathrm{C} \text { chain } \\
\text { unnamed }\end{array}$ & ALTVPELTQQMFDAK & Oxidation (M) & 2 & 52.707 & 3361265.38 \\
\hline gi|26344902| & $\begin{array}{l}\text { protein } \\
\text { product [Mus }\end{array}$ & LAYINPDLALEEK & & 1 & 52.815 & 129858.134 \\
\hline
\end{tabular}




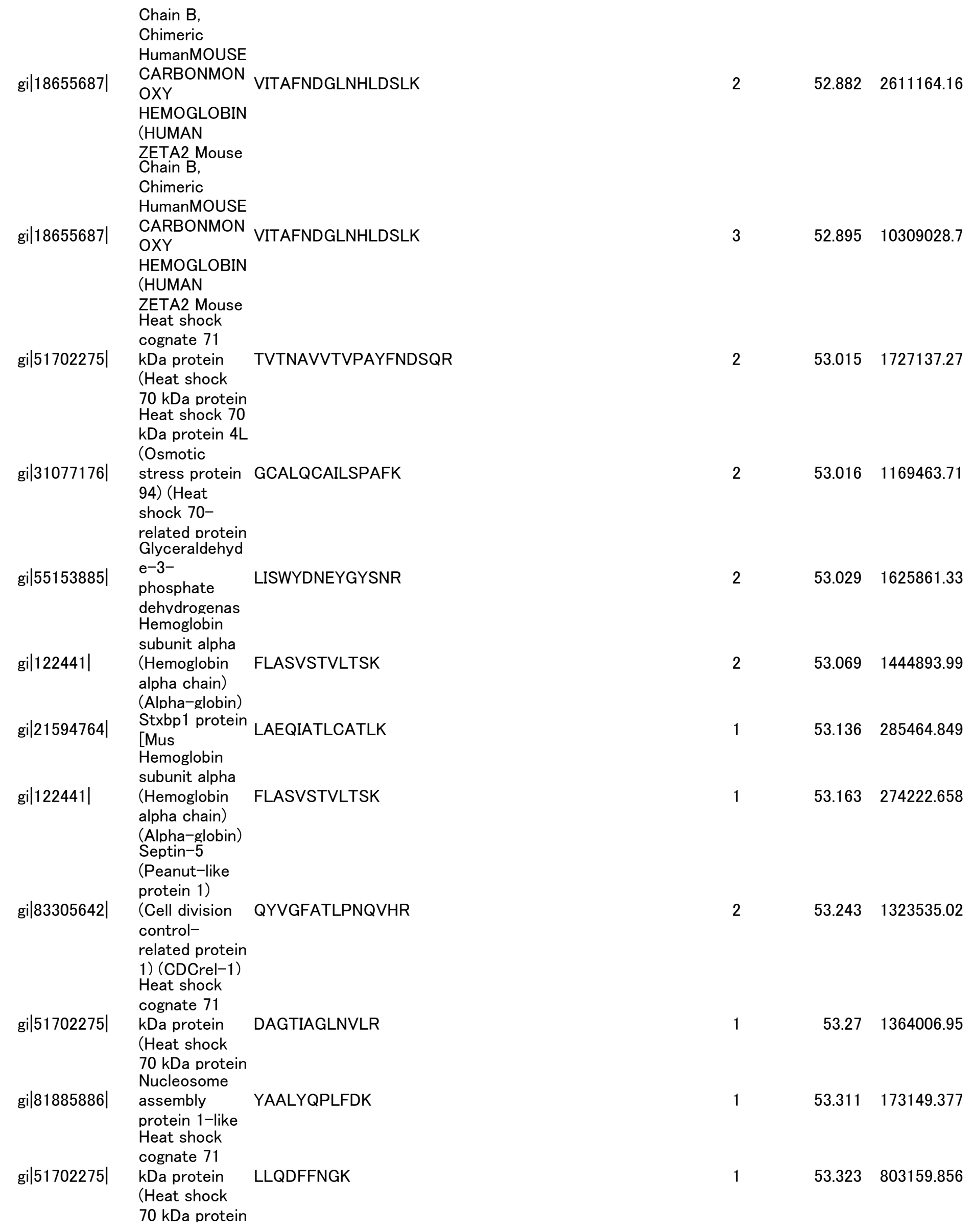




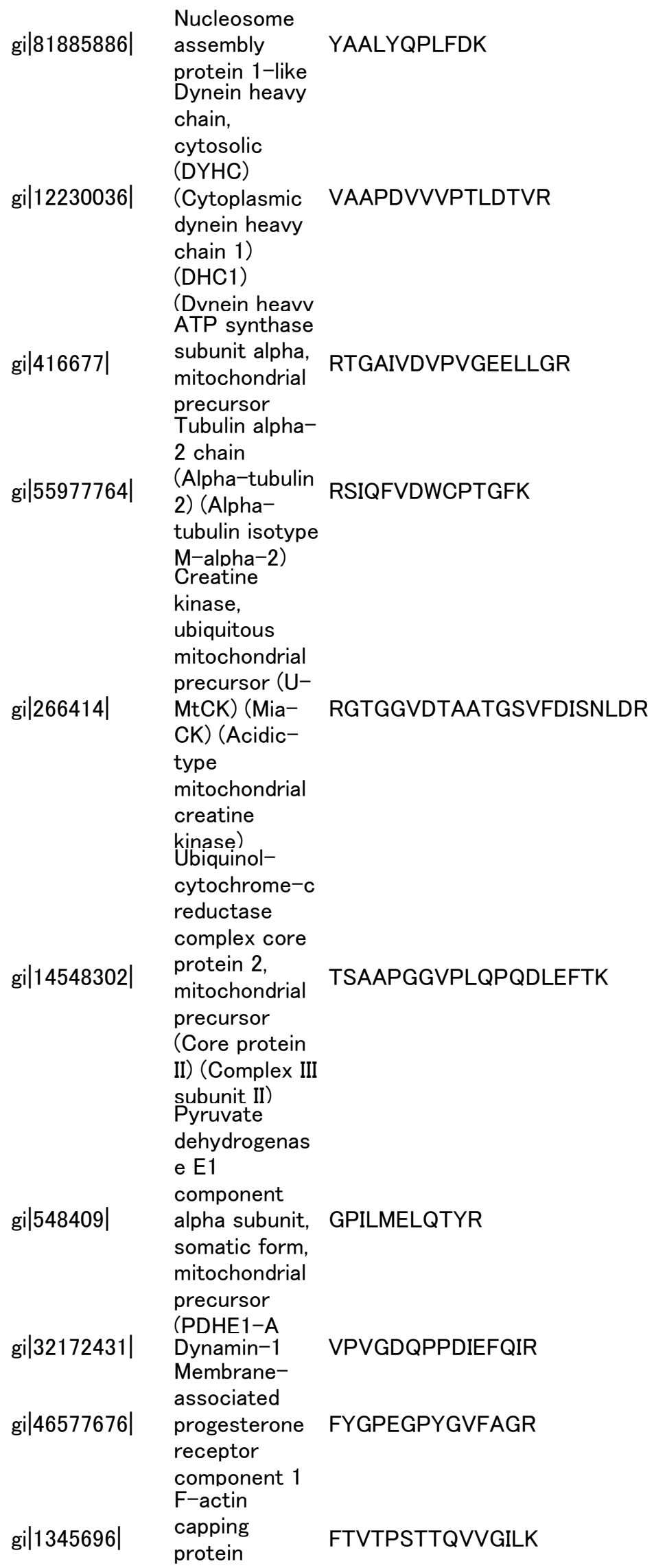

Dynein heavy

chain,

cytosolic

(DYHC)

gi|12230036) (Cytoplasmic dynein heavy

mitochondrial precursor (PDHE1-A

gi|32172431| Dynamin-1 Membraneassociated

gi|46577676| progesterone receptor component 1 F-actin

gi|1345696| capping protein 


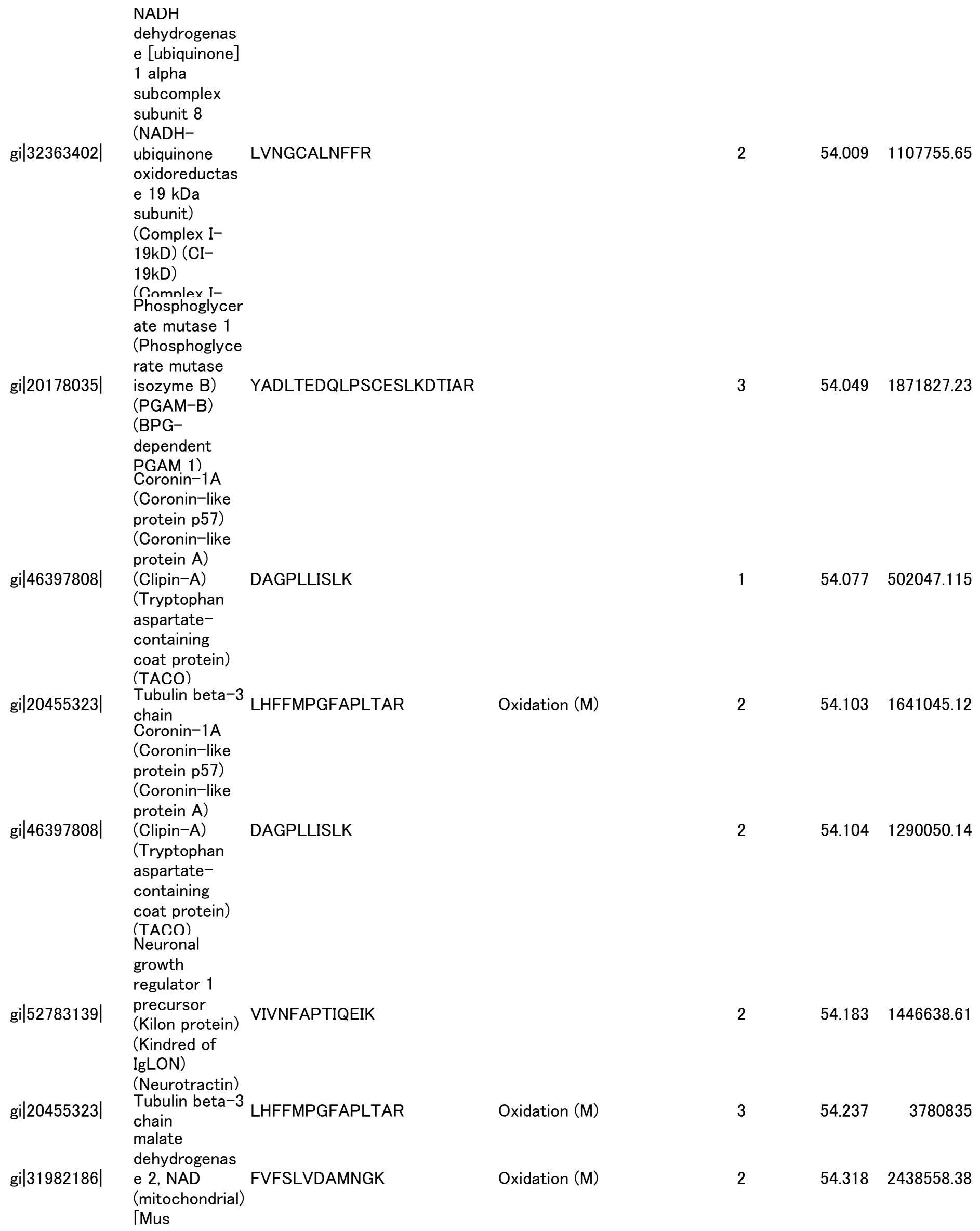




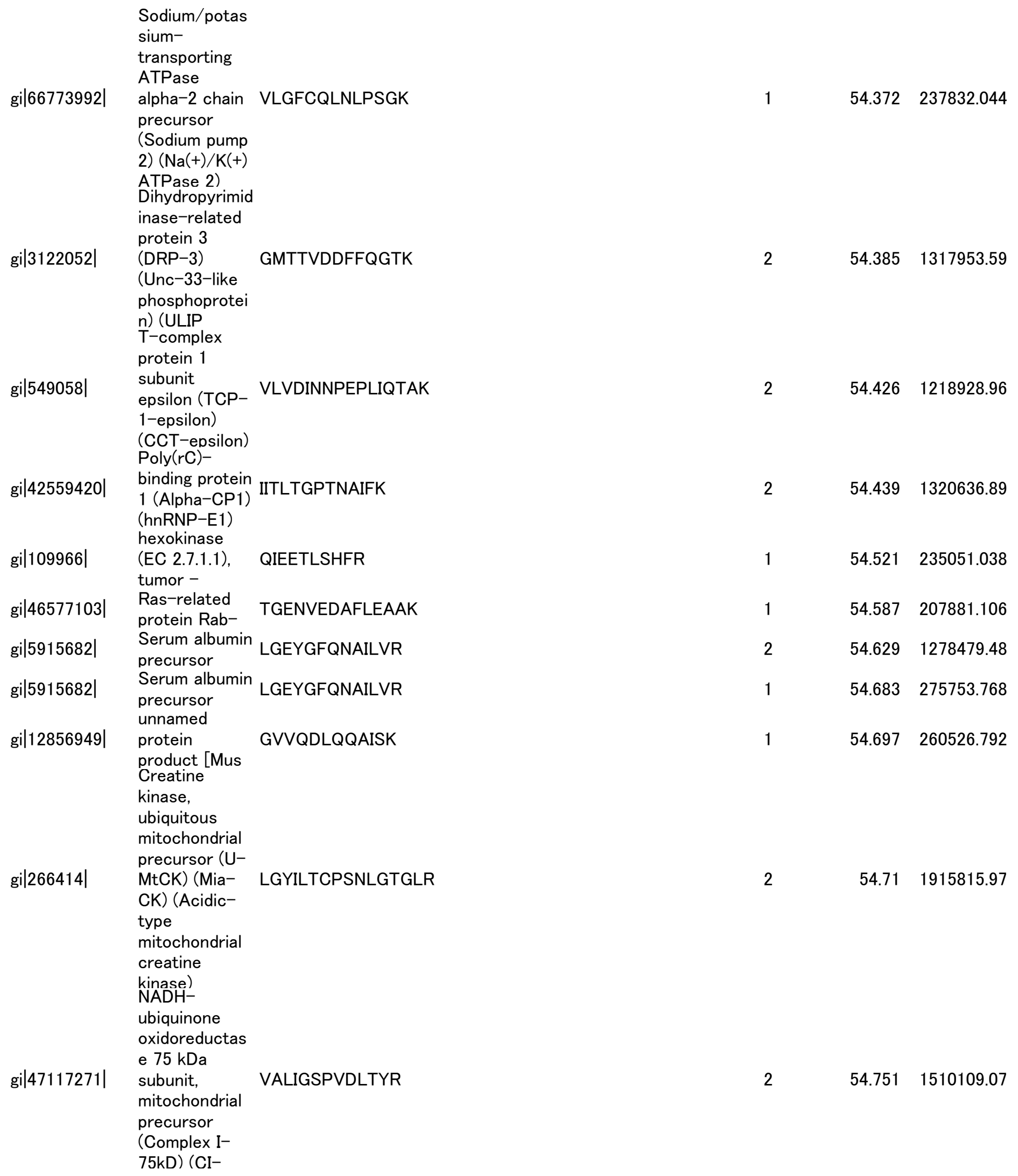




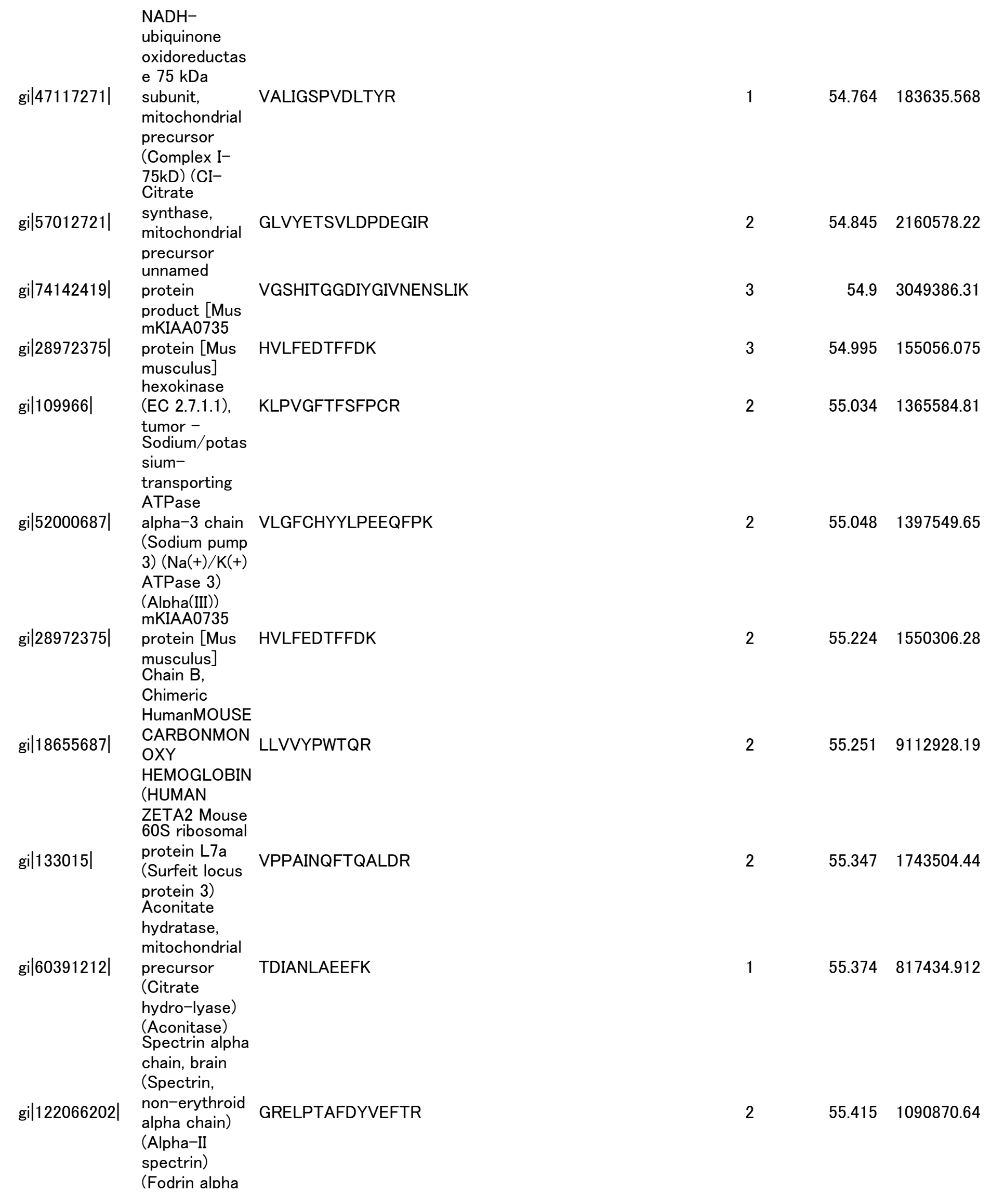




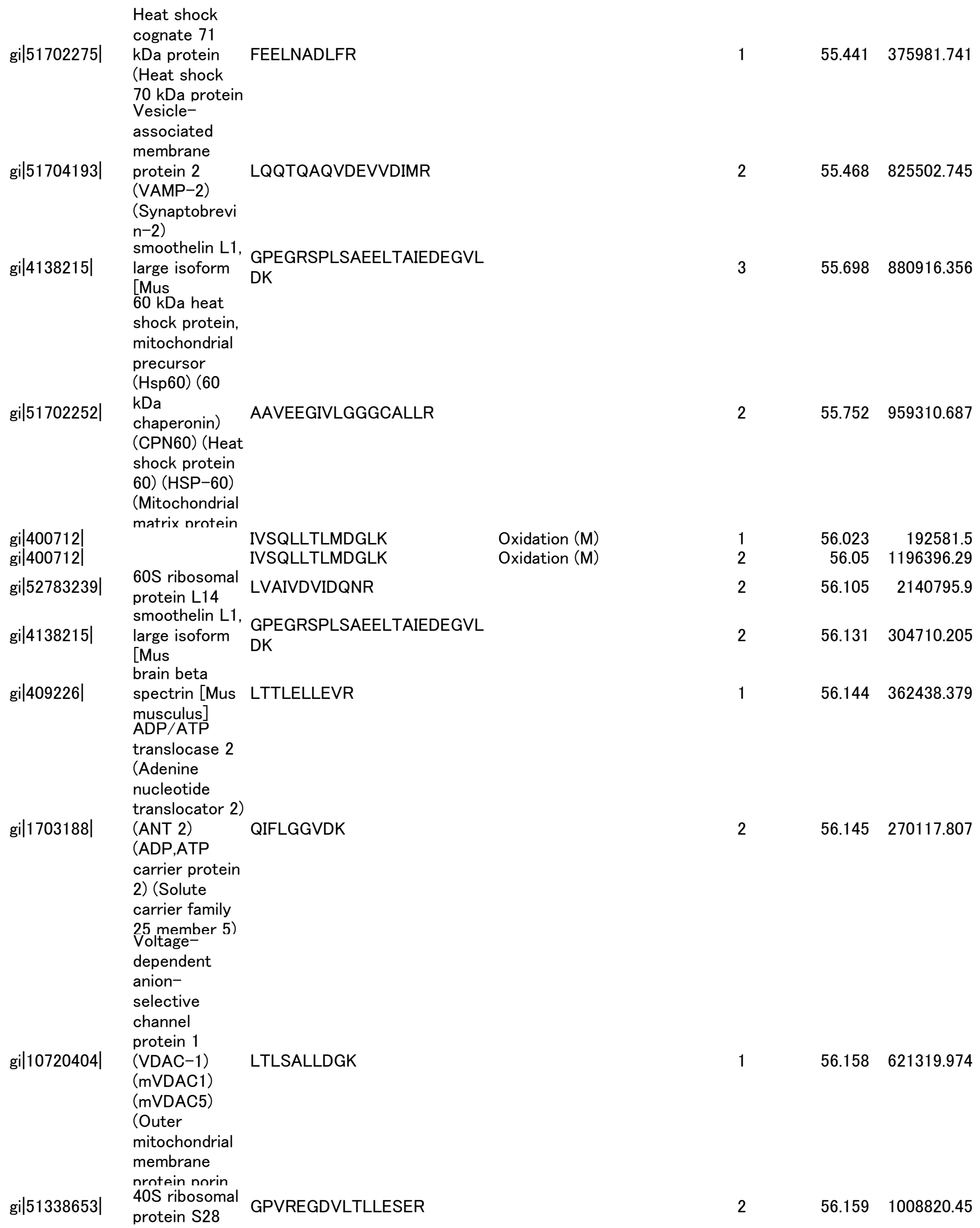




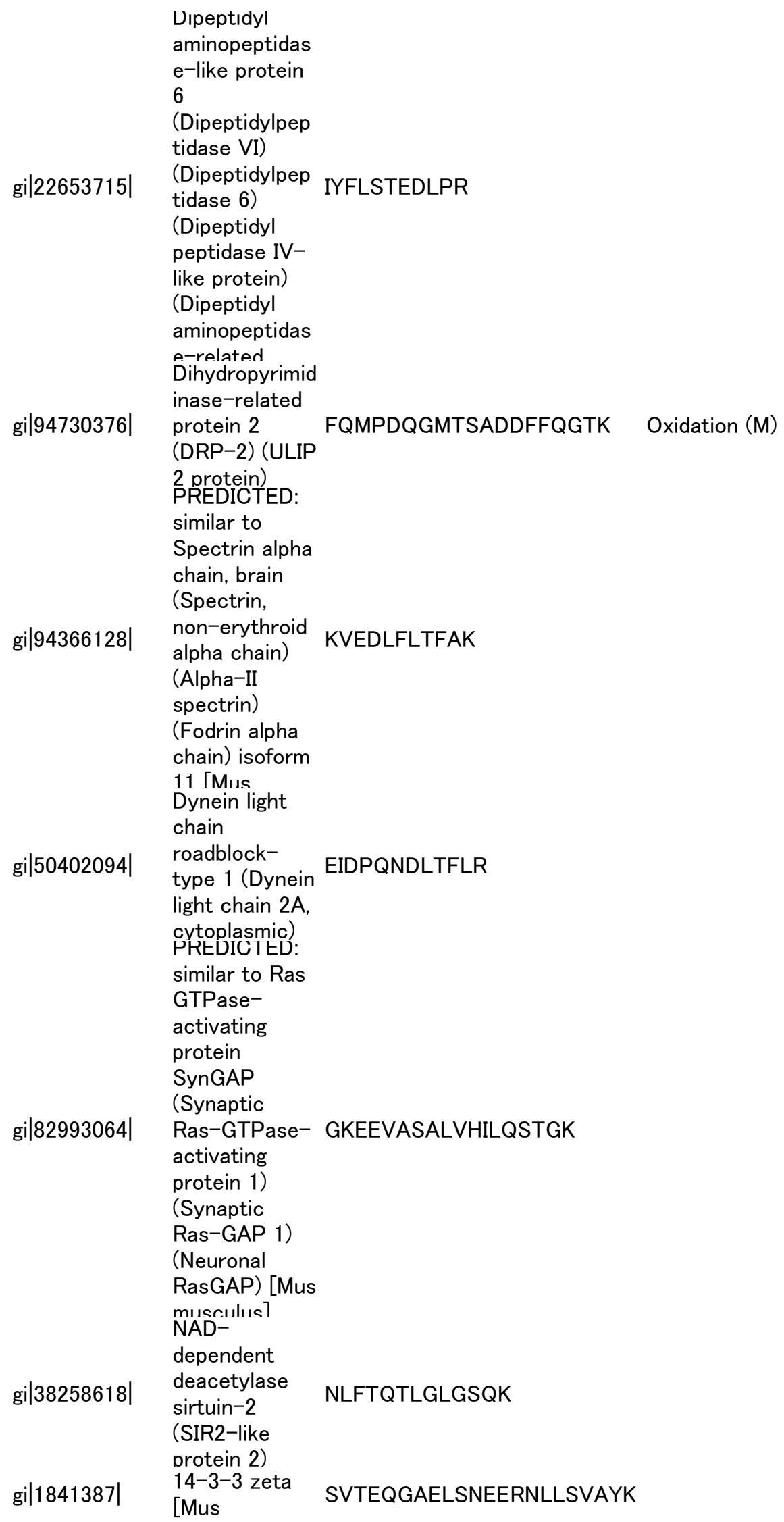

(Dipeptidyl peptidase IVlike protein)

(Alpha-II

spectrin)

(Fodrin alpha

chain) isoform

11 「Mus

Dynein light

chain

gi|50402094| roadblock-

type 1 (Dynein EIDPQNDLTFLR

light chain $2 A$,

cytoplasmic)

similar to Ras

GTPase-

activating

protein

SynGAP

(Synaptic

(SIR2-like protein 2) 


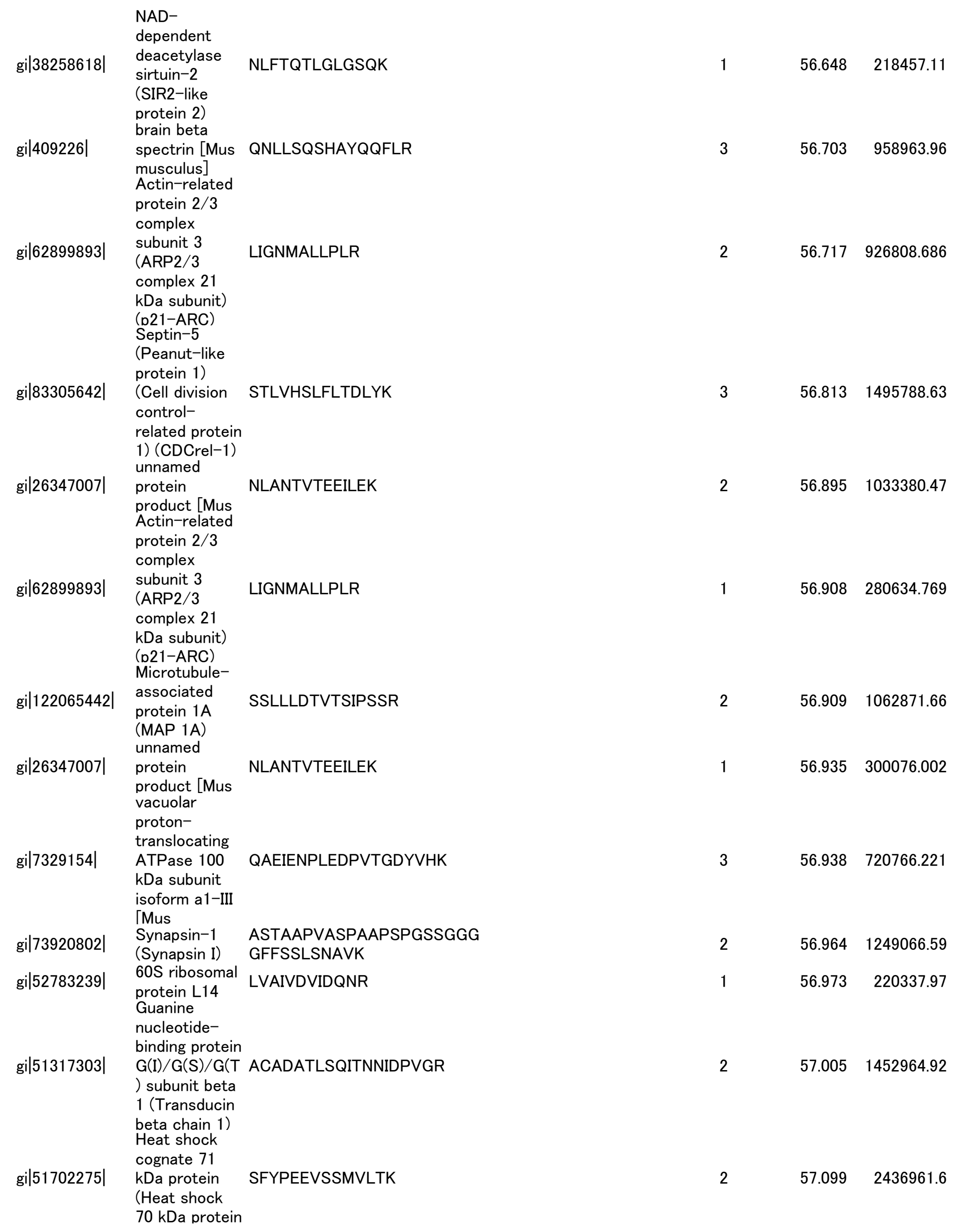




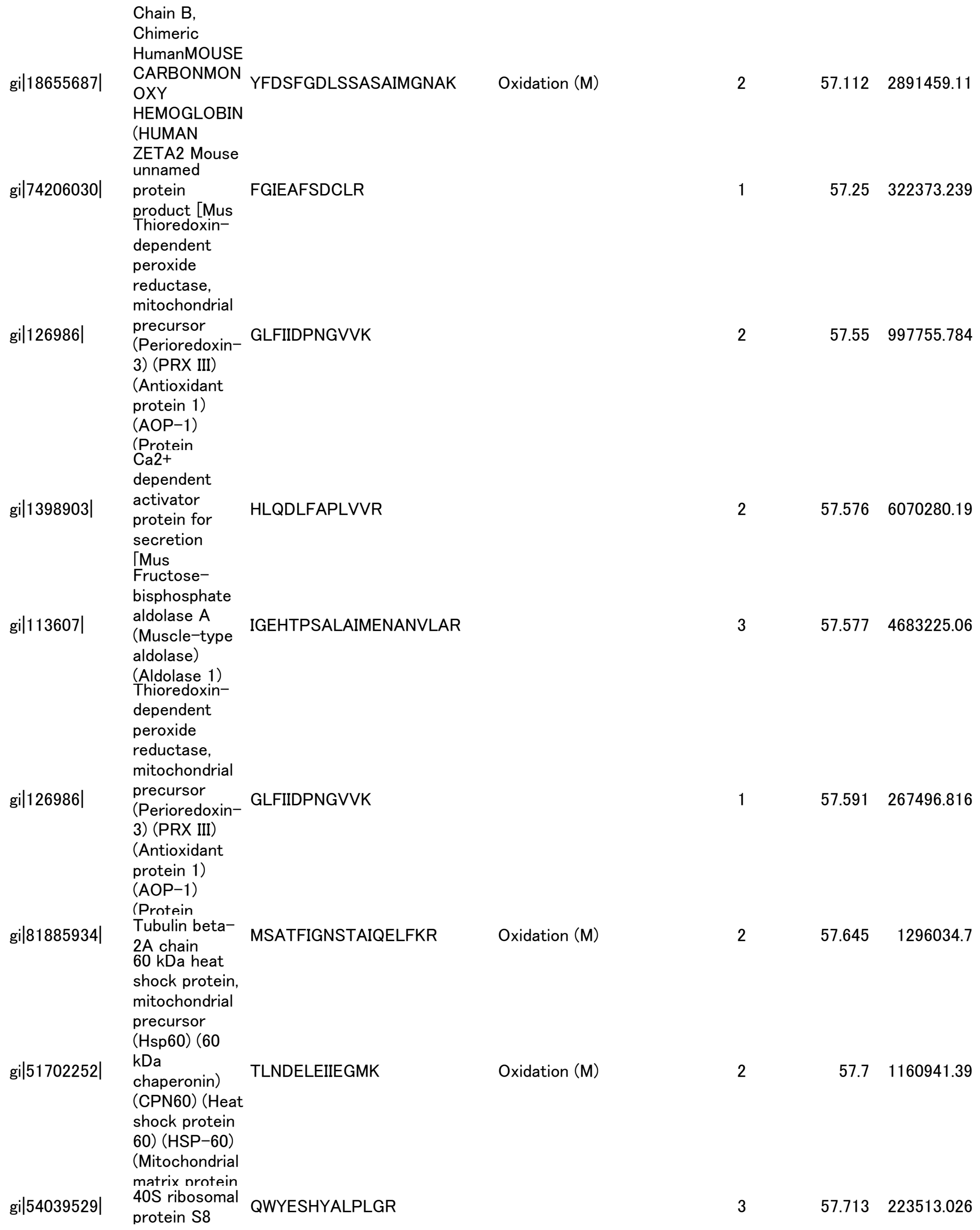
(CPN60) (Heat shock protein 60) (HSP-60) (Mitochondrial matrix nrotein $40 \mathrm{~S}$ ribosomal protein S8 


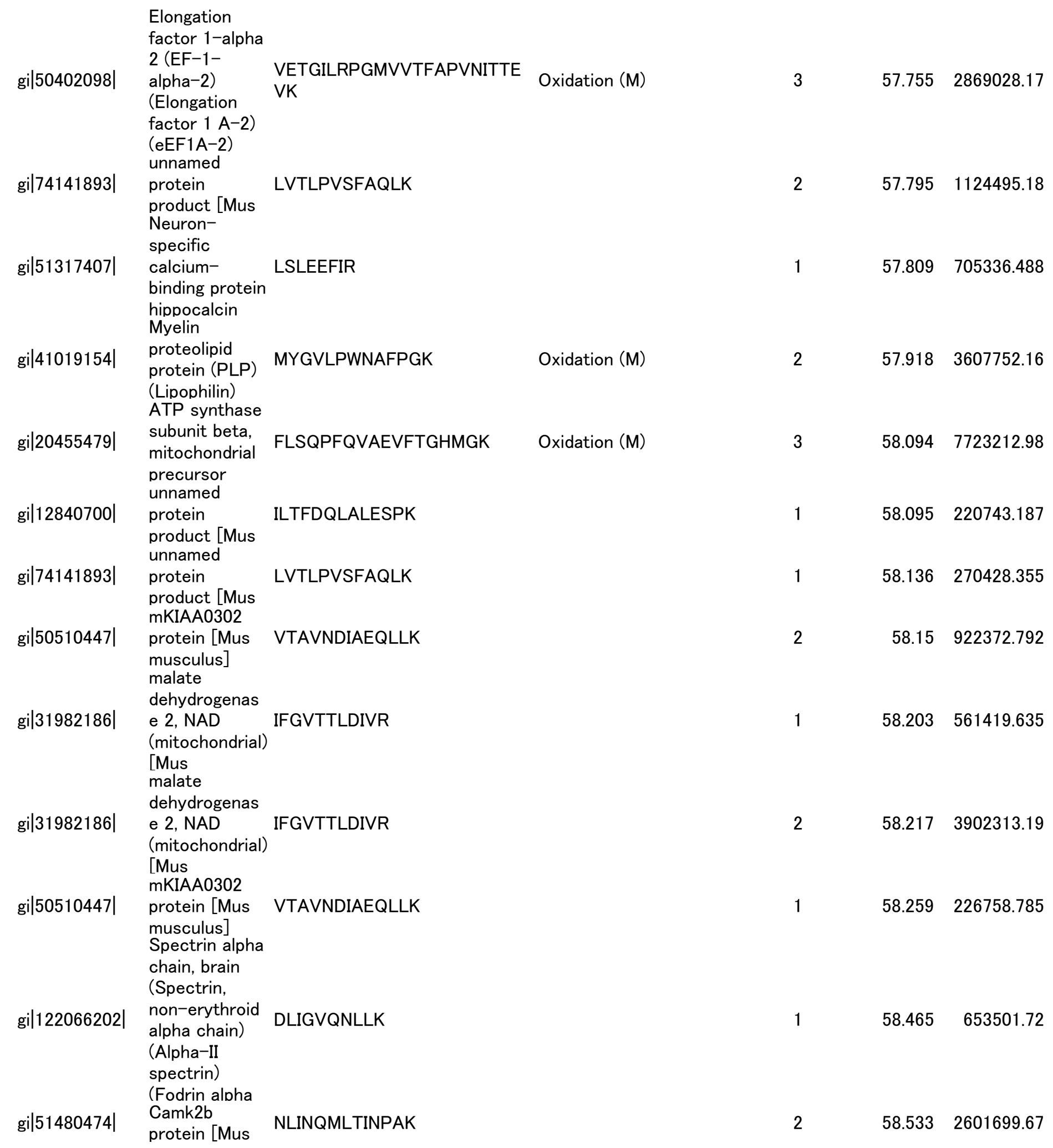




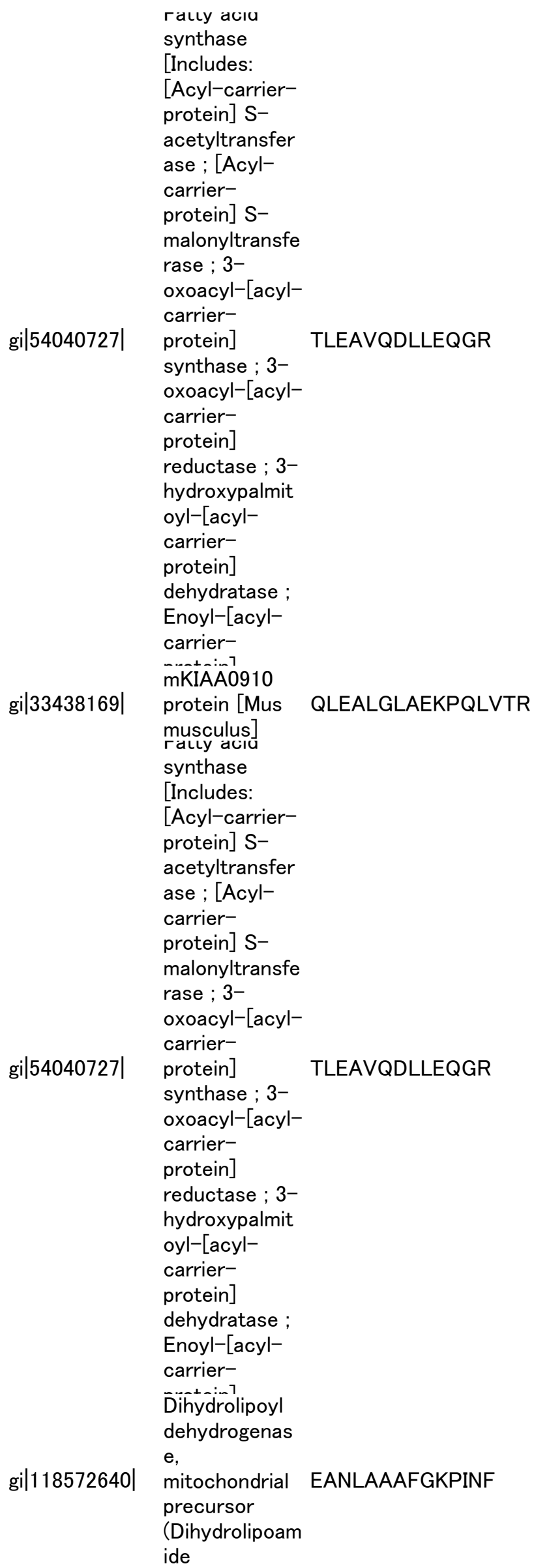

(Dihydrolipoam ide 


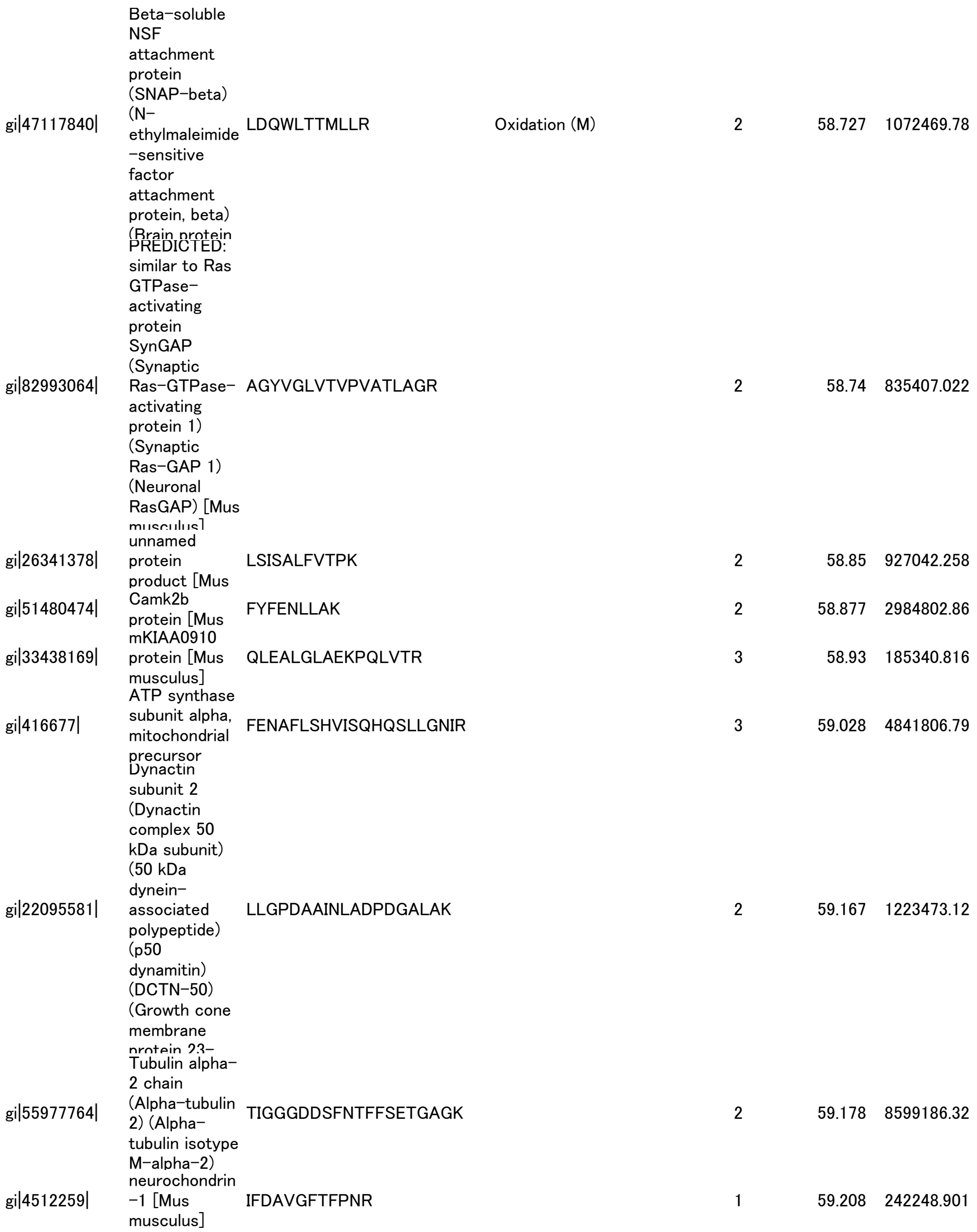

gi|416677|

precursor

Dynactin

subunit 2

(Dynactin

complex 50

kDa subunit)

(50 kDa

dynein-

gi|22095581| associated

LLGPDAAINLADPDGALAK

(p50

dynamitin)

(DCTN-50)

(Growth cone

membrane

nrotein 23-

Tubulin alpha-

2 chain

gi|55977764| (Alpha-tubulin

2) (Alpha-

TIGGGDDSFNTFFSETGAGK tubulin isotype M-alpha-2) neurochondrin

gi|4512259|$$
-1 \text { [Mus }
$$

IFDAVGFTFPNR musculus] 


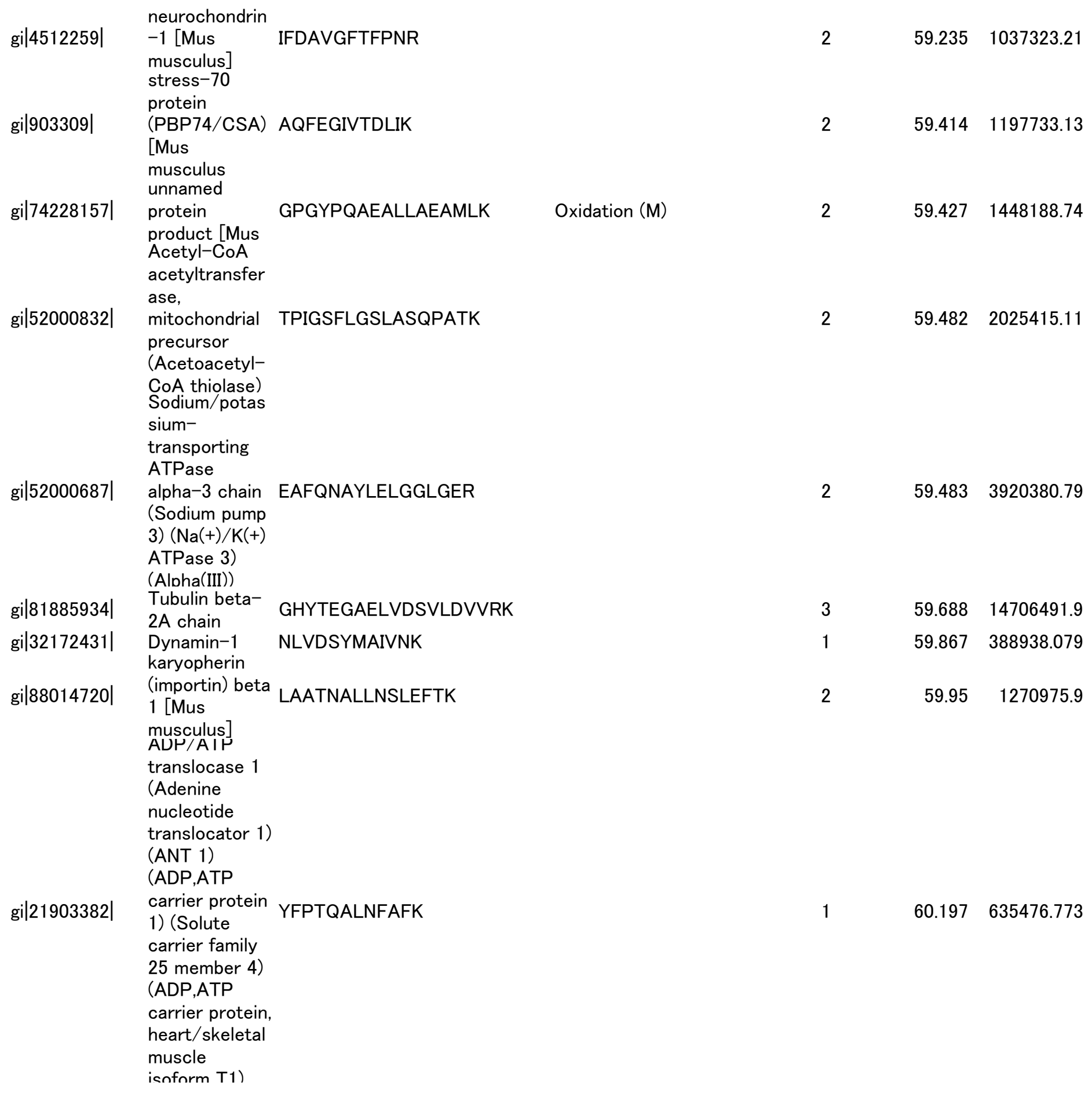




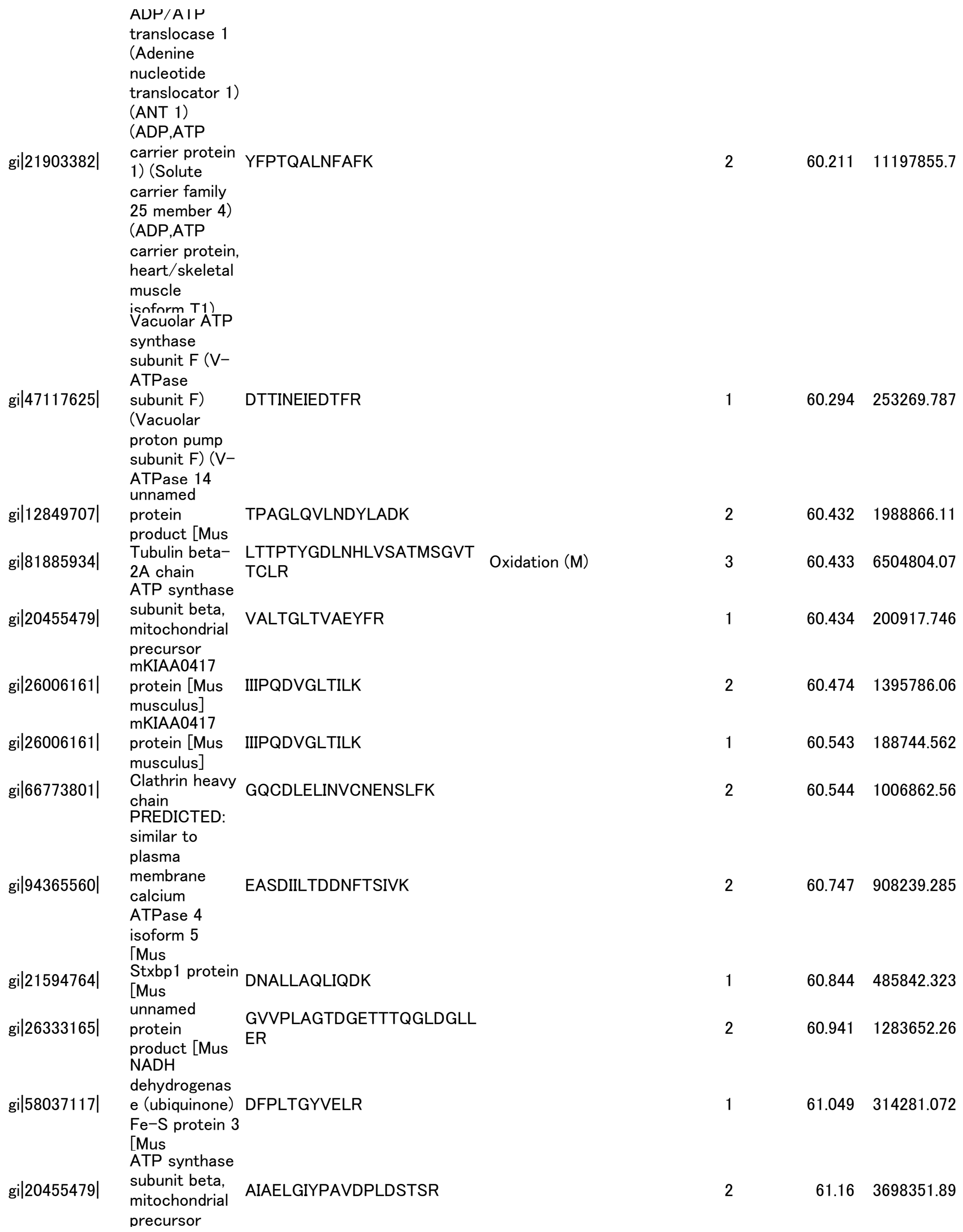




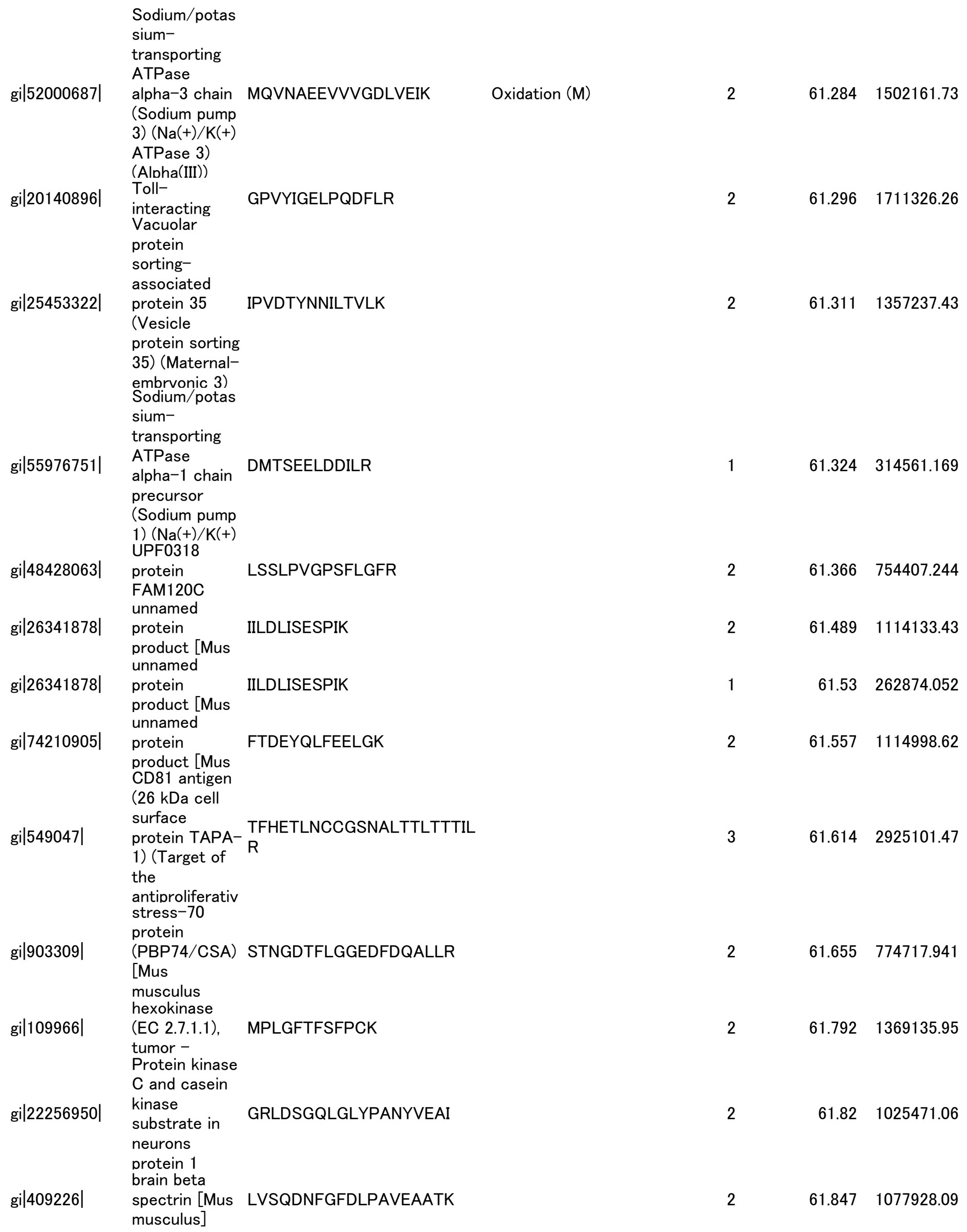




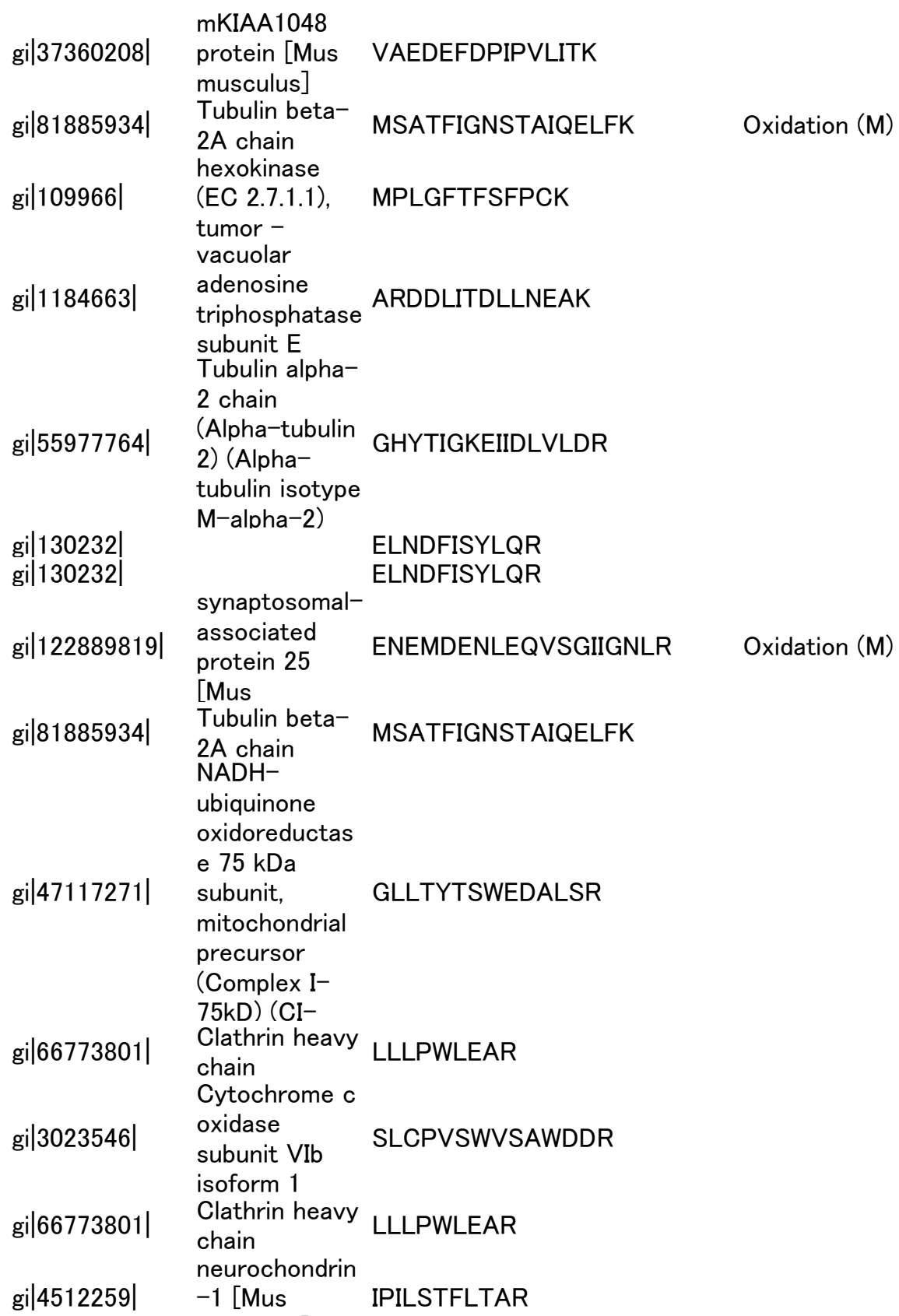

gi|4512259|

neurochondrin

IPILSTFLTAR 


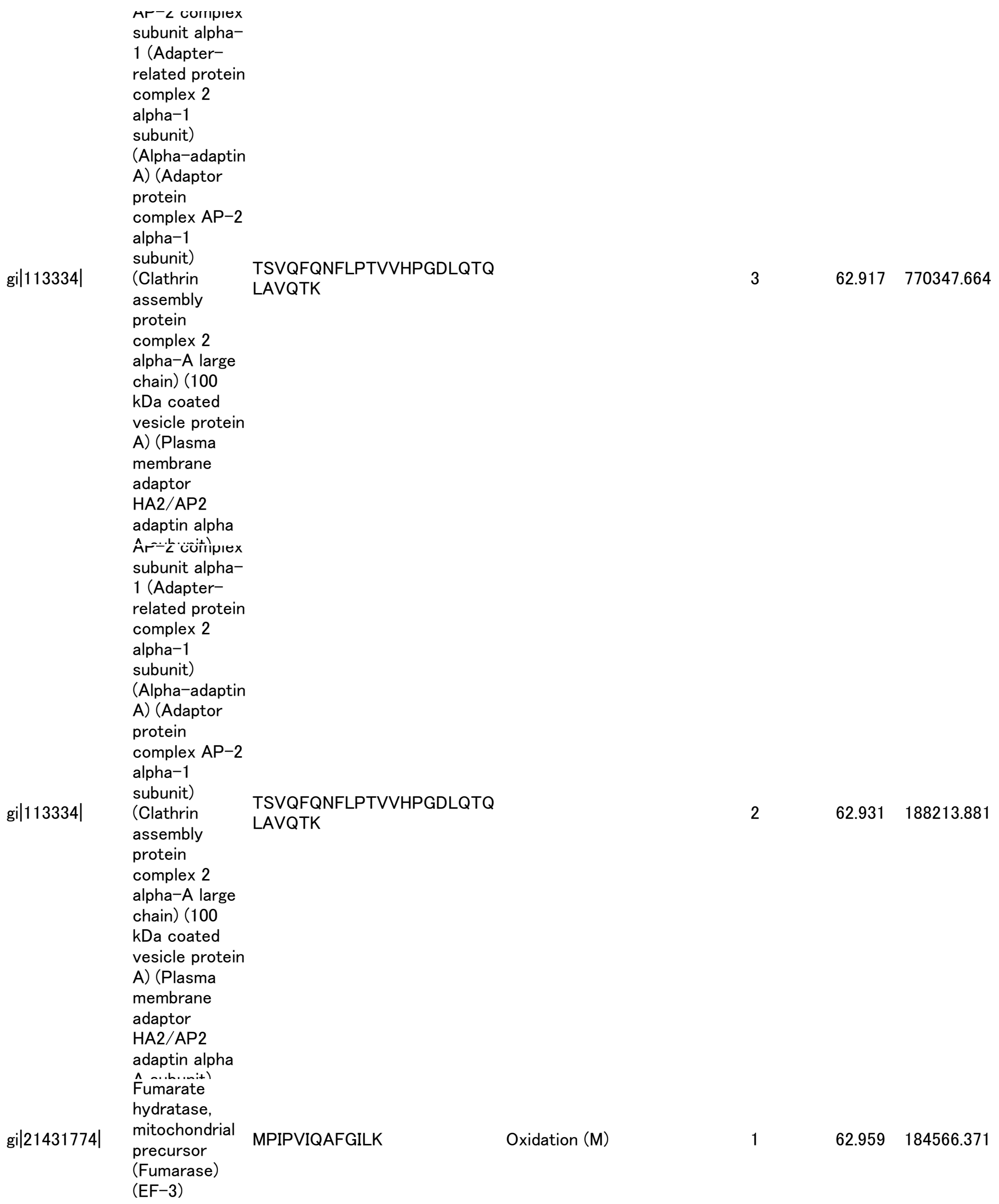




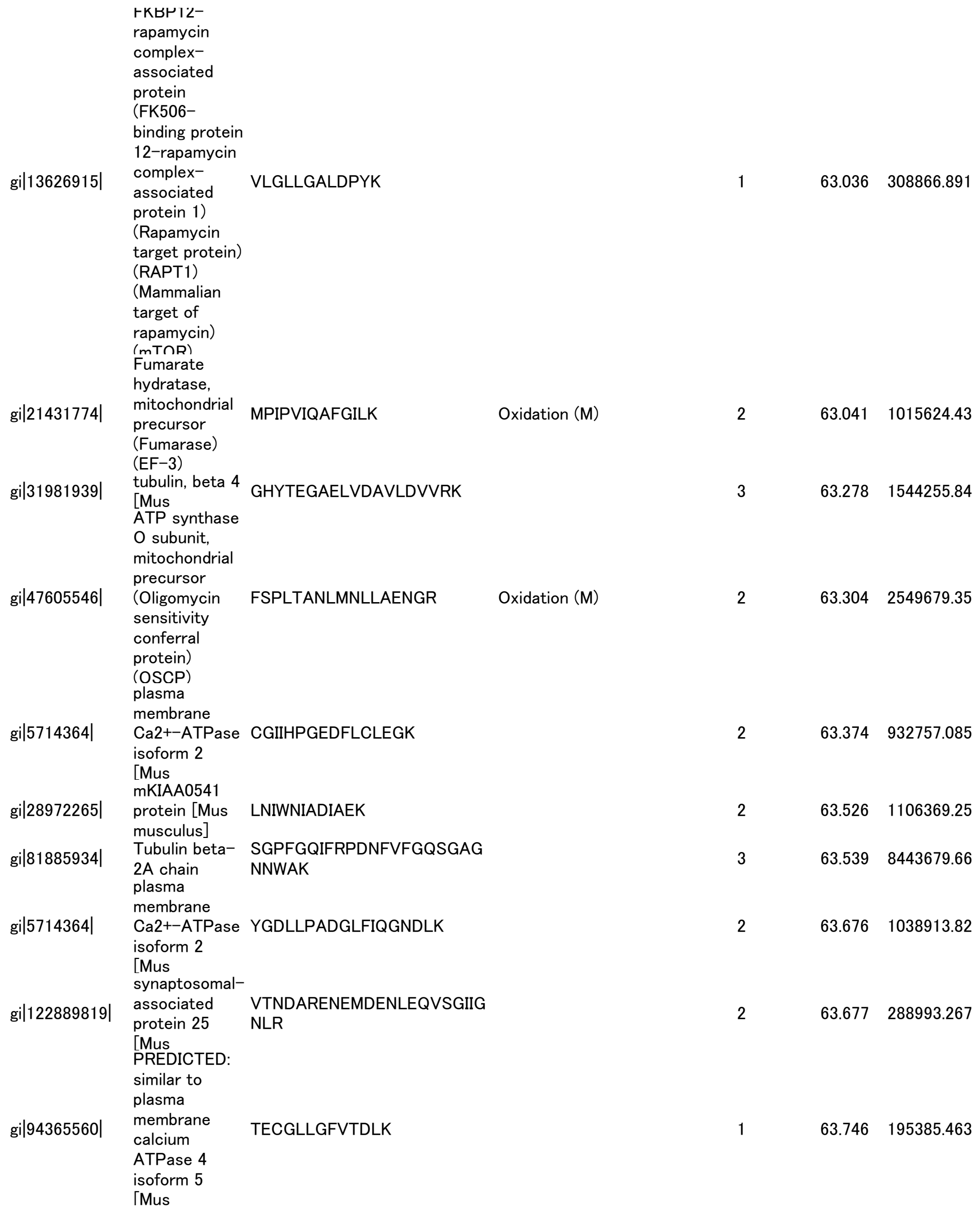




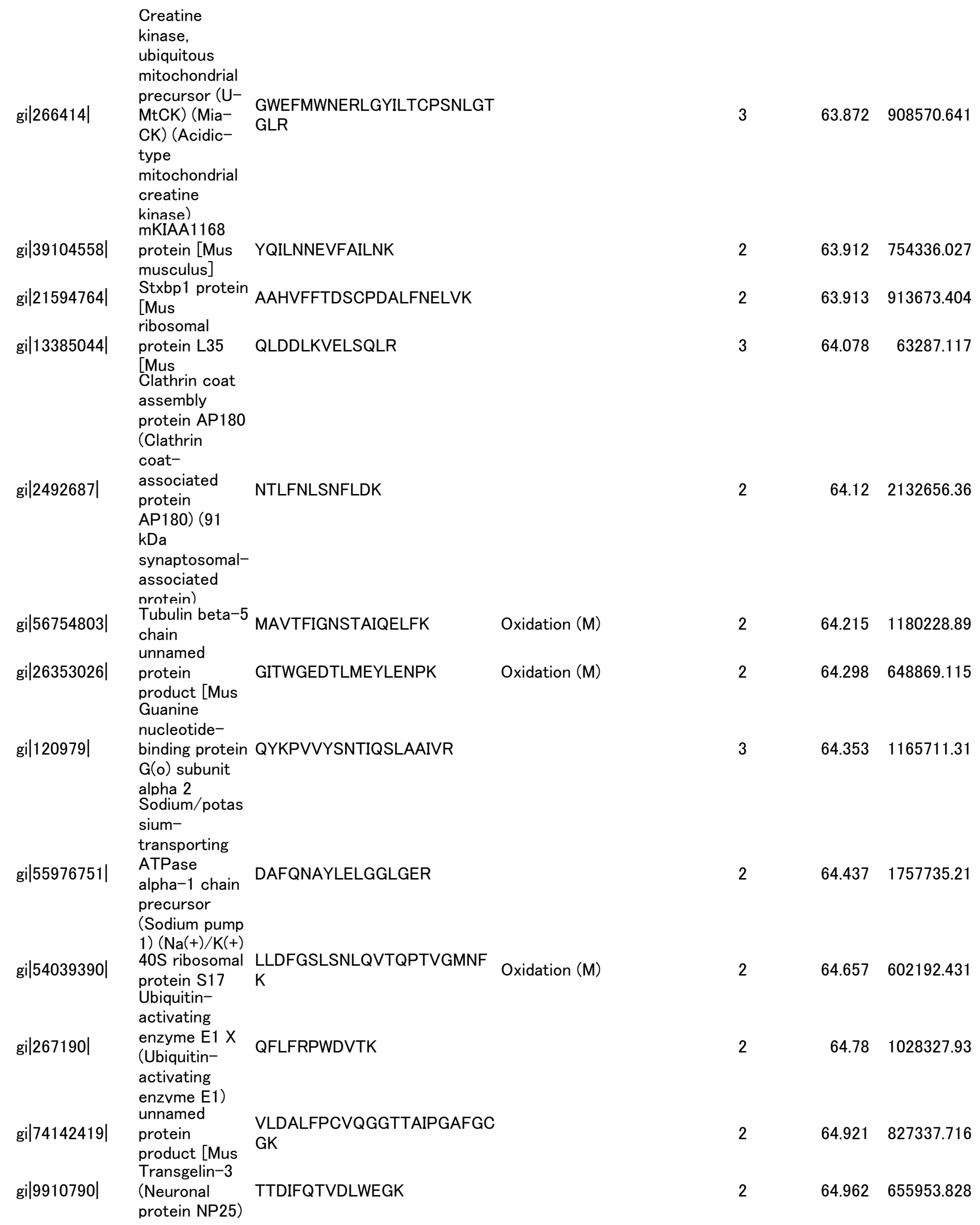




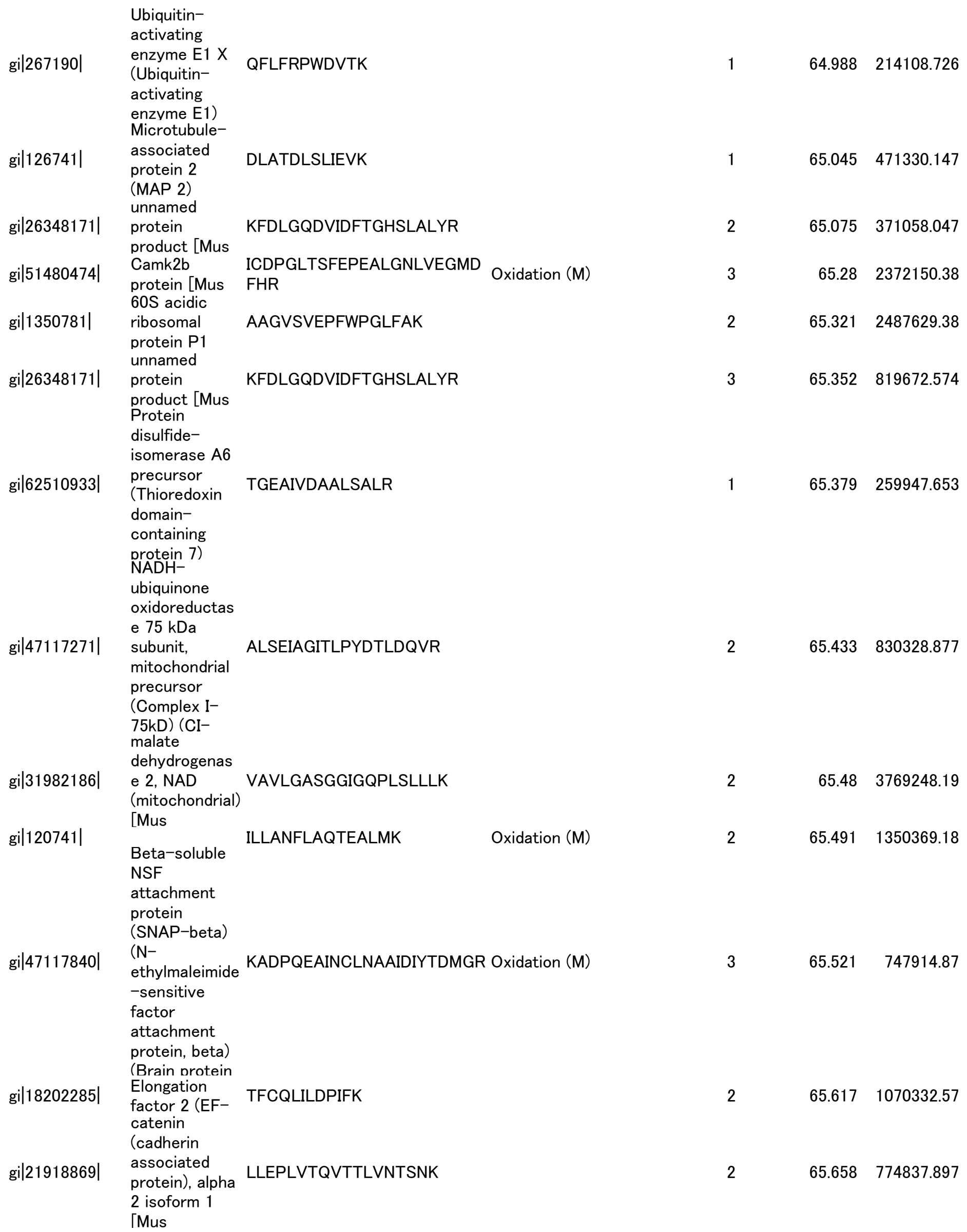




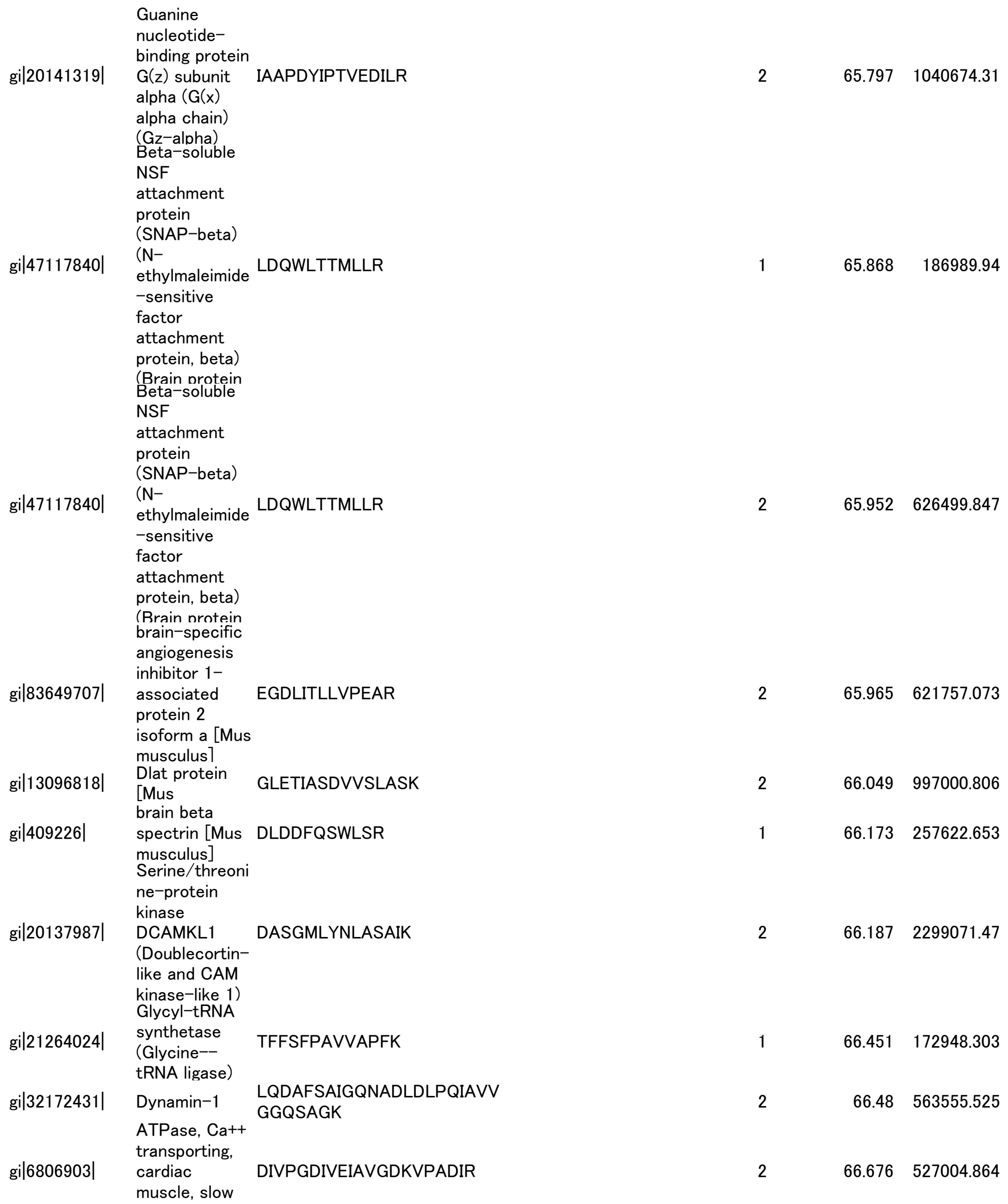




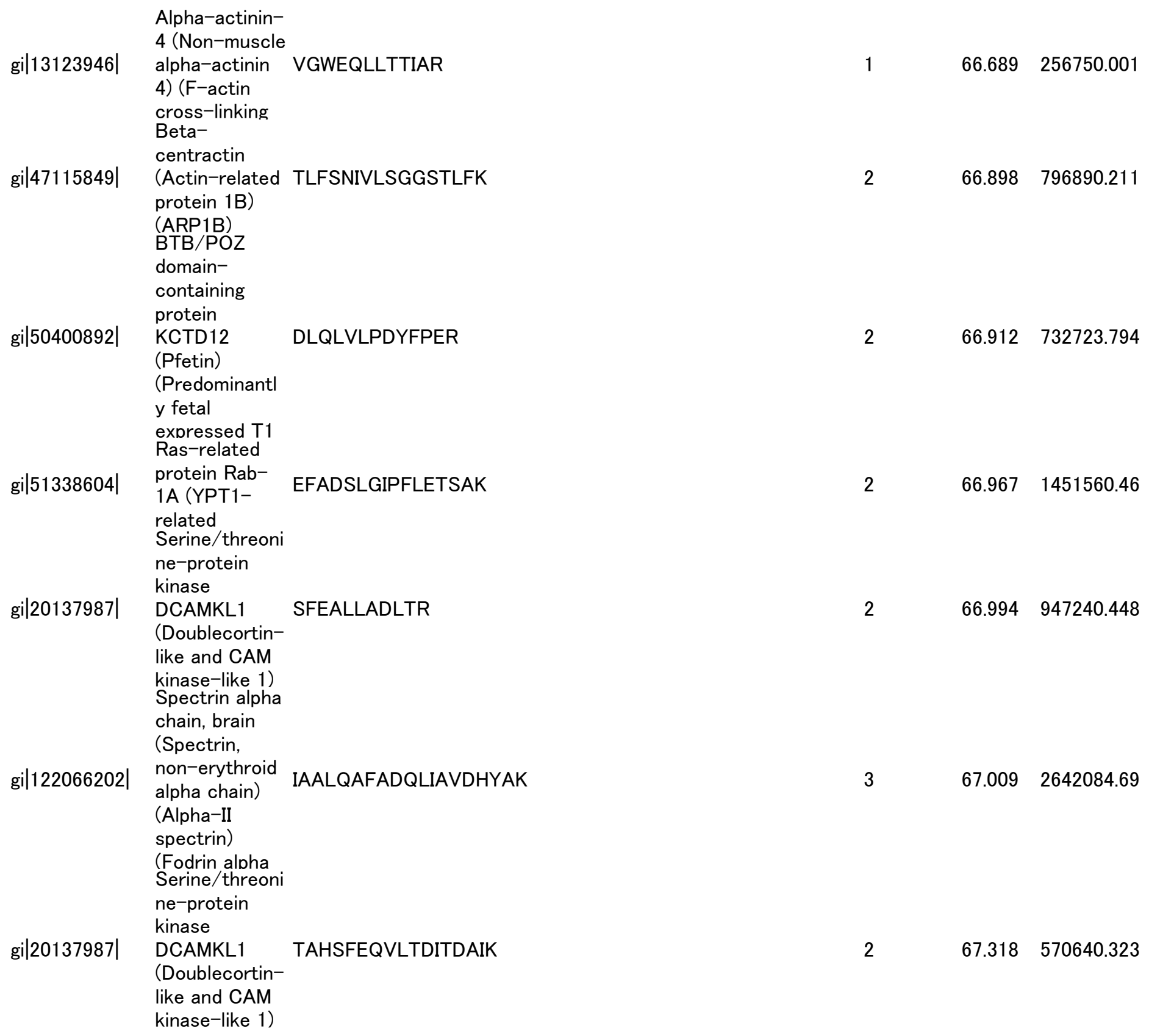




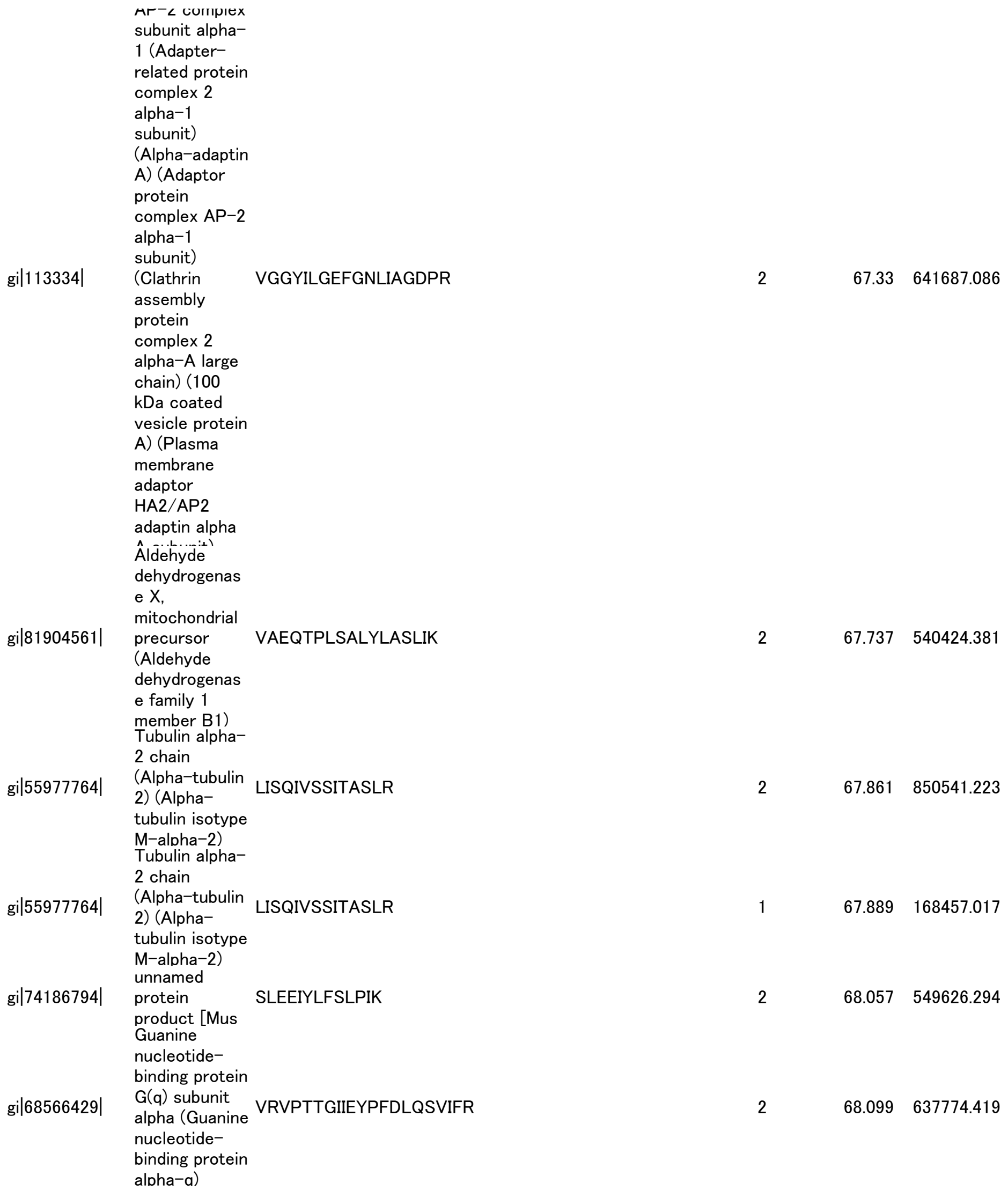

tubulin isotype

M-alpha-2)

Tubulin alpha-

2 chain

gi|55977764| (Alpha-tubulin

2) (Alpha-

LISQIVSSITASLR

tubulin isotype

M-alpha-2)

gi|74186794 unnamed protein SLEEIYLFSLPIK

product [Mus

Guanine nucleotidebinding protein

gi|68566429| G(q) subunit alpha (Guanine nucleotidebinding protein alpha-a) 


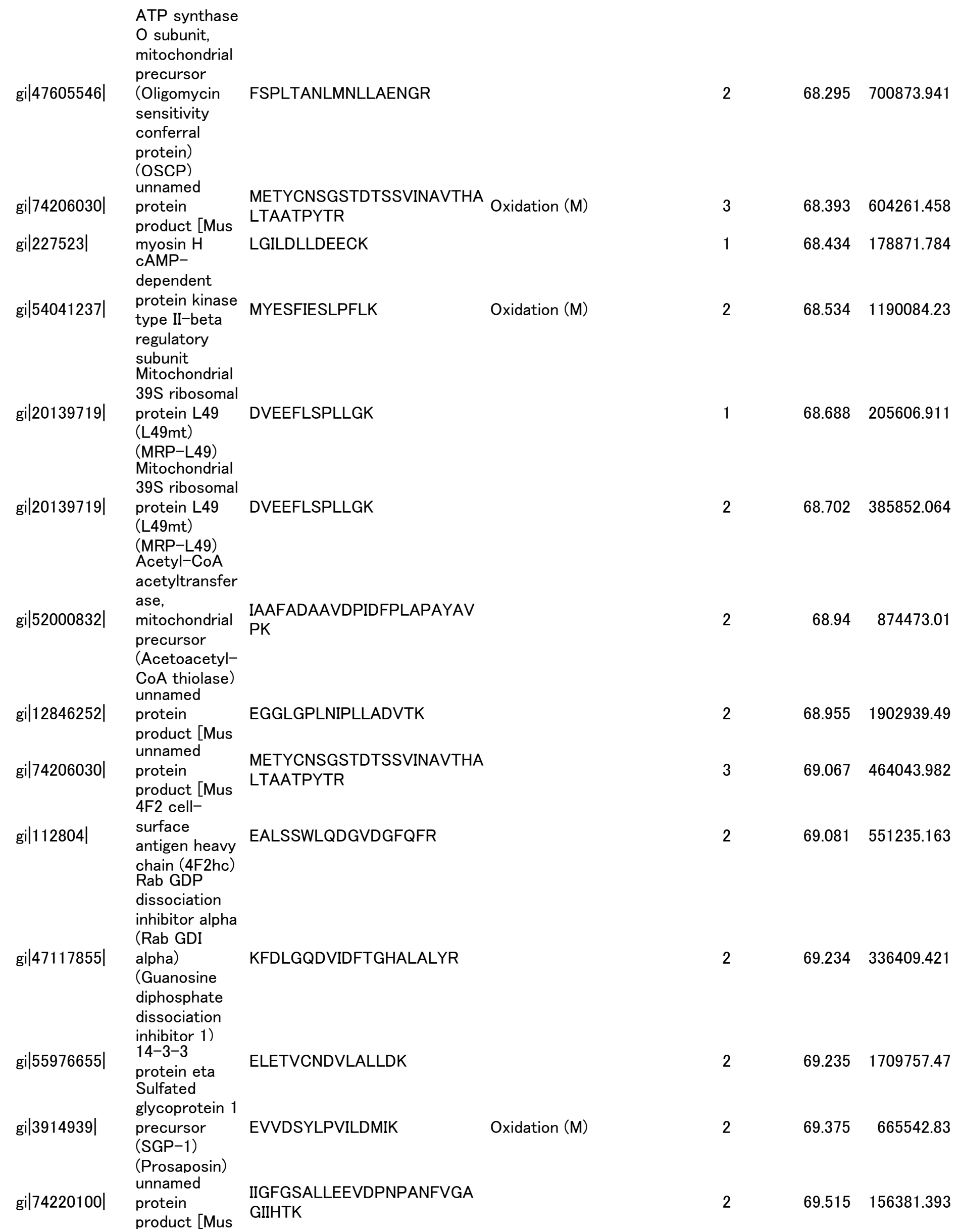




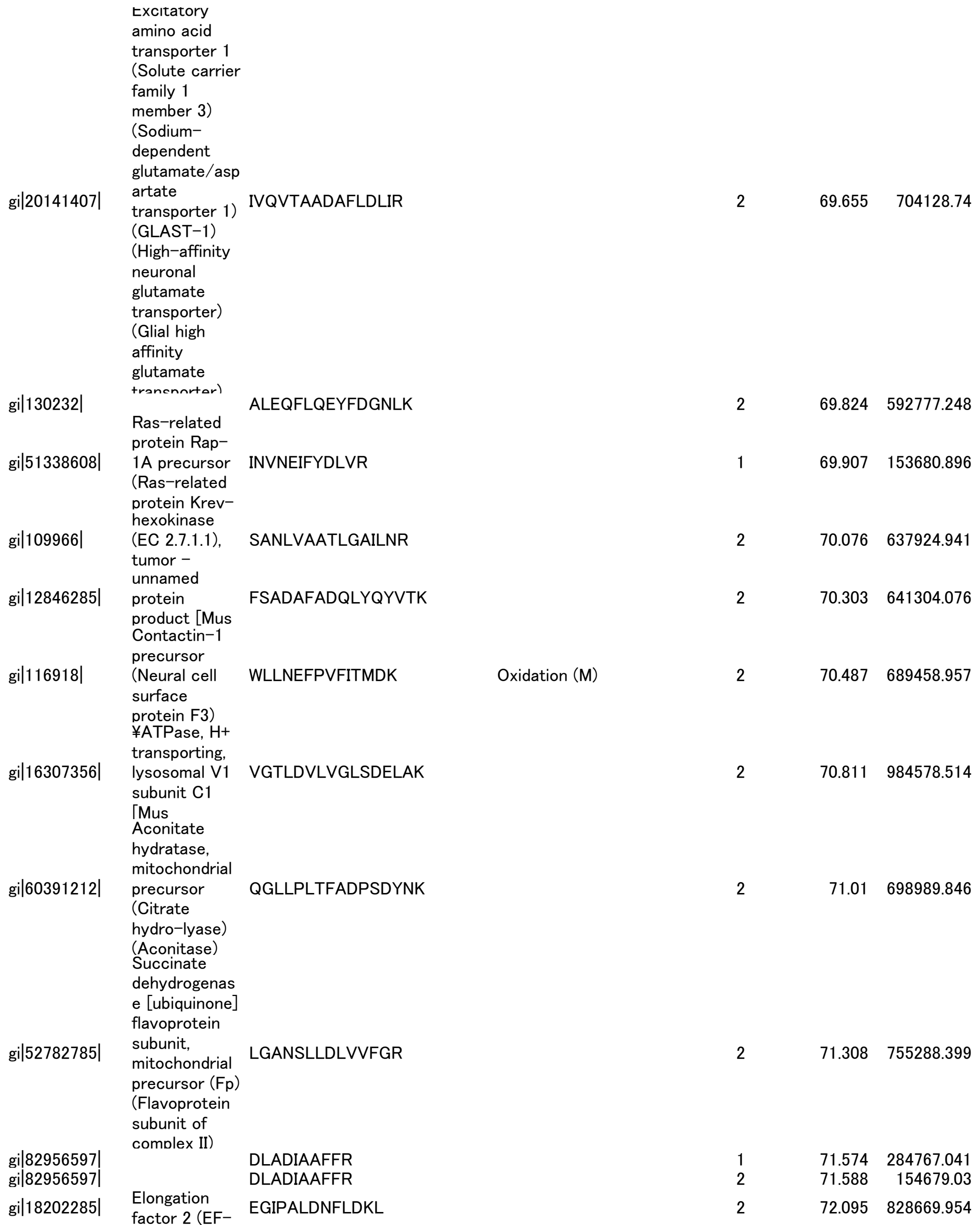




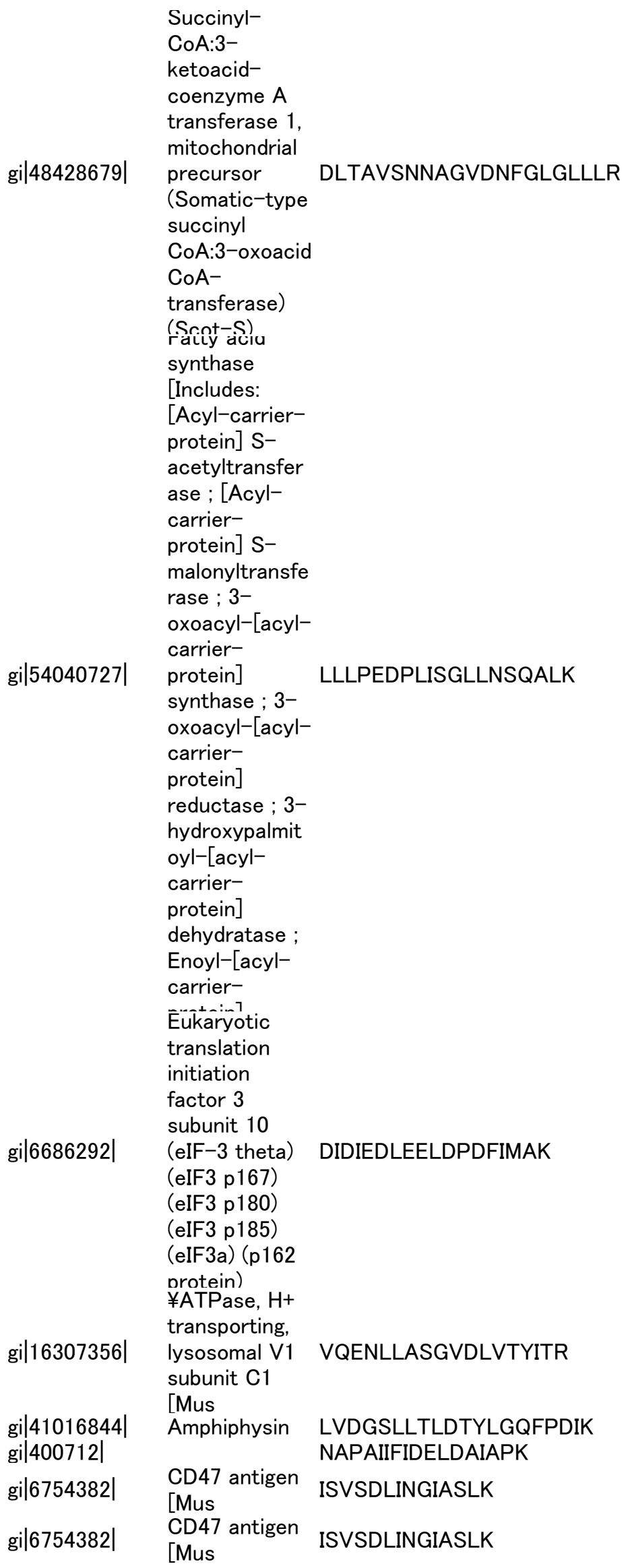

ISVSDLINGIASLK 


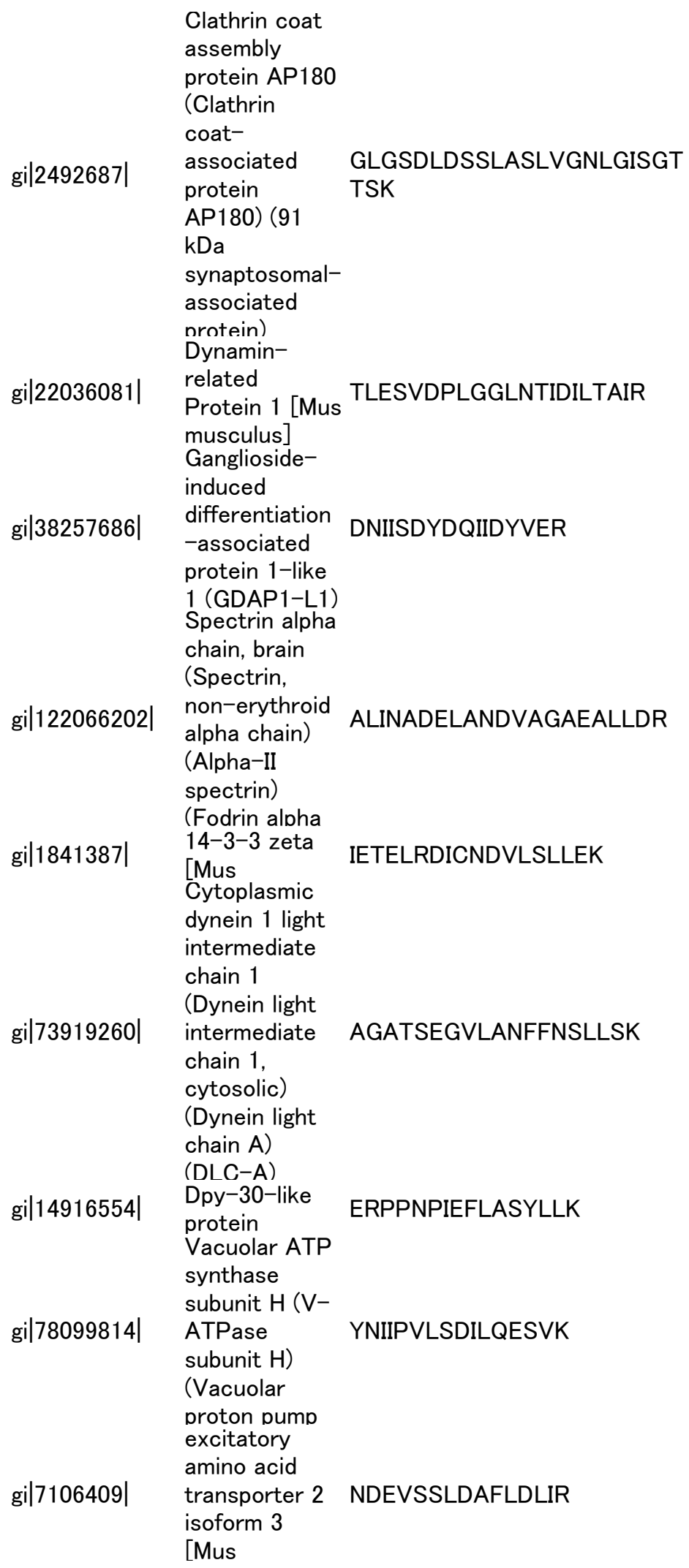

Cytoplasmic dynein 1 light intermediate chain 1

(Dynein light

gi|73919260| intermediate chain 1, cytosolic)

(Dynein light chain A)

(DLC-A)

gi|14916554| Dpy-30-like protein

Vacuolar ATP

synthase subunit $\mathrm{H}(\mathrm{V}-$

[Mus 


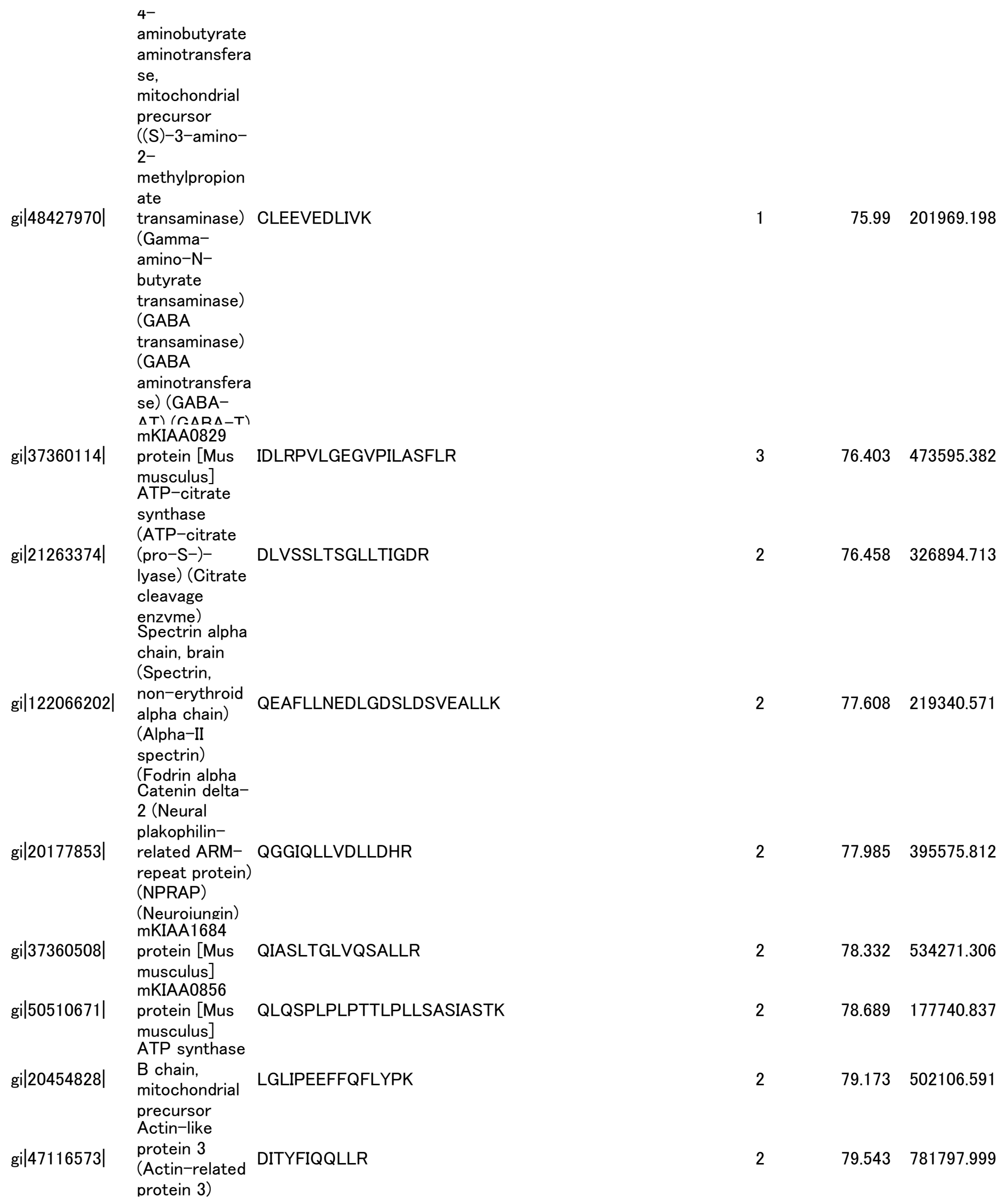




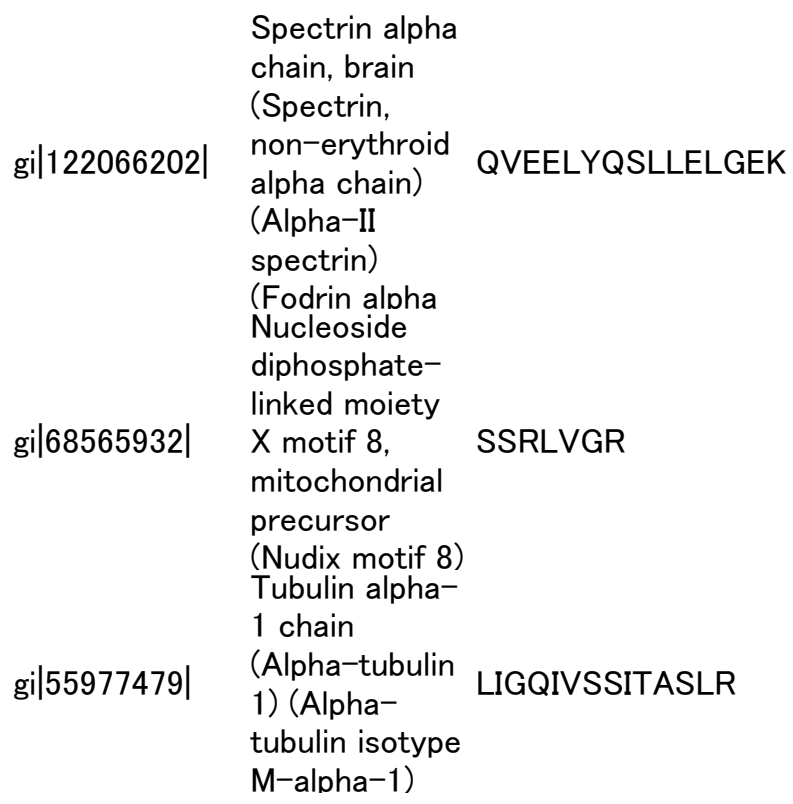

